Técnica de agrupamento de dados baseada em redes complexas para o posicionamento de cluster heads em rede de sensores sem fio 



\title{
Técnica de agrupamento de dados baseada em redes complexas para o posicionamento de cluster heads em rede de sensores sem fio
}

\section{Leonardo Nascimento Ferreira}

Orientador: Prof. Dr. Zhao Liang

\begin{abstract}
Dissertação apresentada ao Instituto de Ciências Matemáticas e de Computação - ICMC-USP, como parte dos requisitos para obtenção do título de Mestre em Ciências - Ciências de Computação e Matemática Computacional. VERSÃO REVISADA
\end{abstract}


Ficha catalográfica elaborada pela Biblioteca Prof. Achille Bassi e Seção Técnica de Informática, ICMC/USP, com os dados fornecidos pelo(a) autor(a)

Ferreira, Leonardo Nascimento

F383t Técnica de agrupamento de dados baseada em redes complexas para o posicionamento de cluster heads em rede de sensores sem fio / Leonardo Nascimento Ferreira; orientador Zhao Liang. -- São Carlos, 2012. $102 \mathrm{p}$.

Dissertação (Mestrado - Programa de Pós-Graduação en Ciências de Computação e Matemática Computacional) -Instituto de Ciências Matemáticas e de Computação, Universidade de São Paulo, 2012.

1. Redes Complexas. 2. Detecção de Comunidades. 3. Rede de Sensores Sem Fio. 4. Posicionamento de Cluster Heads. I. Liang, Zhao, orient. II. Título. 
Aos meus pais e meus avós. 



\section{Agradecimentos}

Gostaria de agradecer aos meus pais, Silvana e Lelo, pois sem eles não chegaria onde cheguei.

Agradeço a todos os amigos, próximos e distantes, que muitas vezes não me deixaram concentrar nesse trabalho.

Agradeço à Nicole, por ser companheira, atenciosa e compreensiva.

Agradeço ao professor Alex, que além de contribuir com esse trabalho, tornou-se um grande amigo.

Agradeço ao meu orientador professor Zhao, pela excelente orientação.

Por fim, agradeço à Universidade de São Paulo e ao CNPq pelo financiamento e suporte à minha pesquisa. 



\section{Resumo}

$\mathrm{R}$

edes de Sensores Sem Fio são um tipo especial de rede ad-hoc que são posicionadas em uma região para monitorar fenômenos físicos. Considerando que os sensores dessas redes são independentes e possuem um raio de cobertura pequeno, é comum a utilização de um grande número de sensores para monitorar uma área grande. Um problema nesses tipos de redes é garantir que o máximo de dados capturados por esses sensores sejam coletados e transmitidos até uma estação base para que possam ser analisados por usuários. Uma abordagem para resolver esse problema é por meio da utilização de sensores especiais chamados cluster heads. Esses sensores são posicionados estrategicamente para coletar a informação de um grupo de sensores e transmiti-la para a estação base. Assim surge a necessidade de agrupar esses sensores. Nesse trabalho é proposta uma técnica híbrida baseada no algoritmo de agrupamento de dados K-Médias e em detecção comunidades em redes complexas. Esse algoritmo, chamado de QK-Médias, tenta aproveitar as vantagens das duas abordagens em duas etapas. Primeiro a rede é quebrada em comunidades usando uma técnica de detecção de comunidades. Em seguida essas comunidades são quebradas em subcomunidades de tal forma que os cluster heads consigam gerenciar. Os resultados obtidos a partir do agrupamento de sensores utilizando o QK-Médias mostram que é possível diminuir o número de mensagens perdidas na rede utilizando menos cluster heads que algoritmos tradicionais de agrupamento em redes de sensores sem fio.

Palavras-chave: Detecção de Comunidades em Redes Complexas, Redes de Sensores Sem Fio, Posicionamento de Cluster Head. 



\section{Abstract}

$\mathrm{W}$

ireless Sensor Networks are a special kind of ad-hoc network that are deployed in a monitoring field in order to detect some physical phenomenon. Due to the low dependability of individual nodes and small radio coverage, it is common to use a large number of sensors. A common problem in this sort of network is to guarantee that the highst number of captured data was sucessfull broadcast to the base station. One approach to solve this problem use special sensors called cluster heads. These sensors are responsible for collecting data from a group of common sensors and broadcast it to a base station. Thus, it is necessary to cluster these sensors. Here we propose a hybrid clustering algorithm based on community detection in complex networks and traditional K-means clustering technique: the QK-Means algorithm. This new algorithm is composed by two steps. First, the network is broken into communities and then broken into subcommuinties that the cluster heads can deal with. Simulation results show that QK-Means can decrease the rate of lost messages in the network using less cluster heads than tradicional clustering algorithms.

Palavras-chave: Complex Networks, Community Detection, Wireless Sensor Networks, Cluster Head Deployment. 


\section{Sumário}

Resumo $\quad$ x

Abstract $\quad$ xii

Sumário $\quad$ xiv

$\begin{array}{ll}\text { Lista de Figuras } & \text { Xv }\end{array}$

Lista de Tabelas $\quad$ xxi

Lista de Algoritmos $\quad$ xxiii

Lista de Símbolos $\quad$ xxiii

1 Introdução 1

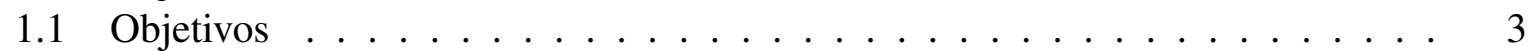

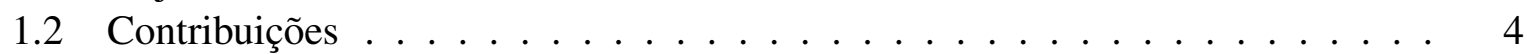

1.3 Apresentação dos Capítulos . . . . . . . . . . . . . . . 5

2 Agrupamento de Dados $\quad 7$

2.1 Dados . . . . . . . . . . . . . . . . . . . 8

2.2 Função de Similaridade ou Dissimilaridade . . . . . . . . . . . . . . . . . 10

2.3 Etapas do Processo de Agrupamento . . . . . . . . . . . . . . . . . . . . 11

2.4 Técnicas de Agrupamento . . . . . . . . . . . . . . . . . . . . . . 12

2.4.1 Algoritmos Hierárquicos . . . . . . . . . . . . . . . . . . . . 13

2.4.2 Algoritmos Baseados em Particionamento . . . . . . . . . . . . . . 16

2.4.3 Algoritmos Baseados em Distribuição . . . . . . . . . . . . . . . . . . 19

2.4.4 Algoritmos Baseados em Densidades . . . . . . . . . . . . . . . . . . . . 21

2.4.5 Algoritmos Baseados em Grafo . . . . . . . . . . . . . . . . . . . 26

2.5 Considerações Finais . . . . . . . . . . . . . . . . . . . . 28

3 Agrupamento de Dados em Redes de Sensores Sem Fio 31

3.1 Redes de Sensores Sem Fio . . . . . . . . . . . . . . . . . . . . . . . 31

3.2 Aplicações . . . . . . . . . . . . . . . . . . . . 32

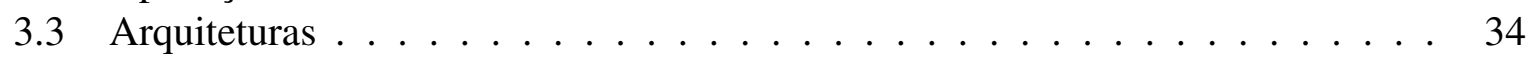

3.3.1 Redes Multihop Planas . . . . . . . . . . . . . . . . . . . . 35

3.3.2 Redes Multihop Hierárquicas . . . . . . . . . . . . . . . . . . 35 
3.4 Objetivos do Agrupamento de Dados . . . . . . . . . . . . . . . . . . . . . . 36

3.5 Taxonomia dos Atributos de Agrupamento . . . . . . . . . . . . . . . . . . 37

3.6 Algoritmos de Agrupamento . . . . . . . . . . . . . . . . . . . . . . . . . . . . . . . . . 39

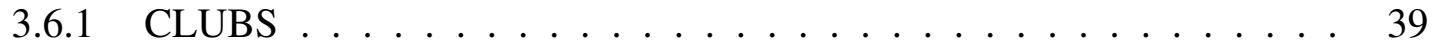

$3.6 .2 \mathrm{LEACH} \ldots \ldots \ldots \ldots \ldots \ldots \ldots . \ldots \ldots \ldots$

3.6 .3 HEED . . . . . . . . . . . . . . . . . . 43

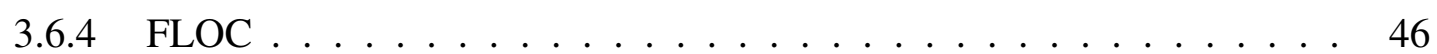

3.7 Considerações Finais . . . . . . . . . . . . . . . . . . 48

4 Detecção de Comunidades em Redes Complexas 51

4.1 Conceitos de Rede . . . . . . . . . . . . . . . . . . . . . . 51

4.2 Redes Complexas . . . . . . . . . . . . . . . . . . . . . . 54

$4.2 .1 \quad$ Rede Aleatória . . . . . . . . . . . . . . . . . . 55

4.2.2 Rede Pequeno Mundo . . . . . . . . . . . . . . . . . . . 55

4.2 .3 Rede Livre de Escala . . . . . . . . . . . . . . . . . . . . . . . . 56

4.3 Detecção de Comunidades . . . . . . . . . . . . . . . . 56

4.3.1 Método Baseado em Betweenness . . . . . . . . . . . . . . . . 57

4.3.2 Método Baseado em Caminhada Aleatória . . . . . . . . . . . . . . . . 60

4.3.3 Método Baseado em Sincronização . . . . . . . . . . . . . . . . . 61

4.3.4 Método Baseado em Competição de Partículas . . . . . . . . . . . . . . . . 62

4.3.5 Método Baseado em Movimentação de Vértices . . . . . . . . . . . . . 65

4.3.6 Método Baseado em Modularidade . . . . . . . . . . . . . . . . . . 68

4.4 Considerações Finais . . . . . . . . . . . . . . . . . . . . . . 71

5 QK-Médias $\quad 73$

5.1 Técnica de Agrupamento de Dados em RSSF . . . . . . . . . . . . . . . . 73

5.2 Modelo de Simulação de RSSF . . . . . . . . . . . . . . . . . . . . . . . . 77

5.3 Metodologia de Avaliação de Experimentos . . . . . . . . . . . . . . . . . . . 79

5.3.1 Variação do Tamanho do Buffer dos CHs . . . . . . . . . . . . . . 80

5.3.2 Variação do Tamanho do Buffer dos Escravos . . . . . . . . . . . . . . 80

5.3.3 Variação do Tamanho das subcomunidades . . . . . . . . . . . . . . . . 82

5.3.4 Variação no Raio de Cobertura e no Buffer dos CHs . . . . . . . . . . . 82

5.3.5 Variação nos Raios de Cobertura dos CHs e dos Escravos . . . . . . . . 84

5.3.6 Variação na Probabilidade de Geração de Mensagens e no tamanho do Buffer do CHs . . . . . . . . . . . . . . . . . . . . . 84

5.3.7 Algoritmos Tradicionais de Agrupamento em RSSF . . . . . . . . . . . 85

5.4 Considerações Finais . . . . . . . . . . . . . . . 86

6 Conclusão e Trabalhos Futuros 89

6.1 Conclusões . . . . . . . . . . . . . . . . . . . . . . 89

6.2 Trabalhos futuros . . . . . . . . . . . . . . . . . 90

$\begin{array}{ll}\text { Referências Bibliográficas } & 93\end{array}$

A Caminhos Mais Curtos de Todos os Pares 99 


\section{Lista de Figuras}

1.1 Conjunto de dados com grupos de formas variáveis (Karypis et al., 1999). . . . 2

2.1 Exemplo de agrupamento de dados. (a) Conjunto de dados originais representados em forma de pontos cartesianos. Cada cor representa um grupo sendo possível, por exemplo, encontrar: (b) Dois grupos ou (c) Seis grupos, entre outros. 7

2.2 Etapas do processo de agrupamento de dados (Xu \& Wunsch, 2008). . . . . . . 12

2.3 (a) Exemplo de um dendrograma que representa o resultado de um algoritmo de agrupamento hierárquico de um conjunto de dados composto por cinco pontos $\left\{p_{1}, \ldots, p_{5}\right\}$. (b) apresenta a mesma informação do dendrograma utilizando anotação de conjuntos. A cada iteração do algoritmo, se esse for divisivo, então tanto o dendrograma quanto a ordem dos conjuntos é vista de cima para baixo. Se o algoritmo for aglomerativo, então é tomado a ordem inversa, de baixo para cima. . . . . . . . . . . . . . . . .

2.4 Medidas de distância entre grupos: (a) conexão única, a menor distância é utilizada. (b) conexão completa, a maior distância é utilizada. (c) média de grupo, é tomado a média entre as distâncias de todos pares de objetos. (Tan et al., 2005)

2.5 Exemplo de agrupamento de dados usando o algoritmos Hierárquicos. A Figura (a) mostra o conjunto de dados formado por 6 pontos bidimensionais. Em seguida, são exibidos os resultados para alguns algoritmos: (b) Conexão única, (c) Conexão completa, (d) média do grupo, (e) de Ward. Para cada dendrograma, a altura na qual dois grupos são fundidos informa a distância de dois grupos. (Tan et al., 2005) . . . . . . . . . . . . . . . . .

2.6 Exemplo de iterações para o algoritmo K-Médias. A Figura (a) exibe o posicionamento inicial aleatório dos centróides. Cada centróide é representado pelo símbolo ' + ' e os grupos por pontos de mesmo símbolo. As Figuras (b), (c) e (d), nessa ordem, mostram as iterações seguinte do algoritmo, onde é possível observar o reposicionamento dos centróides e a reassociação dos pontos. $\mathrm{Na}$ última iteração cada centróide está localizado no ponto médio de cada grupo (Tan et al., 2005)

2.7 Exemplo de aplicação do algoritmo EM em conjunto de dados bidimensionais representados por aproximadamente 1000 pontos, gerados a partir da combinação de duas distribuições gaussianas, cada uma com aproximadamente 500 pontos. A primeira com centro no ponto $(-4,1)$ e $\sigma=2$. A segunda com centro no ponto $(0,0)$ e $\sigma=0.5$. O algoritmo resulta em dois grupos cujos pontos é representado por mesmo símbolo (Tan et al., 2005). . . . . . . . . . . . . . 
2.8 Nessa figura são exemplificadas as três classificações de pontos quando utilizada densidade baseada em ponto central. O Ponto A é central. B é um exemplo de ponto de limite e $\mathrm{C}$ é um ponto de ruído. . . . . . . . . . . .

2.9 Exemplo de agrupamento de dados usando o algoritmo DBSCAN. Parâmetros: MinPts $=4$ e Eps $=10$. (a) Dados da amostra com 3000 pontos. (b) Resultado do agrupamento onde cada símbolo representa um grupo, exceto o $\mathrm{X}$ que representa os pontos de ruído. (c) Pontos de centro (-), pontos de limite (+) e pontos de ruído $(\mathrm{x})$. (Tan et al., 2005) . . . . . . . . . . . . . .

2.10 Exemplos de grafos KNN: (a) Dados originais. (b) conectando apenas o vértice mais próximo. (c) conectando os dois mais próximos e (d) conectando os três mais próximos (Karypis et al., 1999). . . . . . . . . . . . . . 26

2.11 Etapas do algoritmo Chameleon (Karypis et al., 1999) . . . . . . . . . . . .

2.12 Resultado do agrupamento para conjunto de dados artificiais formados por (a) 10000 pontos e (b) 8000 pontos bidimensionais, onde cada cor representa um grupo. Os parâmetros utilizados são $k=10$ para gerar a rede e $\alpha=2$ (Karypis et al., 1999). . . . . . . . . . . . . . . . . . . .

3.1 Exemplo de arquitetura de RSSF com a presença de sensores escravos e uma estação base (sink) que envia dados para o usuário por meio da internet. Adaptado de (Zheng \& Jamalipour, 2009). . . . . . . . . . . . . . . . . . . . . .

3.2 Diferença entre as formas de envio de mensagens dos sensores até à(s) estação base (sink). (a) Rede single hop: a transmissão é feita diretamente para o sink. (b) Rede multihop plana: os dados são transmitidos aos nós mais próximos até chegarem no sink. Adaptado de (Zheng \& Jamalipour, 2009). . . . . . . . . . .

3.3 Redes hierárquicas e seus tipos de arquitetura de grupos: (a) Single hop, os sensores do grupo transmitem diretamente para o cluster head. (b) Multihop, existem sensores intermediários entre os sensores do grupo e o $\mathrm{CH}$. Adaptado de (Zheng \& Jamalipour, 2009). . . . . . . . . . . . . . . . . .

3.4 taxonomia para a classificação de algoritmos de agrupamento de sensores (Abbasi \& Younis, 2007). . . . . . . . . . . . . . . . . . . . . .

3.5 Resultado do processo de agrupamento utilizando o algoritmo CLUBS. (a) Pontos pretos são os CHs, pontos cinzas (recrutadores) são os sensores e os círculos pretos são os raios de cobertura dos CHs. (b) Resultado final com a formação dos grupos. Nós que estão em áreas de interseção pertencem a mais de um $\mathrm{CH}$ (sobreposição). (Nagpal \& Coore, 1998) . . . . . . . . . . . . . .

3.6 Formação dos grupos em duas rodadas, (a) e (b), do algoritmo LEACH. Pontos pretos maiores $(\bullet)$ simbolizam os $\mathrm{CHs}$, os outros pontos simbolizam os sensores, sendo que símbolos iguais definem os grupos (Heinzelman et al., 2002) . .

3.7 Estados da variável status no algoritmo FLOC (Demirbas et al., 2004). . . . .

4.1 (a) Um grafo não-direcionado. (b) Um grafo direcionado. (c) Grafo não direcionado com pesos. (d) Grafo direcionado com pesos. (e) Caminho em um grafo partindo do vértice 1 até 5. (f) Circuito em um grafo partindo do vértice 1 retornando ao mesmo vértice. (g) Grafo com os graus de cada vértices. (h) Grafo desconexo com dois componentes representados pelas cores azul e vermelho. . 
4.2 Interação entre proteínas de leveduras. Nós vermelhos representam proteínas essenciais e se removidas causam a morte da célula. Nós alaranjados representam proteínas com alguma importância e que, se removidas, retardaram o crescimento da célula. Nós verdes e representam proteínas com pouco significância e nós amarelos representam proteínas com significância desconhecida (Barabási \& Oltvai, 2004) . . . . . . . . . . . . . . . . . . . . . . . .

4.3 Processo de transformação de uma rede regular em uma rede aleatória sem aumentar vértices ou arestas. A rede regular inicial possuí 20 vértices, cada um deles conectado ao seus 4 vértices mais próximos. O processo de geração da rede foi repetido três vezes para diferentes valores de $p$, sendo que a rede pequeno mundo é gerada para valores pequenos de $p$. Extraído e adaptado de (Watts \& Strogatz, 1998). . . . . . . . . . . . . . . . . . . . . . .

4.4 Variação do caminho médio $L(p)$ e do coeficiente de clusterização $C(p)$ em função da probabilidade $p$ de reconexão de arestas. Esse gráfico foi gerado com a média dos valores obtidos após repetir 20 vezes o processo descrito na Figura 4.3 normalizados com valores de $L(0)$ e $C(0)$ para a rede regular inicial. A rede utilizada possuía $n=1000$ vértices com grau médio $k=10$. O efeito de pequeno mundo pode ser observado para valores pequenos de $p$ onde $L$ é pequeno e $C$ é grande (Watts \& Strogatz, 1998) . . . . . . . . . . . . . .

4.5 Rede livre de escala seguindo regra da potência. A rede possui 200 vértices e 199 arestas onde os vértices coloridos tem maior numero de arestas (hubs) (Strogatz, 2001)

4.6 Rede com três comunidades circundadas com linhas pontilhadas. . . . . . . .

4.7 Rede de amizade de crianças em escola dos Estados Unidos. Cada vértice representa uma criança e a sua etnia é representada pela cor do vértice. Nós verde representam a etnia afro-descendente, nós bege representam crianças brancas e nós rosa representam outras etnias. As duas comunidades mais acima representam as crianças do ensino médio e as outras duas inferiores representam as crianças do ensino fundamental (Moody, 2002) . . . . . . . . . . . . . . .

4.8 Exemplo de iterações em algoritmos de detecção de comuinidades aglomerativos e divisivos . . . . . . . . . . . . . . . . . . .

4.9 Simulação computacional do método de detecção de comunidades por sincronização utilizando 128 neurônios $(n=128), c_{Y}=c_{E}=0,1$. (a) Rede aleatória onde os vértices de mesma cor são da mesma comunidade. (b) Disparos dos neurônios ao longo do tempo (Quiles et al., 2009). . . . . . . . . . . . . . . . .

4.10 Detecção de comunidades utilizando técnica de competição de partículas. O número de vértices é $n=128$, apresenta 4 comunidades e a média dos graus dos vértices é $\langle k\rangle=16$. A Figura (a) exibe o estado inicial com quatro partículas posicionadas aleatoriamente sendo representadas pelas cores amarelo, laranjado, azul claro e azul escuro. A cor vermelho é utilizada para representar vértices que ainda não pertencem a uma partícula. (b) 250 iterações. (c) 3500 iterações. (d) 7000 iterações, demonstrando a estabilização do sistema (Quiles et al., 2008) . . . . . . . . . . . . . . . . . . . . . . .

4.11 Rede artificial após a detecção de comunidades onde cada comunidade é representada por uma cor (de Oliveira et al., 2008). . . . . . . . . . . . . . . . 67

4.12 Atualização e convergência dos ângulos (de Oliveira et al., 2008). . . . . . . . 67 
5.1 Redes artificiais com 1000 nós escravos distribuídos em: (a) 16 gaussianas e (b) 8 bananas. ................

5.2 Resultado da detecção de comunidades realizada pelo QK-Médias na base de dados artificial da Figura 5.1(b), sendo que cada cor representa um grupo de sensores. O processo de agrupamento é feito em duas etapas: (a) detecção de comunidades utilizando o algoritmo proposto por Clauset et al. (2004) (Alg. 10) e (b) detecção de subcomunidades utilizando o algoritmo K-Médias (Alg. 2). 76

5.3 Um exemplo do modelo de RSSF onde os nós escravos são representados por círculos, os cluster heads representados por triângulos e a nó mestre (estação base) representado por um losango. Os círculos com linha tracejadas exibe os clusters. . . . . . . . . . . . . . . . . .

5.4 Variação do tamanho do buffer dos cluster head e a influência sob a porcentagem de mensagens perdidas (LM) para alguns algoritmos de agrupamento. Para essa simulação foram considerados 1000 sensores escravo divididos em forma de 8 bananas (Fig. 5.1(b)). Os parâmetros de simulação são: $S_{r}=50 \mathrm{~m}$, $C H_{r}=25 m, S_{b}=50$ mensagens e $\lambda=10 \%$. Cada ponto do gráfico representa a média dos resultados de 30 execuções da simulação. . . . . . . . . . . . . .

5.5 Variação do $S_{b}$ e sua influência sob $L M$ para alguns algoritmos de clusterização. Para essa simulação foram considerados 1000 sensores escravo divididos em forma de 8 bananas (Fig. 5.1(b)). Os parâmetros de simulação são: $S_{r}=50 \mathrm{~m}$, $C H_{r}=25 m, C_{b}=50$ mensagens e $\lambda=10 \%$. Cada ponto do gráfico representa a média dos resultados de 30 execuções da simulação. . . . . . . . .

5.6 Variação de $\lambda$ e sua influência sob $L M$ para alguns algoritmos de clusterização. Para essa simulação foram considerados 1000 sensores escravo divididos em 16 gaussianas (Fig. 5.1(a)). Os parâmetros de simulação são: $S_{r}=50 \mathrm{~m}$, $C H_{r}=25 \mathrm{~m}, S_{b}=50$ mensagens e $C H_{b}=2500$ mensagens. Cada ponto do gráfico representa a média dos resultados de 30 execuções da simulação. . . . .

5.7 Variação do tamanho das subcomunidades e influência sob a cobertura da rede e $L M$. Para essa simulação foram considerados 1000 sensores escravo divididos em 16 gaussianas (Fig. 5.1(a)). Os parâmetros de simulação são: $S_{r}=50 \mathrm{~m}$, $C H_{r}=25 m, S_{b}=50$ mensagens, $C H_{b}=2500$ mensagens e $\lambda=10 \%$. Cada ponto do gráfico representa a média dos resultados de 30 execuções da simulação. 83

5.8 Variação do $C H_{r}$ e $C H_{b}$ e sua influência sob $L M$. Para essa simulação foram considerados 1000 sensores escravo divididos em forma de 8 bananas (Fig. 5.1(b)). Os parâmetros de simulação são: $S_{r}=50 \mathrm{~m}, S_{b}=50$ mensagens e $\lambda=10 \%$. Cada ponto do gráfico representa a média dos resultados de 30 execuções da simulação. . . . . . . . . . . . . . . . . . .

5.9 Influência da variação do $C H_{r}$ e $S_{r}$ sob $L M$. Para essa simulação foram considerados 1000 sensores escravo divididos em forma de 8 bananas (Fig. 5.1(b)). Os parâmetros de simulação são: $S_{b}=50, C H_{b}=1000$ mensagens e $\lambda=10 \%$. Cada ponto do gráfico representa a média dos resultados de 30 execuções da simulação. . . . . . . . . . . . . . . . . . .

5.10 Influência da variação do $\lambda$ e $C H_{b}$ sob $L M$. Para essa simulação foram considerados 1000 sensores escravo divididos em forma de 8 bananas (Fig. 5.1(b)). Os parâmetros de simulação são: $S_{b}=50$ mensagens, $S_{r}=25 \mathrm{~m}$ e $C H_{r}=50 \mathrm{~m}$. Cada ponto do gráfico representa a média dos resultados de 30 execuções da simulação. . . . . . . . . . . . . . . . . . . . . 
5.11 (a) Influência da variação de $\lambda$ para alguns algoritmos tradicionais de agrupamento de dados em RSSF. Para essa simulação foram considerados 1000 sensores escravo divididos em forma de 16 gaussianas (Fig. 5.1(a)). Os parâmetros de simulação são: $S_{r}=25 \mathrm{~m}, C H_{r}=50 \mathrm{~m}, S_{b}=200$ e $C H_{b}=500$. Cada ponto do gráfico representa a média dos resultados de 30 execuções da simulação. (b) Porcentagem de CHs utilizado pelos algoritmos de agrupamento. . . . . . . . .

5.12 (a) Influência da variação de $\lambda$ para alguns algoritmos tradicionais de agrupamento de dados em RSSF. Para essa simulação foram considerados 1000 sensores escravo posicionados esparsamente aleatorios em uma área de $2800 \times 2800$. Os parâmetros de simulação são: $S_{r}=5 \mathrm{~m}, \mathrm{CH}_{r}=10 \mathrm{~m}, S_{b}=50$ e $C H_{b}=$ 1000. Cada ponto do gráfico representa a média dos resultados de 30 execuções da simulação. (b) Porcentagem de CHs utilizado pelos algoritmos de agrupamento. . . . . . . . . . . . . . . . . . . .

5.13 (a) Influência da variação de $\lambda$ para alguns algoritmos tradicionais de agrupamento de dados em RSSF. Para essa simulação foram considerados 1000 sensores escravo divididos em forma de 16 gaussianas (Fig. 5.1(a)). Os parâmetros de simulação são: $S_{r}=25 \mathrm{~m}, C H_{r}=50 \mathrm{~m}, S_{b}=200$ e $C H_{b}=500$. Cada ponto do gráfico representa a média dos resultados de 30 execuções da simulação. (b) Porcentagem de $\mathrm{CHs}$ utilizado pelos algoritmos de agrupamento. . . . . . . . .

A.1 Exemplo de grafo ponderado. . . . . . . . . . . . . . . . . 100 


\section{Lista de Tabelas}

2.1 Exemplo de dados climáticos. Cada linha representa um dado (data) e cada coluna representa os atributos de cada dado: temperatura, pressão e presença de

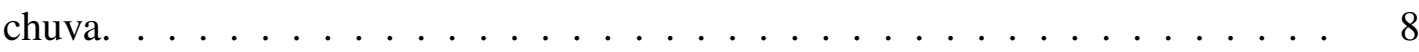

2.2 Tipos de Atributos. . . . . . . . . . . . . . . . . . . 9

2.3 Algumas funções de dissimilaridades (Tan et al., 2005) . . . . . . . . . . . . 10

2.4 Coeficientes da fórmula de Lance-Willians. . . . . . . . . . . . . . . . . . . 15

3.1 Características Algoritmos de Agrupamento . . . . . . . . . . . . . . . . . . 49

3.2 Taxonomia . . . . . . . . . . . . . . . . . . . . . 49 


\section{Lista de Algoritmos}

1 Algoritmo básico para agrupamento hierárquico aglomerativo . . . . . . . . . . 14

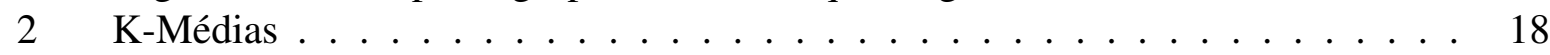

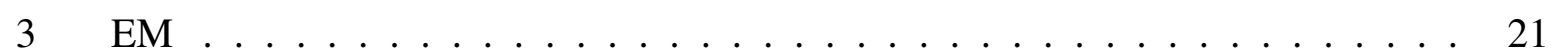

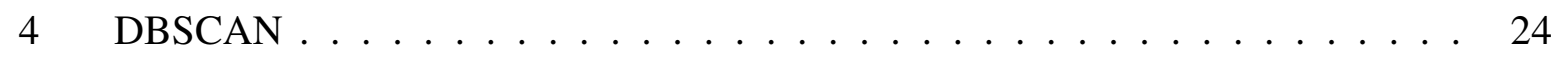

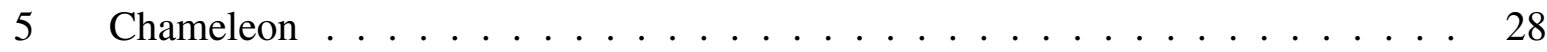

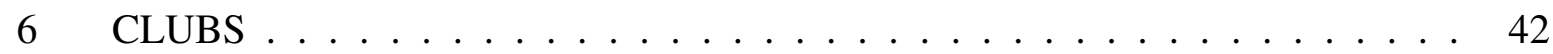

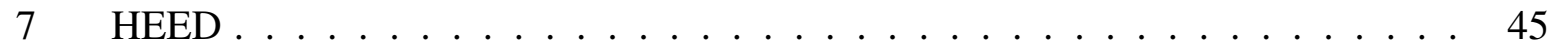

8 Detecção de Comunidade com betweenness . . . . . . . . . . . . . . . . 58

9 Clusterização de dados por meio de movimentação de vértices . . . . . . . . . . 69

10 Detecção de Comunidade . . . . . . . . . . . . . . . . . . 71

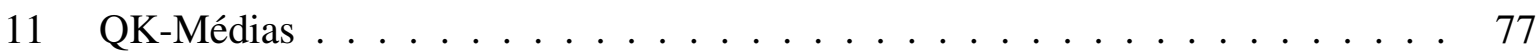

12 Fase de Monitoramento da Simulação . . . . . . . . . . . . . . . . . . 79

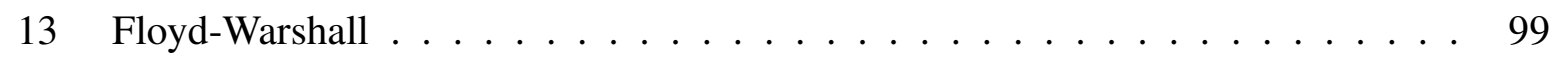





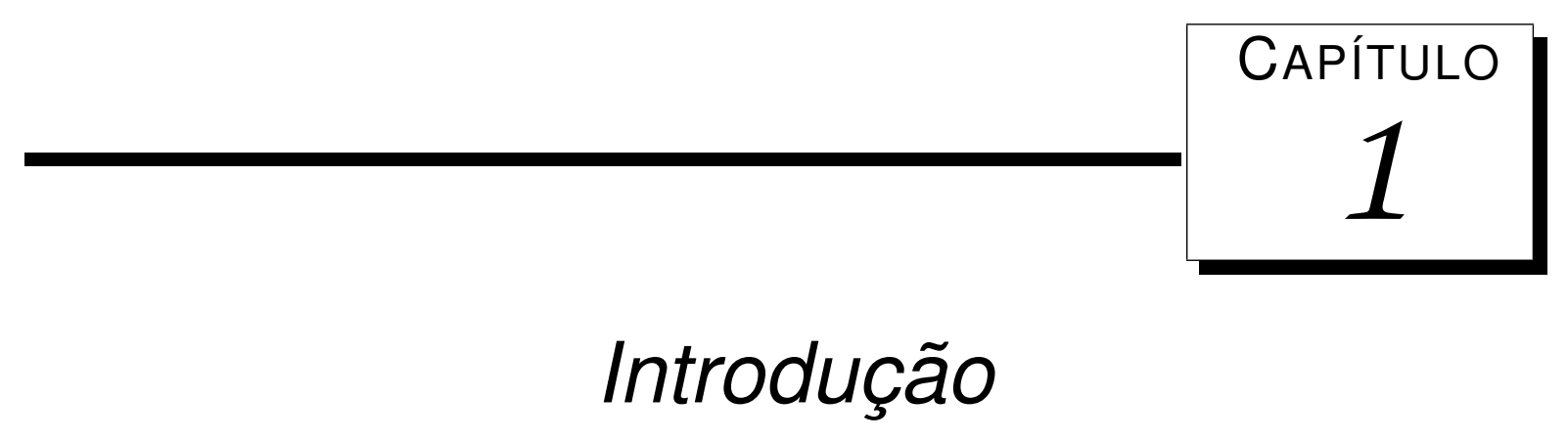

Redes de Sensores Sem Fio (RSSF) têm sido consideradas das mais importantes tecnologias do século XXI (Week, 1999). Devido a avanços tecnológicos nas áreas de eletrônica, sistemas mecânicos e comunicação sem fio, foi possível construir sensores pequenos e de baixo custo, que ligados em rede, podem monitorar uma área física. Esses microsensores podem ser posicionados no chão, no ar, dentro da água, no corpo humano, em veículos e dentro de construções, e podem ser ligados em redes para controlar casas, cidades e ambientes em geral (Chong et al., 2003).

As RSSF são compostas por sensores que possuem um módulo de comunicação, processadores, memória e bateria. Esse conjunto de nós da rede pode ser composto por sensores do mesmo tipo ou conter sensores especiais. Uma estação base envia tarefas a esses sensores que são capazes de coletar os dados do ambiente, comunicar uns com ou outros para realizar as tarefas desejadas e retornar a informação para a estação base. A partir dessas comunicações, é possível construir várias topologias de redes. É comum que essas redes sejam formadas por grandes quantidades de nós, onde os nós são posicionados no ambiente que se deseja ser monitorado. Essa estratégia de posicionamento de grandes quantidades de sensores de baixo custo apresenta algumas vantagens como: 1) tolerância a falhas devido às operações distribuídas; 2) cobertura uniforme do ambiente monitorado; 3) facilidade de posicionamento dos sensores; 4) redução no consumo de energia e 5) prolongamento da vida útil da rede.

Uma topologia de RSSF muito utilizada é chamada de cluster tree e se caracteriza pela presença de grupos (ou clusters) de sensores conectados entre si. Nesse tipo de rede, são utilizados sensores especiais, chamados cluster heads, que tem como principal objetivo coletar os dados de cada sensor do grupo, visando aumentar a cobertura da rede e diminuir o número de mensagens perdidas na rede. Entretanto, nesse tipo de topologia surge o problema de como agrupar esses sensores e depois posicionar os cluster heads de cada grupo. 


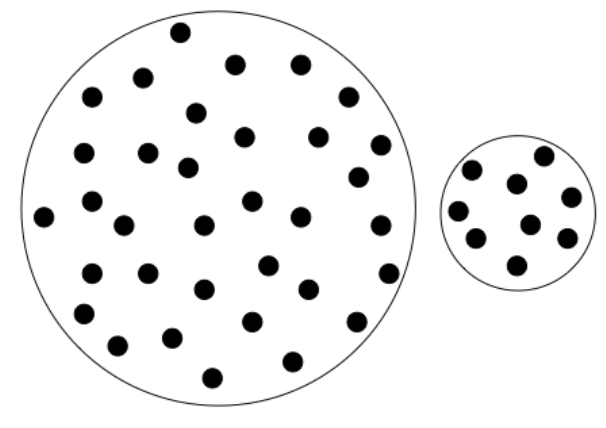

(a)

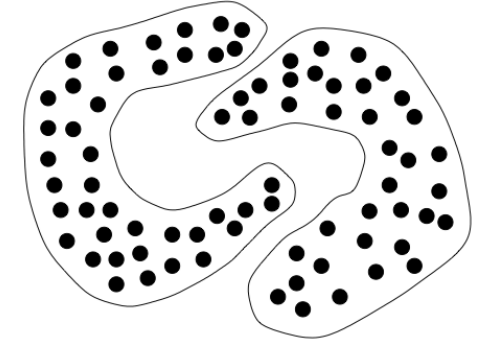

(b)

Figura 1.1: Conjunto de dados com grupos de formas variáveis (Karypis et al., 1999).

Em linhas gerais, a tarefa de agrupamento de dados resume-se em utilizar a informação encontrada nos dados e seus relacionamentos para dividir os dados em grupos, sendo os elementos de um grupo semelhantes (ou relacionados) entre si, mas diferentes (ou não relacionados) dos elementos de outros grupos. Para realizar essa tarefa existem vários algoritmos de agrupamento de dados que são aplicados em vários campos da ciência, principalmente na área de mineração de dados, reconhecimento de padrões, aprendizado de máquina, etc. A maioria desses algoritmos realiza o agrupamento por meio da otimização de uma função objetivo. O algoritmo K-Médias, por exemplo, é baseado no conceito de centróides e tenta encontrar os grupos minimizando a função da soma das distâncias quadradas entre cada ponto e seu respectivo centróide (Forgy, 1965; Macqueen, 1967). Entretanto, o principal problema dessas abordagens é que elas não apresentam bons resultados para conjuntos de dados de formas variáveis. Por exemplo, o K-Médias restringe-se a identificação de grupos de forma elipsoidal. Na Figura 1.1 são exemplificados dois conjuntos de dados, cada um formado por dois grupos de formas bem variáveis. No primeiro caso (Fig. 1.1(a)) o tamanho dos grupos é bem diferente e no segundo caso (Fig. 1.1(b)) os grupos apresentam formatos côncavos. Para esses casos, algoritmos como o K-Médias não apresentam bons resultados.

No intuito de melhorar a detecção de grupo, foram propostas outras técnicas de agrupamento, entre elas uma baseada em grafos. O Chameleon é um algoritmo baseado em grafo, proposto por Karypis et al. (1999), que consegue detectar grupos de formas e tamanhos variados. Inicialmente ele modela os dados por meio de um grafo esparso, onde cada dado é representado por um nó e os pesos das arestas representam a similaridade entre os dados. Depois o algoritmo realiza o agrupamento em duas etapas. Primeiro, o Chameleon utiliza um algoritmo de particionamento de grafos para encontrar uma grande quantidade de grupos pequenos. Na segunda fase, é utilizado um algoritmo aglomerativo hierárquico para encontrar de fato os grupos. $\mathrm{O}$ problema em utilizar teoria dos grafos para encontrar grupos é que os algoritmos de agrupamento tentam buscar soluções ótimas. É muito comum encontrar no mundo real bases de dados muito grandes, com milhões ou bilhões de dados, e isso inviabiliza a utilização de tais técnicas. Nesse sentido surge a área de Redes Complexas que tem como objetivo estudar essas redes de grande porte e propor algoritmos que sejam executados em tempo razoável. 
Em muitas redes reais, a topologia da rede, ou seja, a maneira como esses nós da rede foram conectados, não foi feita aleatoriamente mas também não apresenta um padrão rígido muito bem definido. A topologia das redes complexas está em um meio termo, não sendo aleatórias nem regulares. Um dos primeiros trabalhos em Redes Complexas se deu em 1929 quando o escritor húngaro Frigyes Karinthy escreveu Chains-Links. Esse texto passava a idéia de que todas as pessoas do mundo estão conectadas por poucas pessoas, ou seja, uma pessoa conhece outra pessoa, que conhece outra e assim sucessivamente faz com que todos estejam conectados formando uma grande rede de relacionamentos. Essa hipótese foi testada por Milgram (1967) que verificou que são necessárias em média seis pessoas para que cartas cheguem aos seus destinatários passando de mão em mão. Esse fato ficou conhecido como a teoria dos seis graus de separação (ou pequeno mundo), tendo sido estudada a fundo por de Sola Pool \& Kochen (1978). Mais tarde, Watts \& Strogatz (1998) estudaram redes reais e propuseram um modelo de rede que apresentasse o fenômeno de pequeno mundo. Da mesma forma, outros modelos de redes foram propostos a partir da observação de redes reais. Outro modelo bem conhecido é o grupos das redes livre de escala, estudas por Barabasi \& Albert (1999). Nessas redes, muitos nós tem poucas conexões e poucos nós tem muitas conexões. Esse e outros modelos de redes complexas possibilitaram simular redes reais e estudá-las a fim de entendê-las.

Uma estrutura frequentemente observada nesses tipos de redes é conhecida como comunidade. Esse estrutura é formada por um subconjunto dos nós da rede, que apresenta uma grande quantidade de arestas conectando seus nós mas poucas conexões entre esses nós e os demais da rede. A partir da detecção dessas comunidades é possível entender e revelar informações a respeito da rede estudada. Por exemplo, em redes sociais, é possível utilizar alguma técnica de detecção de comunidades para encontrar grupos de pessoas que possuem gostos musicais semelhantes. Desta forma, se uma nova pessoa desconhecida passa a fazer parte dessa comunidade, então é provável que ela também tenha os mesmo gostos musicais.

Para realizar a detecção de comunidades, várias técnicas foram propostas por diferentes autores. Newman \& Girvan (2003) propuseram uma técnica hierárquica divisiva que calcula o menor caminho entre todos os pares de vértices, conta o número que cada aresta foi percorrida (betweenness) e remove as mais utilizada até que cada vértice esteja em uma comunidade. Clauset et al. (2004) utilizaram a medida de modularidade $Q$, que mede a qualidade de uma partição da rede, para encontrar comunidades. Inicialmente cada nó da rede representa um grupo e os grupos são fundidos iterativamente até que a modularidade da rede pare de crescer.

\subsection{Objetivos}

A cada dia, redes de sensores cada vez maiores são utilizadas. Porém, quanto maior o número de sensores, mais difícil é garantir que os dados capturados pelos sensores cheguem até a estação base e possam ser interpretados pelo usuário. Uma forma de melhorar a cobertura da rede é realizando o agrupamento desses sensores e posicionar um sensor cluster head encarre- 
gado de recolher a informação desse grupo. Entretanto, a utilização de técnicas tradicionais de agrupamento torna-se inviável para essas redes de grande porte pois demandam muito tempo e muitas vezes não apresentam bons resultados.

Algoritmos de detecção de comunidades em redes complexas apresentam boas soluções para o problema de agrupamento de dados em redes de larga escala podendo também encontrar grupos de formas variáveis. Porém, existe uma restrição quanto a aplicação dessas técnicas em Redes de Sensores sem Fio. Os sensores cluster heads tem um raio de cobertura que limita o tamanho máximo das comunidades, portanto, seria interessante que essas comunidades encontradas fossem quebradas em subcomunidades de formato elipsoidal para aumentar a cobertura de todos os sensores da comunidade.

Nesse trabalho, é proposto construir um algoritmo de agrupamento híbrido baseado em detecção de comunidades em redes complexas e no algoritmo tradicional de agrupamento KMédias. Essa nova abordagem híbrida, chamada QK-Médias, tenta aproveitar as qualidades das duas técnicas e minimizar seus defeitos a fim de encontrar um melhor agrupamento. Técnicas baseadas em grafos podem encontrar grupos de formas variáveis e o algoritmo K-Médias pode encontrar subcomunidades de formato elipsoidal. Desta forma, essa técnica pode ser aplicada ao problema de posicionamento de nós cluster head em redes de sensores sem fio pois as subcomunidades encontradas podem ser gerenciadas por um cluster head. Para utilizar o algoritmo K-Médias, é necessário informar o número $K$ de grupos desejados, desconhecido a priori. Para resolver esse problema, o algoritmo QK-Médias calcula o diâmetro de cada subcomunidade, ou seja, a maior distância entre todos pares de vértices da subcomunidade utilizando o algoritmo Floyd-Warshall e divide pelo diâmetro de cobertura dos cluster heads. Dessa forma é possível quebrar as comunidades em subcomunidades em formato elipsoidal dividindo o esforço de monitoração da rede para que os cluster heads possam cobrir toda a comunidade.

Além disso, foi proposto e construído um modelo de RSSF simplificado para que seja possível simular o funcionamento de uma RSSF. Nesse modelo foram considerados alguns parâmetros como: número de sensores e CHs, tamanho do buffer de armazenamento dos sensores escravos e CHs, probabilidade de geração de mensagem, etc. Com esse modelo é possível avaliar essa e outras técnicas considerando algumas medidas de comparação, como o número de mensagens perdidas (Lost Messages) na rede e nível de cobertura dos sensores.

\subsection{Contribuições}

A partir dos experimentos realizados e publicados em (Ferreira et al., 2011), foi possível verificar a influência da variação dos parâmetros de simulação sob a cobertura e o número de mensagens perdidas na rede. A partir da análise dos resultados desses experimentos, foi criado o algoritmo QK-Médias, que foi publicado em (Ferreira et al., 2012) juntamente com outras simulações. Nesses experimentos foram encontradas situações onde o algoritmo QKMédias consegue posicionar os sensores cluster heads de forma eficiente, e consequentemente 
consegue cobrir boa parte dos sensores escravos da rede utilizando menos cluster heads que outra técnicas.

\subsection{Apresentação dos Capítulos}

No Capítulo 2 serão apresentados os conceitos referentes a agrupamento de dados e as abordagens mais comuns na literatura para realizar essa tarefa. No Capítulo 3 são introduzidos conceitos de Redes de Sensores sem Fio, bem como técnicas de agrupamento de sensores em RSSF. Em seguida, serão apresentados no Capítulo 4 alguns modelos de redes complexas e algoritmos de detecção de comunidades. No Capítulo 5, será apresentado o resultado desse trabalho: o algoritmo QK-Médias, o modelo de RSSF proposto e o resultado dos experimentos realizados. Por fim, no Capítulo 6 serão feitas algumas conclusões sobre o modelo e algoritmo proposto, bem como os trabalho futuros que servem como continuidade desse trabalho. 


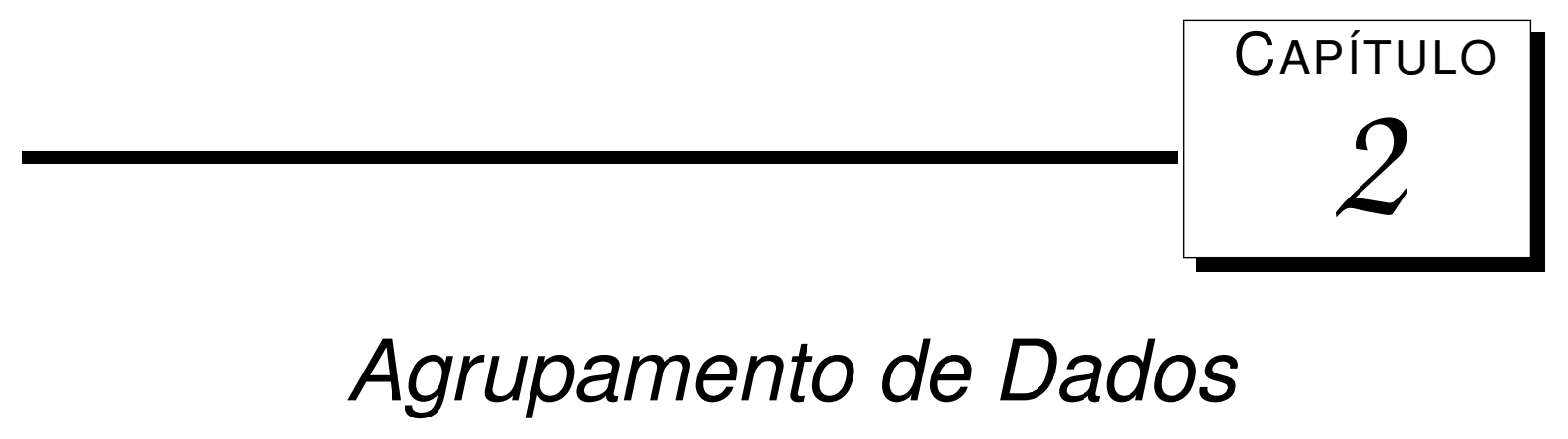

Todos os dias são geradas grandes quantidades de informação que são armazenadas e representadas em forma de dados. Esses dados são guardados para serem processados e tentar extrair conhecimento. Uma forma de extrair conhecimento consiste em dividir os dados em grupos (clusters) que tenham algum significado (Tan et al., 2005). Essa tarefa de agrupamento de dados utiliza a informação encontrada nos dados e seus relacionamentos para dividir os dados em grupos, sendo que os elementos de um grupo sejam semelhantes (ou relacionados) entre si, mas diferentes (ou não relacionados) dos elementos de outros grupos. Quanto maior for a semelhança entre os elementos do grupo e maior a diferença entre os grupos, melhor será o agrupamento. Na Figura 2.1 é apresentado possíveis resultados do processo de agrupamento de dados e possíveis resultados, onde os dados são representados por pontos e as cores informam os grupos. Nesse exemplo, a semelhança entre os pontos do mesmo grupo está na distância euclidiana entre eles, sendo que pontos mais próximos tendem a ficar em um mesmo grupo e pontos mais distantes em grupos separados.

$$
\begin{aligned}
& \text { O OO O } \\
& \text { OO } \mathrm{O} O \mathrm{O}
\end{aligned}
$$

(a)

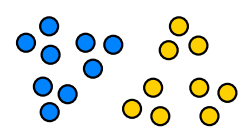

(b)

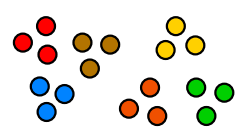

(c)

Figura 2.1: Exemplo de agrupamento de dados. (a) Conjunto de dados originais representados em forma de pontos cartesianos. Cada cor representa um grupo sendo possível, por exemplo, encontrar: (b) Dois grupos ou (c) Seis grupos, entre outros.

Técnicas de agrupamento de dados vem sendo utilizadas em muitos campos científicos (Anderberg, 1973; Everitt et al., 2009; Hartigan, 1975). Na área de engenharia, agrupamento de da- 
dos vem sendo aplicado às areas de reconhecimento biométrico, reconhecimento de fala, análise de sinal de radares, compressão de informação e remoção de ruído. Em ciências da computação, aplicações em mineração de dados, análise de banco de dados espaciais, recuperação de informação, segmentação de imagens. A área de ciências médicas consiste na maior área de aplicação de agrupamento de dados. As mais importantes aplicações estão em definição de taxonomia, identificação das funções de genes e proteínas, diagnóstico e tratamento de doenças. $\mathrm{Na}$ área de astronomia e ciências da terra, agrupamento de dados é aplicado a classificação de planetas e estrelas, investigar a formação de cidades e estudos sobre rios e montanhas. Na área de ciências sociais, essas técnicas são aplicadas em analise de padrão de comportamento, identificação de relações entre diferentes culturas, análise de redes sociais, buscas arqueológicas e classificação de artefatos e estudos de psicologia criminal. Em economia, as técnicas de agrupamento são aplicadas em reconhecimento de padrões de compras e características de usuários, análise de tendência do mercado de ações, etc.

\subsection{Dados}

Os dados de um conjunto podem ter vários nomes como: objetos, registros, vetores, casos, padrões ou exemplos. Esses dados possuem características que os definem e que variam de dado para dado, sendo chamadas de: atributos, variáveis ou características. Esses atributos podem ser do tipo quantitativos ou qualitativos, e também ter características especiais como, por exemplo, relacionamentos específicos entre dados. Os tipos de dados são variados e definem quais técnicas podem ser utilizadas para analisar os dados. Um exemplo de conjunto de dados pode ser visualizado em forma de tabela (2.1) onde cada linha é um item de dado e cada coluna é um atributo do dado.

Tabela 2.1: Exemplo de dados climáticos. Cada linha representa um dado (data) e cada coluna representa os atributos de cada dado: temperatura, pressão e presença de chuva.

\begin{tabular}{ccccc}
\hline Data & $\begin{array}{c}\text { Temperatura } \\
\left({ }^{\circ} \mathrm{C}\right)\end{array}$ & $\begin{array}{c}\text { Pressão } \\
(\mathrm{hPa})\end{array}$ & Presença de Chuva & $\cdots$ \\
\hline $25 / 02 / 12$ & 23 & 1012 & não & $\cdots$ \\
\hline $26 / 02 / 12$ & 25 & 1014 & não & $\cdots$ \\
\hline $27 / 02 / 12$ & 23 & 1015 & sim & $\cdots$ \\
\hline$\vdots$ & $\vdots$ & $\vdots$ & $\vdots$ & $\ddots$ \\
\hline
\end{tabular}

Os atributos que descrevem os dados podem ser contínuos, discretos ou binários (Jain \& Dubes, 1988). Atributos contínuos podem assumir valores dentro de um conjunto infinito incontável. Um exemplo de atributo contínuo é a altura e o peso de uma pessoa. Por outro lado, os valores de atributos discretos estão em um conjunto infinito contável. Exemplos de atributos discretos são as notas de avaliação de um vinho, cores e modelos de carros, etc. Atributos binários são um caso especial de atributos discretos que podem assumir apenas dois valores, por 
exemplo, na Tabela 2.1, o atributo 'Presença de Chuva' é binário, pois pode receber apenas dois valores: sim ou não.

Outra característica dos atributos dos dados é o nível de medida, que reflete o quão significante é o valor do atributo. Os quatro tipos de medidas são: nominal, ordinal, intervalar e proporcional, descritos na Tabela 2.2.

Tabela 2.2: Tipos de Atributos.

\begin{tabular}{ccll}
\hline \multicolumn{1}{c}{ Tipo do Atributo } & Descrição & Exemplos \\
\hline \multirow{3}{*}{ Qualitativos } & Nominal & $\begin{array}{l}\text { São representados por rótulos, } \\
\text { estados ou nomes. }\end{array}$ & $\begin{array}{l}\text { Cor dos olhos, sexo, número de } \\
\text { identificação }\end{array}$ \\
\cline { 2 - 4 } Ordinal & $\begin{array}{l}\text { Também são representados por } \\
\text { nomes mas apresentam informa- } \\
\text { ções suficientes para ordenar da- } \\
\text { dos. }\end{array}$ & $\begin{array}{l}\text { Notas de avaliação (Ruim, Bom, } \\
\text { excelente). }\end{array}$ \\
\hline \multirow{5}{*}{ Intervalar } & $\begin{array}{l}\text { As diferenças entre os valores } \\
\text { são significativas. Existe uma } \\
\text { unidade de medida. }\end{array}$ & $\begin{array}{l}\text { Datas e Temperaturas em Cel- } \\
\text { sius. }\end{array}$ \\
\cline { 2 - 4 } & $\begin{array}{l}\text { Possui todas as características } \\
\text { dos anteriores além do conceito } \\
\text { de zero absoluto tornando as di- } \\
\text { ferenças e as proporções dos da- } \\
\text { dos significativas. }\end{array}$ & $\begin{array}{l}\text { Frequência, Salário, Tempera- } \\
\text { tura em Kelvin. }\end{array}$ \\
\hline
\end{tabular}

Muitas vezes o conjunto de dados apresenta imperfeições geradas devido a erro humano, limitação nos dispositivos de medição, etc. O erro mais comum está na medição e coleta de dados e ocorre quando os valores reais do sistemas são diferentes dos valores registrados. Isso pode ocorrer por falta de equipamentos de medição eficientes ou por erro de digitação dos valores. Os principais defeitos gerados a partir de erros de medição e ou coleta de dados são apresentados a seguir.

- Ruído: O ruído é o considerado um erro de medição aleatório. Ele pode deformar os dados, seja alterando valores reais ou adicionando novos dados que não estão presentes, de fato, nos dados reais.

- Valores faltando: Muitas vezes os dados coletados não apresentam todos os valores de atributos. Isso pode ocorrer por erro de medição ou porque algum atributo não se aplica a um determinado dado. A estratégia mais simples para estes dados seria a remoção dos mesmos. Outra forma de tratar esses dados seria ignorando-os durante a execução do algoritmo de agrupamento.

- Valores inconsistentes: Erros de medição podem gerar inconsistências nos dados. Algumas delas podem ser mais simples de detectar, como por exemplo, quando o valor da altura de uma pessoa é negativo. Outras inconsistências podem ser mais complexas de detectar, por exemplo quando os valores dos dados são dependentes de outros. Em alguns 
casos, quando se conhece as restrições de valores dos dados, é possível corrigir esses valores.

- Dados duplicados: Outro problema comum é a presença de dados duplicados. Essas duplicatas podem ser total, quando todos os atributos são iguais ou parcial, quando quase todos os atributos são iguais. Se a duplicata for total, ela pode ser tratada removendo um desses dados duplicados.

Assim, é importante observar a qualidade dos dados antes de realizar o agrupamento de dados. Para tratar essas deformidades pode ser realizado um pré-processamento dos dados e ou por meio da escolha de algoritmos de agrupamento que tratem a baixa qualidade dos dados.

\subsection{Função de Similaridade ou Dissimilaridade}

Para realizar a tarefa de agrupamento de dados é necessário medir o quão similar (ou dissimilar) são dois registros. Assim, a diferença entre dois objetos $x_{i}$ e $x_{j}$ de um conjunto pode ser expressa por meio de uma medida numérica, calculada por uma função de distância (ou dissimilaridade) $D_{i j}$ geralmente no intervalo $[0,1]$ ou $[0, \infty)$, sendo 0 quando os dois objetos forem totalmente iguais e 1 (ou $\infty$ ) quando forem totalmente diferentes. As funções de dissimilaridade para atributos quantitativos mais utilizadas na literatura são apresentadas na Tabela 2.3. A definição da função de dissimilaridade (ou similaridade) determinará o formato do grupos encontrados pelos algoritmos de agrupamento (serão apresentados na Seção 2.4).

Tabela 2.3: Algumas funções de dissimilaridades (Tan et al., 2005).

\begin{tabular}{|c|c|c|}
\hline Medida & Função & Comentários \\
\hline $\begin{array}{l}\text { Distância de } \\
\text { Minkowski }\end{array}$ & $D_{i j}=\left(\sum_{l=1}^{d}\left|x_{i l}-x_{j l}\right|^{\frac{1}{n}}\right)^{n}$ & Família de medidas mais utilizadas. \\
\hline $\begin{array}{l}\text { Distância de } \\
\text { Manhattan }\end{array}$ & $D_{i j}=\sum_{l=1}^{d}\left|x_{i l}-x_{j l}\right|$ & $\begin{array}{l}\text { Caso específico da Distância Minkowsk } \\
\text { quando } n=1 \text {. }\end{array}$ \\
\hline $\begin{array}{l}\text { Distância } \\
\text { Euclidiana }\end{array}$ & $D_{i j}=\left(\sum_{l=1}^{d}\left|x_{i l}-x_{j l}\right|^{\frac{1}{2}}\right)^{2}$ & $\begin{array}{l}\text { Caso específico da Distância Minkowsk } \\
\text { quando } n=2 \text {. É a unidade de medida } \\
\text { mais utilizada }\end{array}$ \\
\hline $\begin{array}{l}\text { Distância } \\
\text { Suprema }\end{array}$ & $D_{i j}=\max _{1 \leq l \leq d}\left|x_{i l}-x_{j l}\right|$ & $\begin{array}{l}\text { Caso específico da distância Minkowsk } \\
\text { quando } n \rightarrow \infty \text {. }\end{array}$ \\
\hline $\begin{array}{l}\text { Distância de } \\
\text { Mahalanobis }\end{array}$ & $\begin{array}{l}D_{i j}=\left(X_{i}-X_{j}\right)^{T} S^{-1}\left(X_{i}-X_{j}\right) \\
S=E\left[(x-\mu)(x-\mu)^{T}\right] \\
\mu \text { é o vetor de médias }\end{array}$ & $\begin{array}{l}\text { Baseada na correlação entre atributos. Uti- } \\
\text { lizada em classificações biológicas. }\end{array}$ \\
\hline $\begin{array}{l}\text { Semelhança } \\
\text { de Cossenos }\end{array}$ & $S_{i j}=\cos \alpha=\frac{x_{i}^{T} x_{j}}{\left\|x_{i}\right\|\left\|x_{j}\right\|}$ & $\begin{array}{l}\text { Utilizado para comparar par de objetos } \\
\text { com atributos contínuos. Utilizado em } \\
\text { agrupamento de documentos. }\end{array}$ \\
\hline
\end{tabular}


Segundo Xu \& Wunsch (2005), uma função que mede a distância $D$ entre um par de dados $x_{i}$ e $x_{j}$ de um conjunto $X$ deve possuir as seguintes propriedades:

1. Simetria: $D\left(x_{i}, x_{j}\right)=D\left(x_{j}, x_{i}\right)$ para todos $x_{i}$ e $x_{j}$.

2. Positividade: $D\left(x_{i}, x_{j}\right) \geq 0$ para todos $x_{i}$ e $x_{j}$.

3. Diferença Triangular: $D\left(x_{i}, x_{j}\right) \leq D\left(x_{i}, x_{k}\right)+D\left(x_{k}, x_{j}\right)$ para todos $x_{i}, x_{j}$ e $x_{k}$.

4. Reflexão: $D\left(x_{i}, x_{j}\right)=0$ se e somente se $x_{i}=x_{j}$.

Escolher a medida de distância correta para o conjunto de dados requer o conhecimento dos dados e seus atributos. Para isso, alguns pontos devem ser avaliados. Em dados espaciais, a distância euclidiana é a mais comum. Mesmo havendo diferença de escala nos dados, essa distância pode ser aplicada depois de pré-processar os dados, por exemplo, normalizando-os. Quando os dados são textos, é comum utilizar a semelhança de cossenos, pois dessa forma, textos que tenham as palavras semelhantes mas em quantidades diferentes sejam considerados semelhantes. Portanto, a medida ou conjunto de medidas escolhidas devem se adaptar aos dados, sendo muito comum na prática, testar diferentes medidas e verificar se os resultados fazem mais sentido.

\subsection{Etapas do Processo de Agrupamento}

O processo de agrupamento de dados consiste geralmente em quatro etapas (Xu \& Wunsch, 2008) descritas a seguir. Esse processo é ilustrado na Figura 2.2 onde cada caixa representa uma etapa.

1. Seleção ou extração dos atributos: A partir do conjunto de dados, consiste em encontrar o subconjunto de atributos adequados para realizar o agrupamento. A extração de atributos utiliza transformações para gerar novos atributos a partir dos dados originais. Uma boa escolha ou seleção de atributos pode diminuir drasticamente o custo para calcular medidas e armazenar os dados, além de facilitar o processo de agrupamento de dados.

2. Seleção do algoritmo de agrupamento: Nessa etapa é definido o algoritmo de agrupamento de dados. Essa escolha depende do tipo de conjunto de dados. Como a maioria dos algoritmos de agrupamento utilizam função de similaridade e uma função objetivo, essas funções são escolhidas nessa etapa. Assim, a tarefa de agrupamento de dados pode ser considerada um problema de otimização de uma função objetivo. A escolha de um bom algoritmo e parâmetros adequados pode resultar em um melhor agrupamento de dados. Entretanto, não existe um método que seja universal e eficiente para qualquer caso. 
3. Validação dos grupos: O algoritmo de agrupamento de dados pode sempre encontrar grupos mesmo quando não exista uma estrutura real nos dados. Além disso, diferentes algoritmos podem resultar em diferentes agrupamentos. Até o mesmo algoritmo pode resultar em diferentes agrupamentos para configurações diferentes de parâmetros. Assim, medidas de avaliação são necessárias para verificar a qualidade do resultado do agrupamento para que o usuário tenha um grau de confiabilidade. Essas medidas devem avaliar somente o resultado do agrupamento independentemente do algoritmo utilizado e devem responder questões como: quantos grupos existem nos dados ou se o resultado é realmente significativo do ponto de vista prático.

4. Interpretação dos resultados: Depois de obter o agrupamento, a última etapa consiste em analisar o resultado e fornecer ao usuário conhecimento significativo, para que possa desenvolver uma compreensão clara dos dados.

É importante observar que cada etapa da tarefa de agrupamento de dados não é realizada obrigatoriamente apenas uma vez. De fato, alguns algoritmos executam várias vezes até encontrar o melhor agrupamento. Entretanto, em algumas situações é melhor voltar uma etapa, alterar parâmetros ou técnicas, para garantir um melhor agrupamento. Por isso, na Figura 2.2 cada etapa possui duas setas, uma de ida e outra de volta.

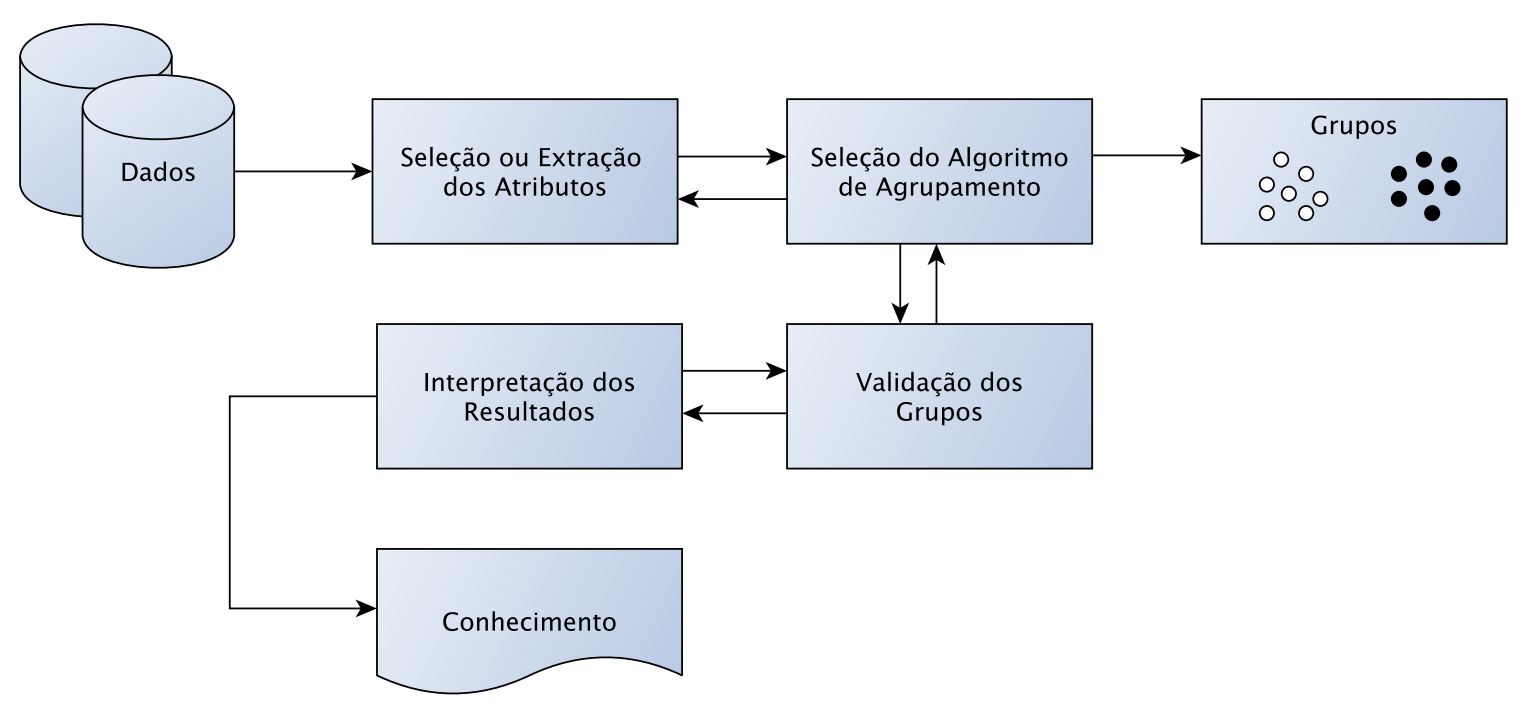

Figura 2.2: Etapas do processo de agrupamento de dados (Xu \& Wunsch, 2008).

\subsection{Técnicas de Agrupamento}

Nesse seção serão apresentadas as abordagens mais comuns de agrupamento de dados e algumas técnicas que usam essas abordagens. Na maioria dos casos, serão utilizados conjuntos 
de dados formados por pontos bidimensionais para ilustrar o resultados dessas técnicas de agrupamento. É importante salientar que essas técnicas não estão limitadas a dados numéricos, mas também podem ser utilizadas para outros tipos de dados.

\subsubsection{Algoritmos Hierárquicos}

Os algoritmos hierárquicos estão entre as mais comuns técnicas de agrupamento e consistem em construir uma hierarquia dos grupos. Esses algoritmos são divididos em duas abordagens: aglomerativos e divisivos. Os algoritmos aglomerativos consideram inicialmente que cada dado é um grupo e, a cada iteração, pares de grupos são fundidos. Os algoritmos divisivos realizam o agrupamento de forma inversa. Considera inicialmente que todo o conjunto de dados é um grupo só e, a cada iteração, quebra em grupos menores.

Um agrupamento hierárquico é representado comumente por um dendrograma, que é um tipo de árvore que exibe a ordem a qual os grupos foram fundidos, em caso de agrupamento aglomerativo, ou a ordem em que foram divididos, em caso de agrupamento divisivo. Um exemplo de dendrograma pode ser visto na Figura 2.3(a), onde um conjunto de cinco pontos $\left\{p_{1}, \ldots, p_{5}\right\}$ são agrupados hierarquicamente. A Figura 2.3(b) mostra a mesma informação do dendrograma em uma notação de conjuntos, onde cada conjunto de pontos representa um agrupamento. Caso seja utilizado um algoritmo hierárquico divisivo, então os passos do algoritmo seguem a ordem de cima para baixo. Caso seja um algoritmo hierárquico aglomerativo, então a ordem inversa representa os passos do algoritmo. Nessa seção, será focado em algoritmos aglomerativos por serem mais comuns e mais utilizados.

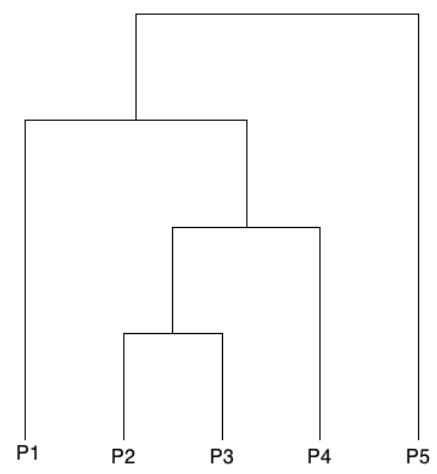

(a)

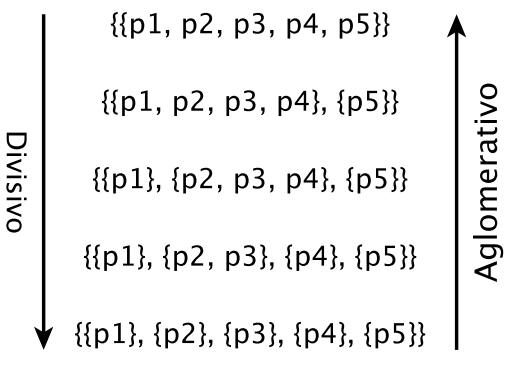

(b)

Figura 2.3: (a) Exemplo de um dendrograma que representa o resultado de um algoritmo de agrupamento hierárquico de um conjunto de dados composto por cinco pontos $\left\{p_{1}, \ldots, p_{5}\right\}$. (b) apresenta a mesma informação do dendrograma utilizando anotação de conjuntos. A cada iteração do algoritmo, se esse for divisivo, então tanto o dendrograma quanto a ordem dos conjuntos é vista de cima para baixo. Se o algoritmo for aglomerativo, então é tomado a ordem inversa, de baixo para cima. 


\section{Algoritmos Aglomerativos}

Os algoritmos aglomerativos são aqueles que consideram inicialmente que cada ponto (objeto) é um grupo e, a cada iteração, funde par de grupos mais próximos (similares). Para isso, pode ser utilizado uma matriz de proximidades $D$, onde cada elemento $d_{i j}$ é a distância entre os grupos $i$ e $j$. Então, fundem-se os dois grupos que sejam mais próximos. Depois da fusão, é necessário atualizar a matriz de proximidades para que reflita a distância do novo grupo para os demais. Esse processo ocorre até que todos os pontos formem apenas um grupo. Independentemente da técnica empregada, o Algoritmo 1 descreve basicamente o procedimento de agrupamento hierárquico.

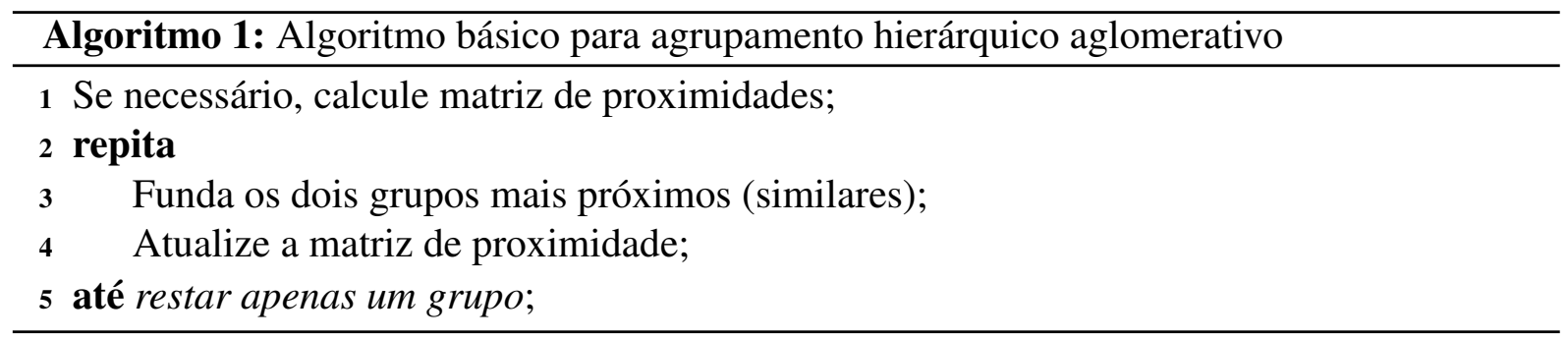

Para realizar o agrupamento hierárquico aglomerativo é necessário utilizar uma função de proximidades (similaridade) para encontrar os grupos que são próximos (similares). As medidas mais comuns para encontrar a distância entre grupos são: conexão única (Sneath, 1957), conexão completa (Sørensen, 1948) e média de grupo (Sokal \& Michener, 1958). No algoritmo de conexão única, a distância entre dois grupos é dada pela menor distância entre elementos de grupos diferentes. O algoritmo de conexão única é bom para lidar com grupos de formas não elípticas porém é sensível a ruídos. Já o algoritmo de conexão completa utiliza a maior distância entre dois elementos de grupos distintos sendo menos susceptível a ruídos mas pode dividir grupos grandes. O algoritmo de média de grupo, como o nome sugere, calcula a média da distância entre todos os pares de objetos. Essas três maneiras de calcular a distância entre grupos são ilustradas na Figura 2.4.

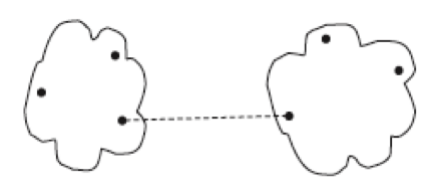

(a)

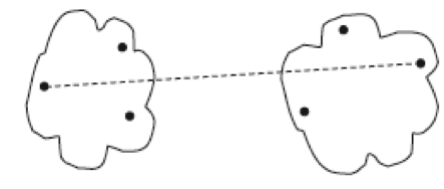

(b)

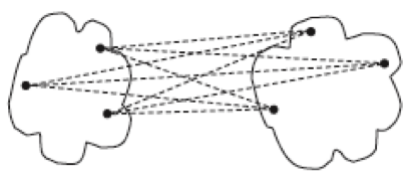

(c)

Figura 2.4: Medidas de distância entre grupos: (a) conexão única, a menor distância é utilizada. (b) conexão completa, a maior distância é utilizada. (c) média de grupo, é tomado a média entre as distâncias de todos pares de objetos. (Tan et al., 2005)

Outra abordagem conhecida utiliza o conceito de centróides (Sokal \& Michener, 1958). Nessa abordagem a distância entre grupos é calculada por meio da distância entre o centróide de cada grupo e são fundidos os grupos que tenham centróides mais próximos. De forma semelhante, o método de Ward (1963) também representa os grupos por centróides. Esse método 
calcula o erro quadrático de cada grupo como a soma das distâncias quadradas do centroíde para cada objeto do grupo. O erro quadrado total do agrupamento é dado pela soma dos erros quadrados de cada grupo. Assim, o método de Ward (1963) funde os grupos que causam a maior redução do erro quadrado total do agrupamento.

Um exemplo de aplicação de algumas técnicas de agrupamento de dados hierárquicos aglomerativos pode ser visto na Figura 2.5. O conjunto de dados é formado por 6 pontos bidimensionais mostrados na Figura 2.5(a). A seguir são exibidos os resultados das técnicas: Conexão única, Conexão completa, média do grupo e de Ward nas Figuras 2.5(b), 2.5(c), 2.5(d) e 2.5(e) respectivamente. Para cada dendrograma, a altura na qual dois grupos são fundidos informa a distância de dois grupos.

As funções de distâncias utilizadas pelos algoritmos discutidos nessa seção podem ser representadas por apenas uma equação. Essa equação (2.1) é chamada de fórmula Lance-Williams onde $\alpha_{i}, \alpha_{j}, \beta$ e $\gamma$ são valores que definem a estratégia do algoritmo. Nessa equação, assume-se que dois grupo $i$ e $j$ tenham $n_{i}$ e $n_{j}$ elementos respectivamente e a distância entre eles é representada por $d_{i j}$. Considera-se também que a fusão desse dois grupos $i$ e $j$ resulta em novo grupo $k$ com $n_{k}=n_{i}+n_{j}$ elementos. Assim, a distância entre o novo grupo $k$ e um grupo existente $h$ é representado por $d_{h k}$. A Tabela 2.4 mostra os parâmetros da fórmula para os diferentes algoritmos.

$$
d_{h k}=\alpha_{i} d_{h i}+\alpha_{j} d_{h j}+\beta d_{i j}+\gamma\left|d_{h i}-d_{h j}\right|
$$

Tabela 2.4: Coeficientes da fórmula de Lance-Willians.

\begin{tabular}{ccccc}
\hline Medida de Agrupamento & $\alpha_{i}$ & $\alpha_{j}$ & $\beta$ & $\gamma$ \\
\hline Conexão Única & $\frac{1}{2}$ & $\frac{1}{2}$ & 0 & $-\frac{1}{2}$ \\
\hline Conexão Completa & $\frac{1}{2}$ & $\frac{1}{2}$ & 0 & $\frac{1}{2}$ \\
\hline Média de Grupo & $\frac{n_{A}}{n_{A}+n_{B}}$ & $\frac{n_{B}}{n_{A}+n_{B}}$ & 0 & 0 \\
\hline Centróide & $\frac{n_{A}}{n_{A}+n_{B}}$ & $\frac{n_{B}}{n_{A}+n_{B}}$ & $\frac{-n_{A} n_{B}}{\left(n_{A}+n_{B}\right)^{2}}$ & 0 \\
\hline de Ward & $\frac{n_{A}+n_{Q}}{n_{A}+n_{B}+n_{Q}}$ & $\frac{n_{B}+n_{Q}}{n_{A}+n_{B}+n_{Q}}$ & $\frac{-n_{Q}}{n_{A}+n_{B}+n_{Q}}$ & 0 \\
\hline
\end{tabular}

A vantagem na utilização de algoritmos hierárquicos aglomerativos está na hierarquia de grupos gerados, importante para aplicações específicas que específicas. Por exemplo, quando se deseja números de grupos diferentes ao longo do tempo mas por restrição não se pode executar o algoritmo com diferentes parâmetros. Nesse caso, é interessante gerar uma hierarquia de grupos e escolher Outra vantagem está na possibilidade de se usar qualquer função válida de distância e não ser necessário informar o número de grupos. A desvantagem está no fato das fusões serem finais, ou seja, não é possível altera-las depois que são feitas. Isso implica que as fusões erradas 


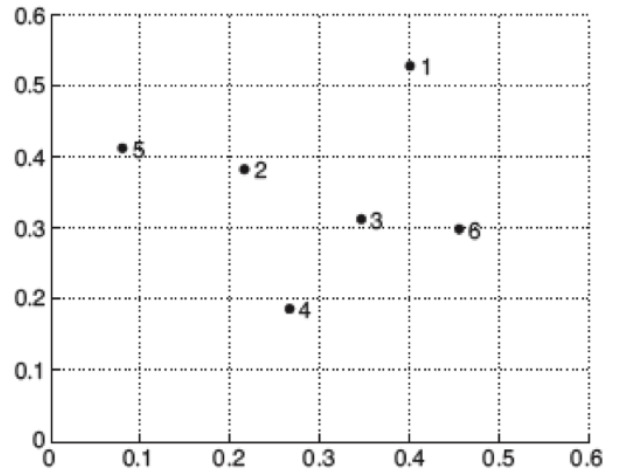

(a)

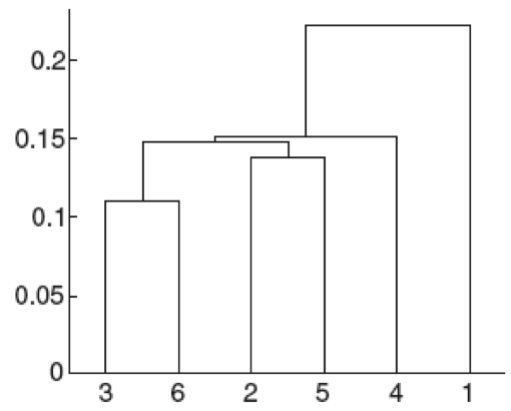

(b)

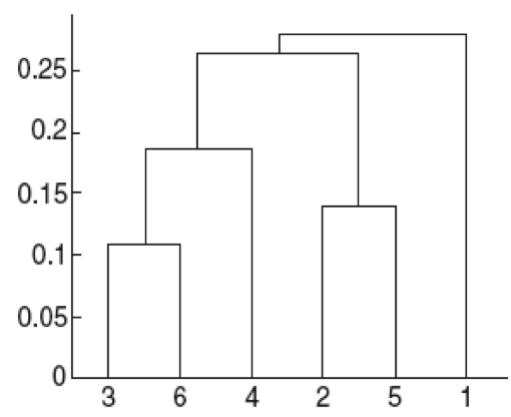

(d)

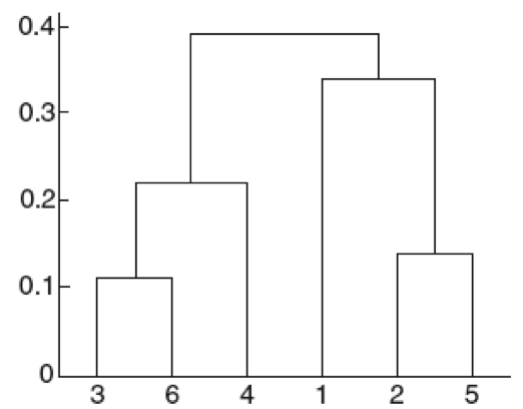

(c)

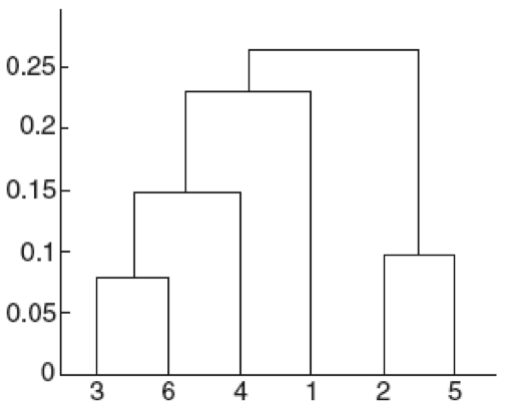

(e)

Figura 2.5: Exemplo de agrupamento de dados usando o algoritmos Hierárquicos. A Figura (a) mostra o conjunto de dados formado por 6 pontos bidimensionais. Em seguida, são exibidos os resultados para alguns algoritmos: (b) Conexão única, (c) Conexão completa, (d) média do grupo, (e) de Ward. Para cada dendrograma, a altura na qual dois grupos são fundidos informa a distância de dois grupos. (Tan et al., 2005)

feitas inicialmente não poderão ser corrigidas ao longo da execução do algoritmo.

\subsubsection{Algoritmos Baseados em Particionamento}

Uma diferença importante entre as técnicas de agrupamento é se essas geram ou não grupos aninhados. Em outras palavras, se o agrupamento é hierárquico ou particional. No agrupamento hierárquico, apresentado na subseção (2.4.1) anterior, o agrupamento funde ou particiona os grupos a cada iteração, resultando em uma hierarquia de grupos. Já no agrupamento particional, os dados são divididos diretamente em um número $K$ de grupos não havendo uma 
hierarquia entre os grupos (Xu \& Wunsch, 2005). Em termos teóricos, para encontrar o melhor particionamento dos dados, poderia ser listada todas as possibilidades de agrupamento e tomar o melhor deles segundo algum critério específico. Entretanto, o custo computacional para calcular e analisar todas as possibilidades é extremamente alto (Liu, 1968). Por exemplo, tomando um conjunto de dados composto por 30 objetos onde se deseja particiona-lo em 3 grupos, o número de possibilidades de agrupamento é $2 \times 10^{14}$. Assim, algoritmos heurísticos foram desenvolvidos para tentar encontrar boas soluções aproximadas.

O objetivo do agrupamento de dados é encontrar uma partição dos dados de tal forma que os objetos que formam os grupo sejam homogêneos entre si e os dados de grupos diferentes estejam bem separados (Xu \& Wunsch, 2005). Essa homogeneidade e separação podem ser avaliadas por uma função objetiva. Uma das funções mais conhecidas é a soma dos erros quadrados. Supondo que o conjunto de dados seja formado por $x_{j} \in \Re^{d}, j=1, \ldots, N$ e deseja-se particiona-los em $K$ grupos $C=\left\{C_{1}, \ldots, C_{K}\right\}$, então, a soma dos erros quadrados pode ser definida pela Equação 2.2:

$$
\begin{aligned}
J_{s}(\Gamma, M) & =\sum_{i=1}^{K} \sum_{j=1}^{N} \gamma_{i j}\left\|x_{j}-m_{i}\right\|^{2} \\
& =\sum_{i=1}^{K} \sum_{j=1}^{N} \gamma_{i j}\left(x_{j}-m_{i}\right)^{T}\left(x_{j}-m_{i}\right)
\end{aligned}
$$

onde $\Gamma=\left\{\gamma_{i j}\right\}$ é a matriz de particionamento tal que

$$
\gamma_{i j}= \begin{cases}1 & \text { se } x_{j} \in \text { ao grupo } i \\ 0 & \text { caso contrário }\end{cases}
$$

sendo que

$$
\sum_{i=1}^{K} \gamma_{i j}=1 \forall j
$$

e $M=\left[m_{1}, \ldots, m_{K}\right]$ é a matriz de centróides onde cada centróide $m_{i}$ é definido pela Equação 2.3 .

$$
m_{i}=\frac{1}{N_{i}} \sum_{j=1}^{N} \gamma_{i j} x_{j}
$$

A partição que minimiza a função da soma dos erros quadrados é considerada ótima. Essa função objetiva é apropriada para grupos compactos e bem separados. Entretanto, essa função pode ser sensível a outliers fazendo com que grupos grandes sejam quebrados em grupos menores e agrupados de forma errada. 


\section{K-Médias}

O algoritmo K-Médias (Forgy, 1965; Macqueen, 1967; Bock, 2007) é um dos mais conhecidos algoritmos de agrupamento de dados. $\mathrm{O}$ algoritmo busca o melhor particionamento dos dados tentando minimizar iterativamente a função das somas dos erros quadrados (Eq. 2.2). Inicialmente o K-Médias posiciona de forma aleatória $K$ centróides que representam os centros de cada grupo. Cada ponto $x_{i}$ é associado ao centróide $C_{l}$ mais próximo e o conjunto de pontos associados a cada centróide representa um grupo. Então, cada centróide é movido em direção ao ponto central (média dos pontos) de cada conjunto e as associações de pontos aos centróides são refeitas. O processo de mover os centróides pára quando todos os pontos não mudam suas associações ou apenas uma pequena parcela deles mudem. O Algoritmo 2 descreve o K-Médias em passos.

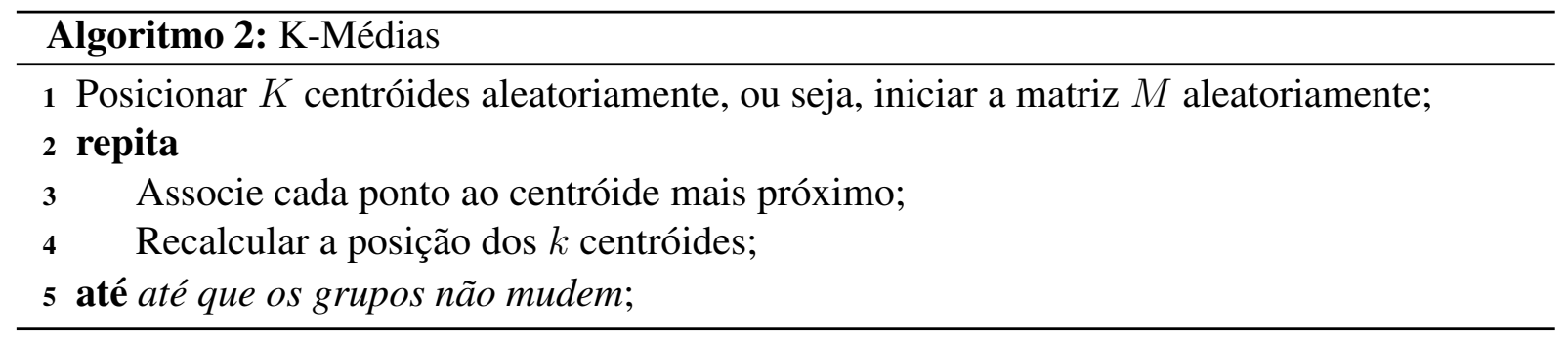

A Figura 2.6 ilustra um exemplo de iteração do algoritmo K-Médias para um conjunto de dados. Inicialmente, na Figura 2.6(a), são posicionados três centróides de forma aleatória e cada ponto é associado ao centróide mais próximos. Cada centróide é representado pelo símbolo '+' e os grupos são representados por pontos de mesmo desenho. As iterações seguintes são ilustradas pelas Figuras 2.6(b), 2.6(c) e 2.6(d), nessa ordem, sendo possível observar ao longo da execução as mudanças das associações e o reposicionamento dos centróides. Na última iteração tem-se o resultado do agrupamento onde cada centróide está localizado no ponto médio de cada grupo.

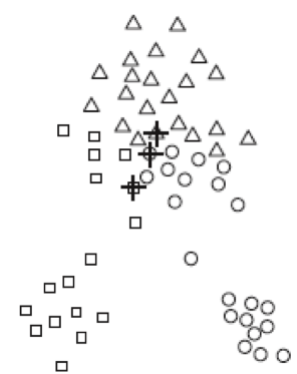

(a)

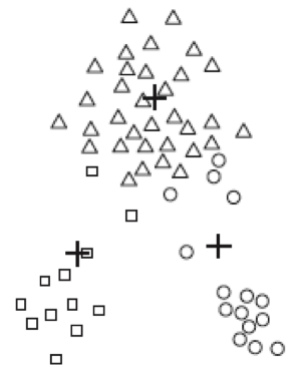

(b)

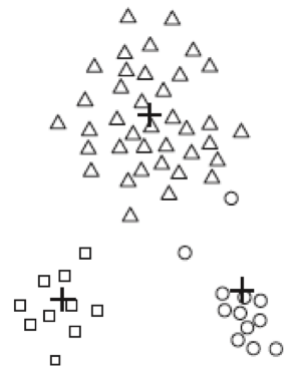

(c)

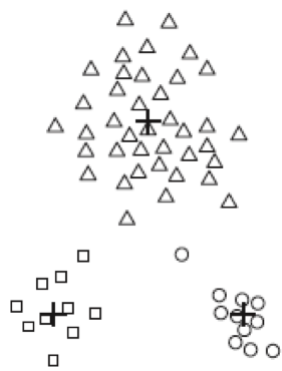

(d)

Figura 2.6: Exemplo de iterações para o algoritmo K-Médias. A Figura (a) exibe o posicionamento inicial aleatório dos centróides. Cada centróide é representado pelo símbolo '+' e os grupos por pontos de mesmo símbolo. As Figuras (b), (c) e (d), nessa ordem, mostram as iterações seguinte do algoritmo, onde é possível observar o reposicionamento dos centróides e a reassociação dos pontos. Na última iteração cada centróide está localizado no ponto médio de cada grupo (Tan et al., 2005). 
O algoritmo K-Médias não garante que seja encontrado o ótimo global da função das somas dos erro quadrados, mas é provado que, pelo menos, converge para um mínimo local (Selim \& Ismail, 1984). Isso implica que a maneira a qual são iniciados os centróides influencia na convergência do algoritmo. Em outras palavras, a escolha inicial dos centróides pode fazer com que esses convirjam para pontos diferentes. Isso faz com que uma boa escolha inicial dos pontos leve a um bom particionamento dos dados. Entretanto, não existe um método universal e eficiente para determinar os centróides iniciais (Xu \& Wunsch, 2008). Para tentar solucionar esse problema, alguns métodos foram desenvolvidos. Krishna \& Narasimha Murty (1999) propuseram o algoritmo GKA que integra o K-Médias com algoritmo genético na tentativa de fazer uma busca global e diminuir o tempo de convergência.

Outra importante questão sobre o algoritmo K-Médias está relacionado ao número desejado de grupos $K$. Esse algoritmo supõem que o usuário saiba a priori o número de agrupamentos de dados, entretanto, isso na maioria das vezes não ocorre. Para resolver o problema de encontrar o número de grupos $K$ também não existe um método universal e eficiente para todos os casos. Algumas heurísticas foram utilizadas para tentar resolver esse problema. Ball \& Hall (1967) propuseram o algoritmo ISODATA, que estima $K$ agrupando ou fundindo grupos de acordo com um parâmetro limitante. Um grupo é dividido de acordo com a variabilidade dos dados de um grupo. Grupos são fundidos de acordo com a distância de seus centróides. Assim, a cada iteração desse algoritmo, encontra-se um $K$ que é utilizado para encontrar o $K$ da próxima iteração.

Quanto a robustez, o K-Médias é sensível a ruído e outliers. Para calcular o ponto médio são utilizados todos os pontos do grupo, incluindo os outliers. Mesmo que um objeto esteja longe do centróide ele é forçado a pertencer à aquele grupo e isso pode atrapalhar o algoritmo a encontra a forma correta do grupo. O algoritmo ISODATA trata os outliers eliminando os grupos que tenham menos elementos que um dado valor passado pelo usuário e, devido ao seu processo de fusão, não permite a possibilidade de grupos de forma muito alongadas. $\mathrm{O}$ algoritmo PAM (Kaufman \& Rousseeuw, 1990) também trata outliers utilizando o conceito de medóide, que é um ponto real do conjunto de dados que tenha a menor distância média para todos os outros pontos do grupo.

\subsubsection{Algoritmos Baseados em Distribuição}

Esses tipos de algoritmos baseiam-se em modelos estatísticos pois consideram que os dados possam ter sido gerados de processos estatísticos (Bilmes, 1997). Assim, esses algoritmos tentam encontrar o melhor modelo estatístico que se adapta aos dados. Nessa seção será apresentado um tipo específico de modelo chamado modelo de misturas, que usam um número de distribuições estatísticas para modelar os dados.

No modelo de misturas, cada distribuição descreve um grupo de dados diferente. Assim, é possível analisar os parâmetros de cada distribuição observando os dados e então descrever 
cada grupo de dados. É importante observar que esse modelo de misturas não atribui um dado a um grupo com $100 \%$ de certeza, mas apresenta a probabilidade de um dado objeto pertencer a um grupo. Para avaliar os parâmetros de um modelo estatístico, a abordagem mais utilizada é chamada de avaliação da probabilidade máxima.

Supondo que existem $K$ distribuições e $m$ dados, $\chi=\left\{x_{1}, \ldots, x_{m}\right\}$ e $\Theta=\left\{\theta_{1}, \ldots, \theta_{K}\right\}$ seja o conjunto de todos os parâmetros, então $\operatorname{prob}\left(x_{i} \mid \theta_{j}\right)$ é a probabilidade que o objeto $x_{i}$ venha da distribuição $\theta_{j}$. Considerando um conjunto de dados gerados a partir de uma distribuição gaussiana unidimensional e supondo que os pontos foram gerados independentemente, então a probabilidade destes pontos é o produto da probabilidade individual. Assim, a Equação 2.4 descreve essa probabilidade, onde $\mu$ e $\sigma$ são os parâmetros da distribuição gaussiana: média e desvio padrão respectivamente. Como essa probabilidade é um número muito pequeno, então torna-se comum utilizar o logaritmo da probabilidade do registro, descrita pela Equação 2.5.

$$
\begin{gathered}
\operatorname{prob}(\chi \mid \Theta)=\prod_{i=1}^{m} \frac{1}{\sqrt{2 \pi} \sigma} e^{-\frac{\left(x_{i}-\mu\right)^{2}}{2 \mu^{2}}} \\
\log \operatorname{prob}(\chi \mid \Theta)=\sum_{i=1}^{m} \frac{\left(x_{i}-\mu\right)^{2}}{2 \mu^{2}}-0.5 m \log 2 \pi-m \log \sigma
\end{gathered}
$$

A idéia desse tipo de agrupamento de dados é tentar escolher os parâmetros da distribuição, ou seja, escolher os parâmetros $\mu$ e $\sigma$, no caso da gaussiana, que maximizem a Equação 2.4. Essa abordagem é conhecida na estatística como princípio da probabilidade máxima e a aplicação dessa abordagem em um conjunto de dados conhecido é conhecida como avaliação da probabilidade máxima. Nessa abordagem, os parâmetros da distribuição são as variáveis e dados conhecidos são as constantes.

O algoritmo mais conhecido que utiliza o conceito de probabilidade máxima é o expectationmaximization (EM) e será apresentado logo a seguir na Subseção 2.4.3. Outros algoritmos utilizam outras distribuições estatísticas. O GMDD é um algoritmo baseado em densidades gaussianas mutivariada que, recursivamente estima sequencialmente cada grupo (Zhuang et al., 1996). O GMDD considera como ruído os pontos que não foram gerados a partir de uma distribuição e utiliza um estimador para construir cada grupo do modelo. O algoritmo AutoClass considera outras distribuições de probabilidade como poisson e bernoulli para encontrar o particionamento ótimo utilizando uma abordagem bayesiana (Cheeseman \& Stutz, 1996).

\section{EM}

O algoritmo EM (Hartley, 1958; Dempster et al., 1977) utiliza a abordagem da probabilidade máxima para avaliar os parâmetros de modelo para um modelo de misturas. Considerando um caso mais simples onde sabemos quais dados do conjunto pertencem a cada distribuição, então o problema se reduz a avaliar apenas os parâmetros de uma distribuição. Entretanto, em casos reais, não se sabe quais distribuições geraram quais dados e, portanto, não seria possível 
calcular a probabilidade de cada ponto. Consequentemente também não seria possível utilizar o princípio da probabilidade máxima para avaliar os parâmetros. Contudo, o algoritmo EM mostra que isso é possível. A idéia é realizar a avaliação da probabilidade máxima através de uma pesquisa iterativa. Dado uma estimativa para os valores dos parâmetros, o algoritmo EM calcula as probabilidades para computar uma nova avaliação para os parâmetros. O Algoritmo 3 descreve como funciona o EM.

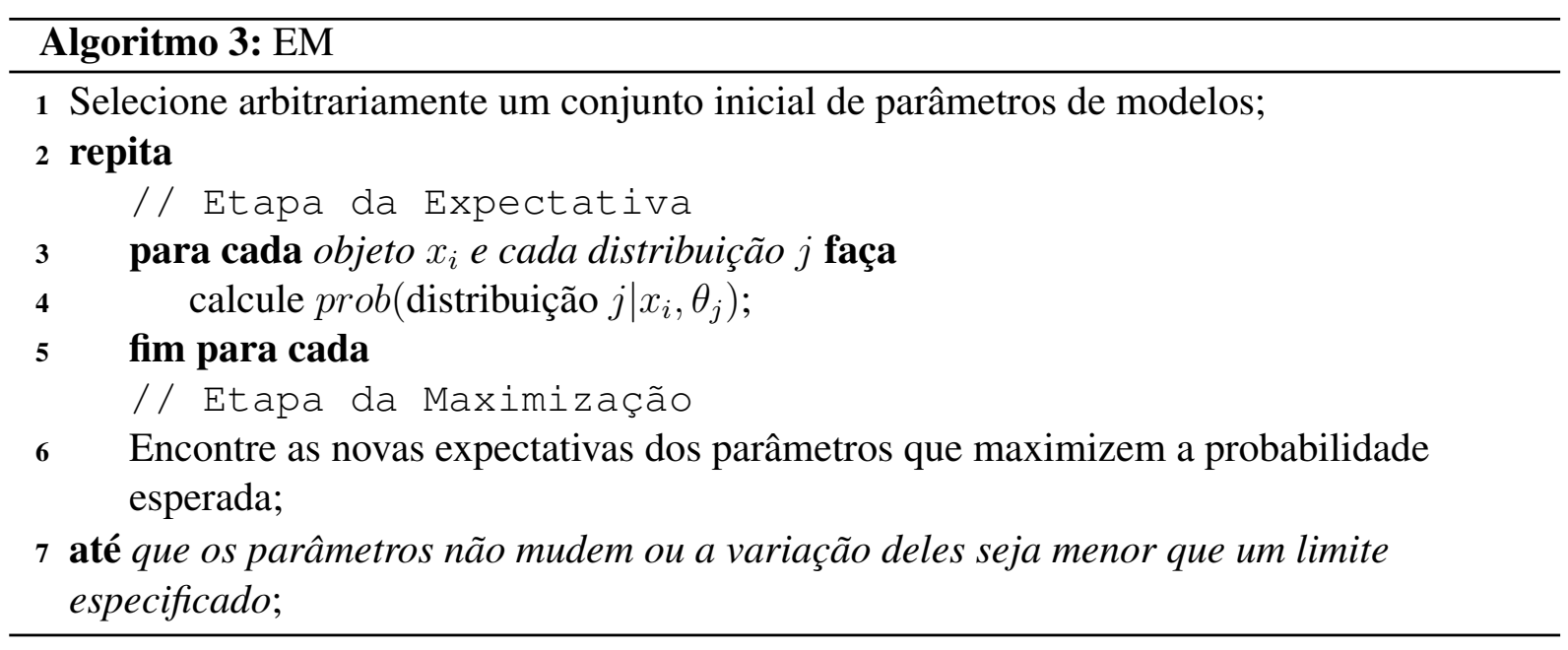

Um exemplo de aplicação do algoritmo EM pode ser visto na Figura 2.7. Nesse caso, o conjunto de dados foi gerado a partir da combinação de duas distribuições gaussianas, cada uma com aproximadamente 500 pontos. A primeira com centro no ponto $(-4,1)$ e desvio padrão $\sigma=2$. A segunda com centro no ponto $(0,0)$ e desvio padrão $\sigma=0.5$. O resultado do agrupamento são dois grupos representados por símbolos diferentes. É importante observar que, mesmo apresentando uma diferença pequena de densidade, o algoritmo EM conseguiu encontrar as duas gaussianas.

A abordagem de modelo de misturas e a utilização do algoritmo EM apresentam vantagens e desvantagens. A vantagem está no fato dos modelos de mistura serem mais gerais que algoritmos como o K-Médias porque podem utilizar vários tipos de distribuições estatísticas. Celeux \& Govaert (1992) provaram que o algoritmo K-Médias é um caso específico (equivalente) do algoritmo EM quando utilizado uma mistura gaussiana esférica. Como muitos conjuntos de dados são realmente gerados de processos aleatórios, eles devem satisfazer às suposições estatísticas destes modelos e portanto o EM deve apresentar bons resultados. A desvantagem é que o EM não apresenta bom agrupamento para conjunto de dados com muitos grupos, além de ser lento. Outro ponto negativo está na dificuldade de se escolher o modelo a ser utilizado.

\subsubsection{Algoritmos Baseados em Densidades}

Algoritmos baseados em densidade encontram regiões com alta densidade de dados que estejam separadas por regiões de baixa densidade. Existem alguns conceitos diferentes que definem densidade, sendo a mais tradicional baseado em centro. Nessa abordagem, a densidade 


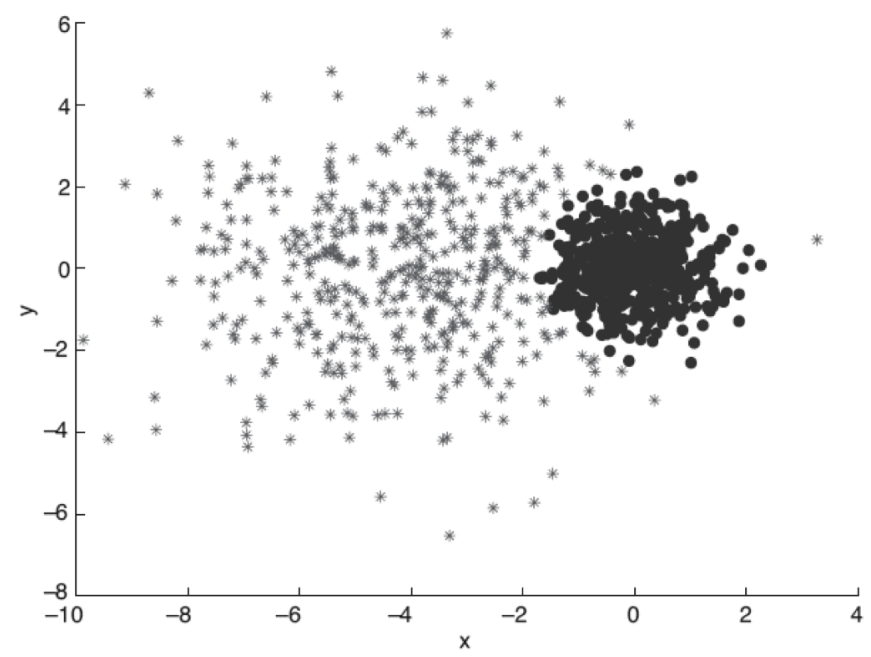

Figura 2.7: Exemplo de aplicação do algoritmo EM em conjunto de dados bidimensionais representados por aproximadamente 1000 pontos, gerados a partir da combinação de duas distribuições gaussianas, cada uma com aproximadamente 500 pontos. A primeira com centro no ponto $(-4,1)$ e $\sigma=2$. A segunda com centro no ponto $(0,0)$ e $\sigma=0.5$. O algoritmo resulta em dois grupos cujos pontos é representado por mesmo símbolo (Tan et al., 2005).

é observado em um ponto do conjunto de dados o qual se contabiliza quantos outros pontos estão dentro de um raio Eps, tendo ele como centro e também pertencente ao grupo. O conjunto de todos os pontos dentro desse raio é chamado Eps-vizinhança. Esse abordagem apresenta o problema da escolha do parâmetro Eps. Se muito grande, todo os pontos agruparam todos os outros pontos e, consequentemente todos os pontos do conjunto serão agrupado em apenas um grupo. Caso contrário, se for escolhido um raio muito pequeno, então cada ponto terá densidade unitária, agrupando somente ele mesmo, fazendo com que cada ponto do conjunto seja um grupo diferente.

A abordagem de densidade baseada em centro considera três tipos de pontos ilustrados na Figura 2.8. 1) centrais: São considerados pontos centrais aqueles que o número de vizinhos com raio menor ou igual a Eps seja maior ou superior a um parâmetro definido pelo usuário MinPts como o número mínimos de pontos. Estes pontos estão dentro de um grupo. O ponto A da Figura 2.8 exemplifica um ponto central. 2) Pontos de limite: estão dentro da vizinhança de um ou mais pontos centrais. O ponto B da Figura 2.8 exemplifica um ponto de limite. 3) Pontos de ruído: qualquer outro ponto que não seja um ponto central ou de limite é considerado ponto de ruído. O ponto $\mathrm{C}$ da Figura 2.8 exemplifica um ponto de ruído.

Outros algoritmos baseados em densidade apresentam conceitos diferentes. O algoritmo Clustering in Quest (CLIQUE) (Agrawal et al., 1998), utiliza o conceito de grades para agrupar subespaços de alta densidade, baseando-se na idéia que áreas densas de alta dimensionalidade implicam a existência de áreas densas menores. O algoritmo Density based clustering (DENCLUE) (Hinneburg et al., 1998) calcula a densidade geral do conjunto de dados que é considerada a soma das funções de influência associadas a cada ponto. A função da densidade geral apresenta picos locais, ou seja, densidades máximas locais que podem ser utilizadas para 


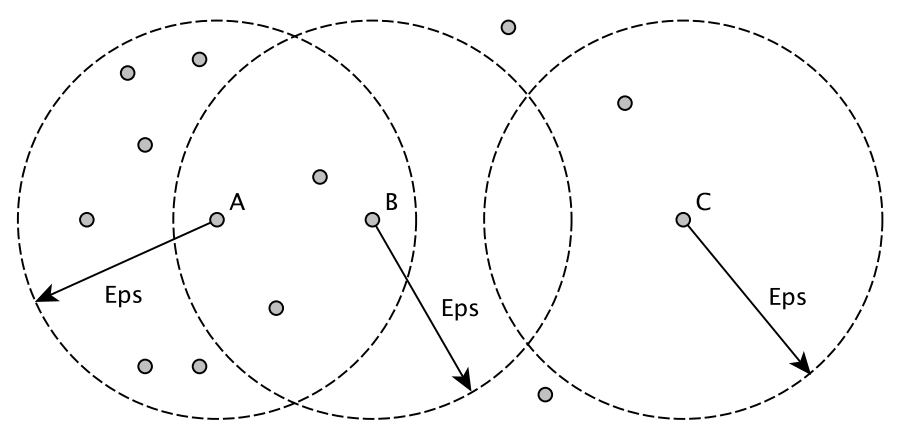

Figura 2.8: Nessa figura são exemplificadas as três classificações de pontos quando utilizada densidade baseada em ponto central. O Ponto A é central. B é um exemplo de ponto de limite e $\mathrm{C}$ é um ponto de ruído.

encontrar grupos.

\section{DBSCAN}

O algoritmo DBSCAN (Density-Based Spatial Clustering of Applications with Noise), proposto por Ester et al. (1996), baseia-se em densidade para realizar o agrupamento de dados. O algoritmo baseia-se na idéia de que, se caso dois pontos de centro tenham distância menor ou igual a Eps, então eles pertencem a um mesmo grupo. Da mesma forma, qualquer ponto de limite que esteja próximo de um ponto central deve ser colocado no mesmo grupo que o ponto central. Pontos de ruído não farão parte de nenhum grupo.

$\mathrm{O}$ algoritmo começa a partir de um ponto $p$ escolhido arbitrariamente e então é tomado sua

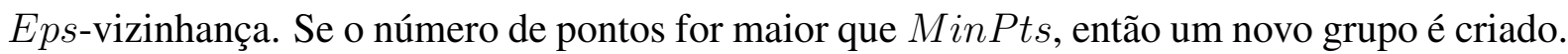
Caso contrário, esse ponto é marcado como ruído. Se um ponto encontrado for de limite, então ele pertence a um grupo e toda sua Eps-vizinhança também pertence a esse grupo. É importante observar que, caso um ponto seja classificado inicialmente como ruído, mais tarde esse ponto pode ser encontrado em uma Eps-vizinhança de um outro ponto e, portanto, ser classificado como ponto de limite. O processo continua até que o grupo todo seja encontrado e então o algoritmo escolhe outro ponto ainda não avaliado e repete esse tarefa a fim de encontrar novos grupos ou ruído. O Algoritmo 4 descreve como é realizado o agrupamento de dados.

Um exemplo de aplicação do algoritmo DBSCAN pode ser observado na Figura 2.9. A Figura 2.9(b) mostra um conjunto de dados formado por 3000 pontos bidimensionais. Em seguida foi aplicado o DBSCAN a esse conjunto de dados com os seguintes parâmetros: MinPts $=4$ e $E p s=10$. A Figura 2.9(b) mostra o resultado do agrupamento onde cada símbolo representa um grupo, exceto o $\mathrm{X}$ que representa os pontos de ruído. Os pontos de centro, pontos de limite e ruído são ilustrados na Figura 2.9(c).

Por ser baseado em densidade, o algoritmo DBSCAN apresenta a vantagem de encontrar e tratar os ruídos presentes nos dados. Outro ponto positivo é a capacidade de encontrar grupos de tamanhos e formas variadas. Entretanto, o DBSCAN apresenta problemas quando os dados 


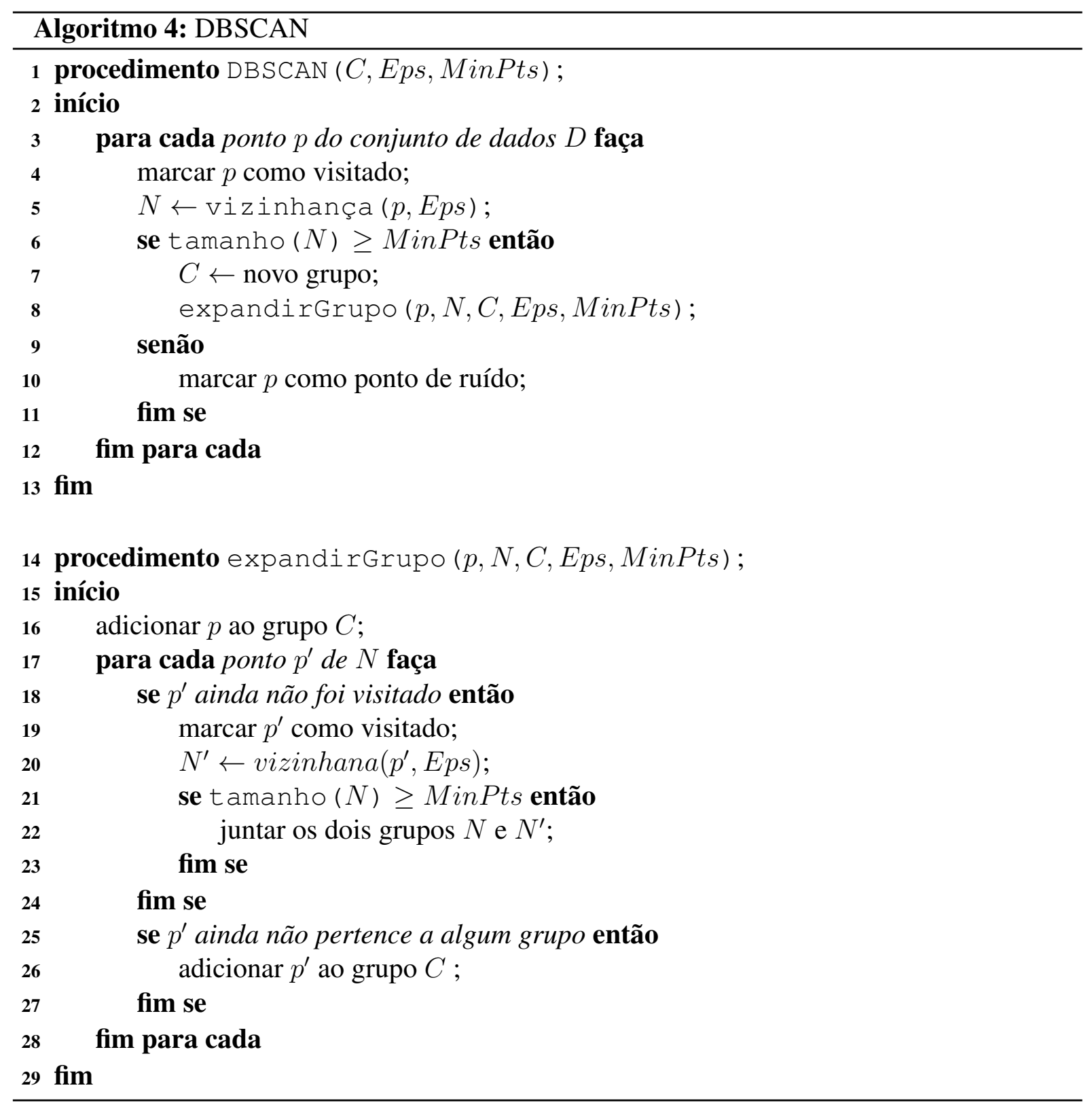




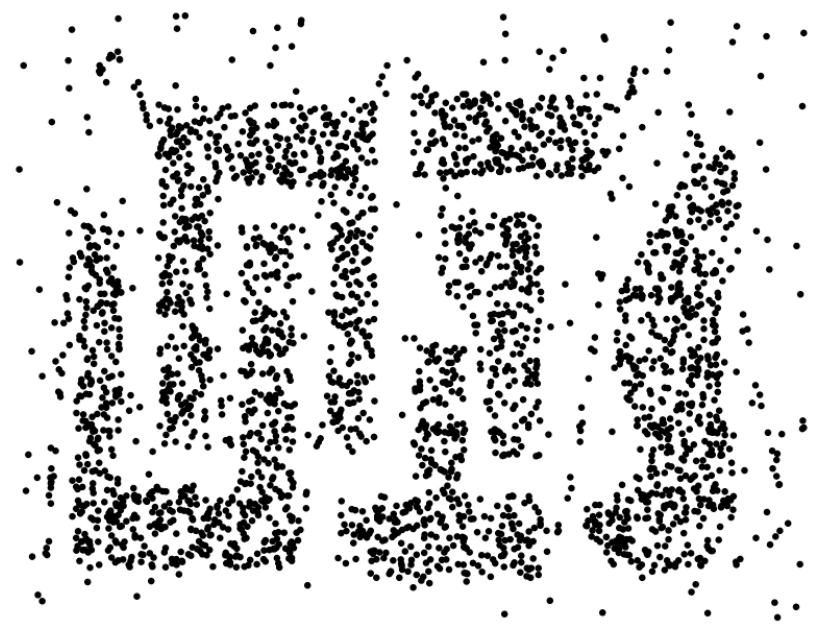

(a)

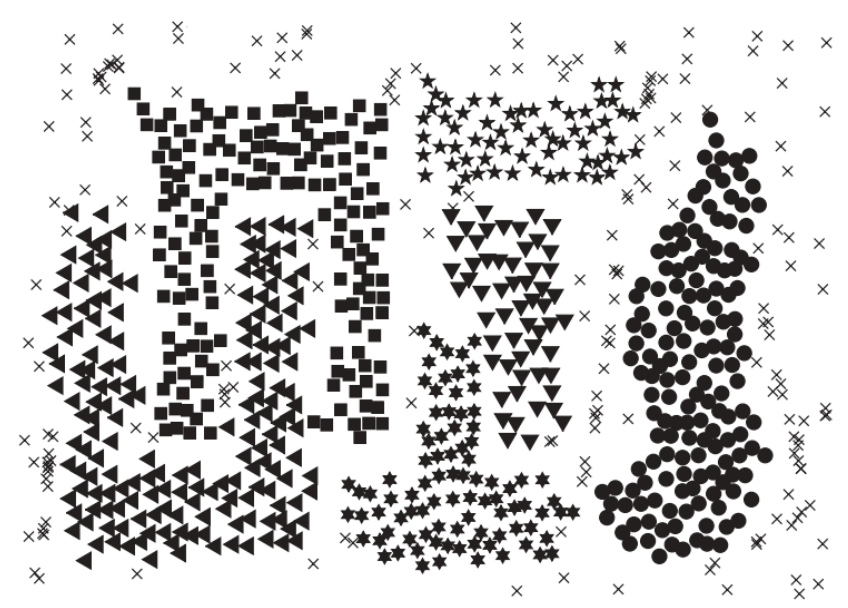

(b)

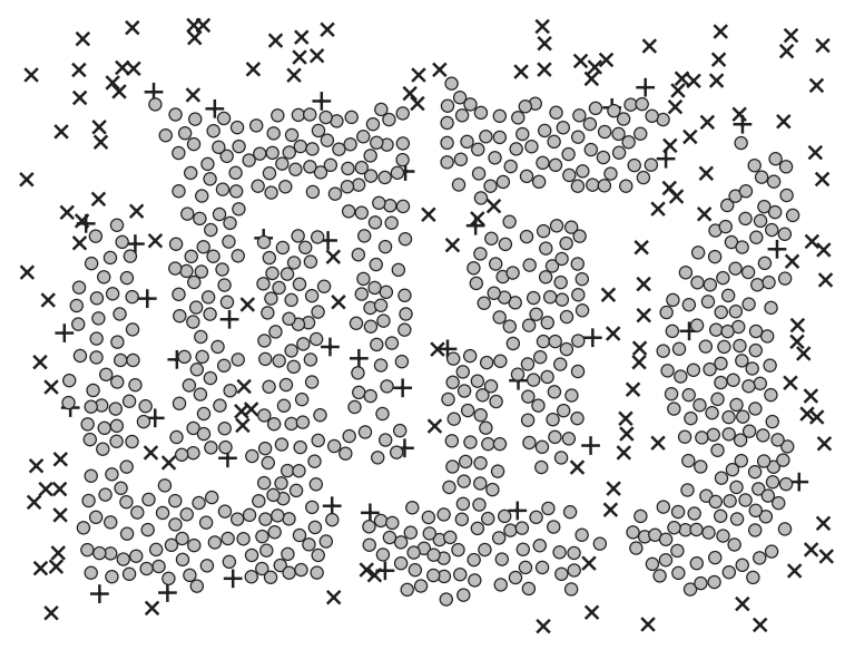

(c)

Figura 2.9: Exemplo de agrupamento de dados usando o algoritmo DBSCAN. Parâmetros: MinPts = 4 e Eps $=10$. (a) Dados da amostra com 3000 pontos. (b) Resultado do agrupamento onde cada símbolo representa um grupo, exceto o X que representa os pontos de ruído. (c) Pontos de centro (-), pontos de limite (+) e pontos de ruído (x). (Tan et al., 2005) 
apresentam densidades variadas ou quando apresentam alta dimensionalidade, pois torna-se difícil definir densidade para esses dados.

\subsubsection{Algoritmos Baseados em Grafo}

Certas bases de dados podem ser facilmente representadas por grafos (definição formal na Seção 4.1), onde os objetos são os vértices e a similaridade entre eles representada por arestas ligando os dados. Caso o dado tenha apenas um atributo nominal binário (exemplo, uma pessoa conhece ou não outra) a existência ou não da aresta define o relacionamento. Se a relação é definida por um atributo intervalar ou proporcional, então um peso pode ser associado a cada aresta. Dessa forma a rede pode ser totalmente conectada (todos os vértices conectados com todos os outros $n-1$ ) e o peso da aresta define o relacionamento. Nesse caso, o grafo gerado seria denso, pois teria o número máximo de arestas: $n(n-1) / 2$, sendo $n$ o número de vértices (dados). Em grafos densos, a quantidade de arestas a serem processadas é muito grande e muitas vezes desnecessárias. Dessa forma, a geração de um grafo com menos arestas (esparso), é mais interessante pois o algoritmo de agrupamento precisa avaliar menos arestas e consequentemente é mais eficiente computacionalmente.

Tendo em vista que a tarefa de agrupamento deseja encontrar grupos de dados semelhantes entre si e diferentes entre grupos, uma maneira de gerar um grafo esparso, a partir de uma matriz de semelhança, é usar alguma técnica da dispersão que elimina arestas onde a similaridade é muito baixa (ou dissimilaridade muito alta) (Tan et al., 2005). A maneira mais intuitiva de fazer a dispersão é considerar um valor limitante para a criação de arestas entre dois objetos. Dessa forma, só é criada uma aresta caso a similaridade seja menor ou igual a esse valor (ou maior, caso seja dissimilaridade). Outra maneira de fazer a dispersão é por meio do grafo KNN, que mantêm as conexões dos $k$ vizinhos mais próximos. A Figura 2.10 ilustra alguns exemplos de grafos $\mathrm{KNN}$ quando $k=1,2$ e 3 . Após realizada a dispersão, o grafo gerado pode ser particionado para encontrar grupos usando algoritmos como o OPOSSUM (Strehl \& Ghosh, 2000) e o Chameleon (Karypis et al., 1999).

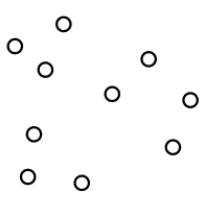

(a)

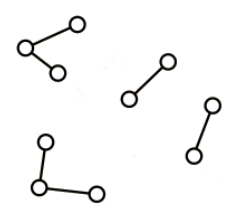

(b)

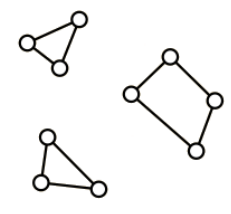

(c)

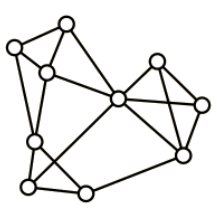

(d)

Figura 2.10: Exemplos de grafos KNN: (a) Dados originais. (b) conectando apenas o vértice mais próximo. (c) conectando os dois mais próximos e (d) conectando os três mais próximos (Karypis et al., 1999). 


\section{CHAMELEON}

Um dos algoritmos baseados em grafo mais conhecidos foi proposto por (Karypis et al., 1999) e se chama Chameleon. Considerando um grafo KNN, esse algoritmo hierárquico aglomerativo realiza o agrupamento dos vértices do grafo por meio de duas etapas. Primeiro, o Chameleon utiliza o algoritmo hMetis (Karypis \& Kumar, 1998) para particionar o grafo e encontrar os grupos iniciais. Esses grupos geralmente são muitos e formados por poucos vértices. Na segunda fase, é utilizado um algoritmo para agrupar iterativamente esses dados e gerar uma hierarquia de grupos. Uma visão geral desse algoritmo é ilustrada na Figura 2.11.

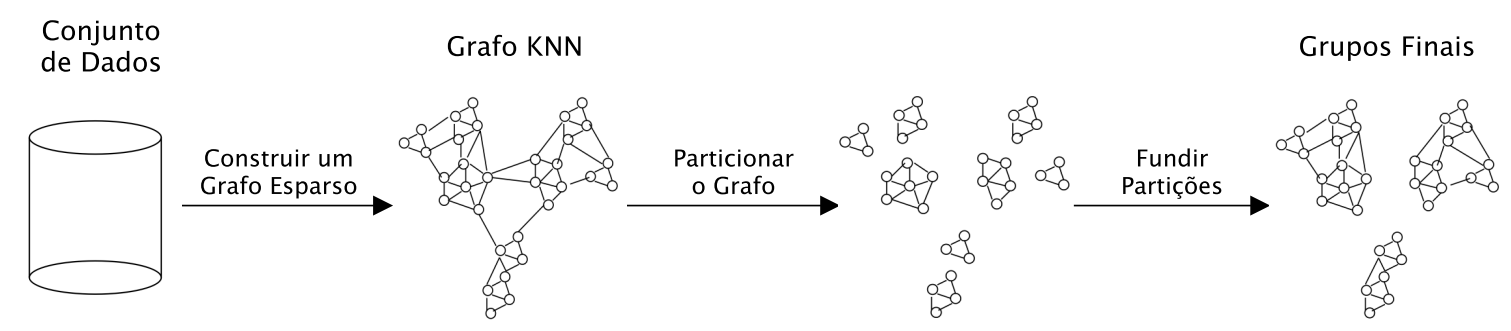

Figura 2.11: Etapas do algoritmo Chameleon (Karypis et al., 1999)

Para fundir os grupos o algoritmo Chameleon avalia duas medidas: Interconectividade Relativa (IR) e Proximidade Relativa (RC), e funde os grupos onde essas duas medidas são altas, ou seja, escolhe os grupos que tem alta conectividade dos vértices do grupo e estão próximos uns dos outros. Essa duas medidas serão explicadas a seguir.

- Interconectividade relativa (IR): A Interconectividade Relativa entre os grupos $C_{i}$ e $C_{j}$ é dado pelas suas interconectividades absolutas normalizadas pelas suas interconectividades internas, sendo expressa pela Equação 2.6. Considerando que um corte no grafo é a remoção de alguma arestas que tornam o grafo desconexo, a interconectividade interna de um grupo é dado pela soma das arestas que cruzam o corte-mínimo que divide o cluster em duas partes iguais (bisseção mínima).

$$
R I\left(C_{i}, C_{j}\right)=\frac{\left|E C\left(C_{i}, C_{j}\right)\right|}{\frac{\left|E C\left(C_{i}\right)\right|+\left|E C\left(C_{j}\right)\right|}{2}}
$$

- Proximidade relativa $(R C)$ : Dois grupos serão combinados se os pontos no grupos resultante estiverem tão próximos quanto estão nos grupos separados. Matematicamente é a proximidade absoluta de dois grupos normalizados pela proximidade interna dos grupos, expressa pela Equação 2.7

$$
R C\left(C_{i}, C_{j}\right)=\frac{\bar{S} E C\left(C_{i}, C_{j}\right)}{\frac{\left|C_{i}\right|}{\left|C_{i}\right|+\left|C_{j}\right|} \bar{S} E C\left(C_{i}\right)+\frac{\left|C_{j}\right|}{\left|C_{i}\right|+\left|C_{j}\right|} \bar{S} E C\left(C_{j}\right)}
$$




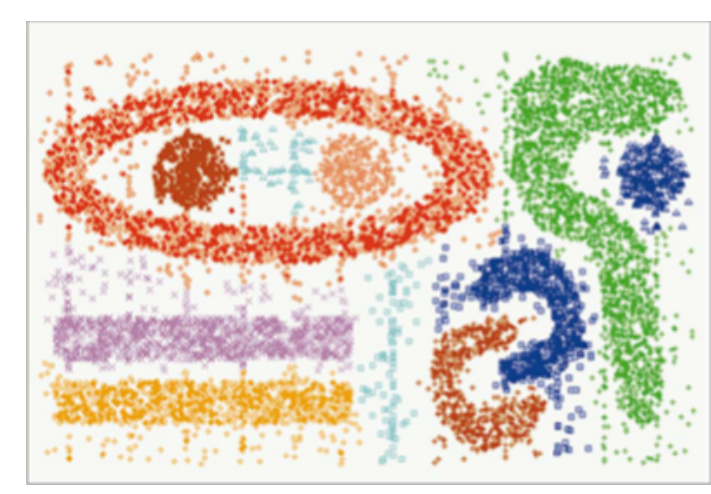

(a)

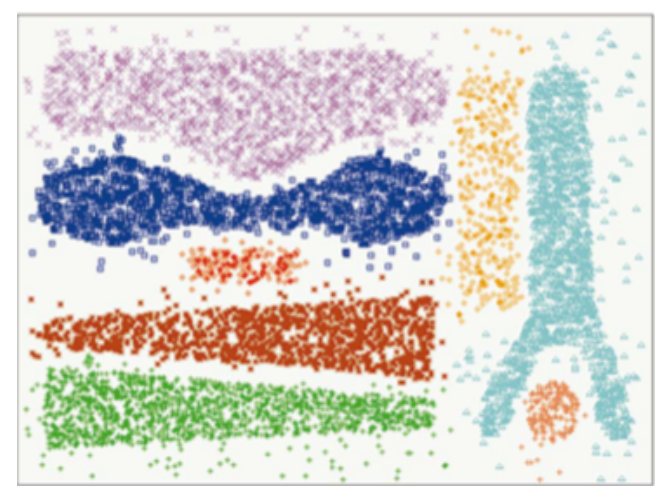

(b)

Figura 2.12: Resultado do agrupamento para conjunto de dados artificiais formados por (a) 10000 pontos e (b) 8000 pontos bidimensionais, onde cada cor representa um grupo. Os parâmetros utilizados são $k=10$ para gerar a rede e $\alpha=2$ (Karypis et al., 1999).

onde $\bar{S} E C\left(C_{i}\right)$ e $\bar{S} E C\left(C_{j}\right)$ são os pesos médios das arestas que cruzam a bisseção mínima dos elementos dos grupos $C_{i}$ e $C_{j}$ respectivamente. $\bar{S} E C\left(C_{i}, C_{j}\right)$ é o peso médio das arestas que conectam $C_{i}$ e $C_{j}$. $\left|C_{i}\right|$ e $\left|C_{j}\right|$ são os números de vértices dos grupos $C_{i} \mathrm{e}$ $C_{j}$.

Existem várias maneiras de combinar essas duas medidas. O Chameleon tenta maximizar as duas tomando a multiplicação de ambas: $R I\left(C_{i}, C_{j}\right) \times R C\left(C_{i}, C_{j}\right)^{\alpha}$ onde $\alpha$ é um parâmetro definido pelo usuário que controla a importância de cada medida. Se $\alpha>1$ então o Chameleon dá mais importância à proximidade relativa, caso contrário, a interconectividade relativa terá mais importância. O Algoritmo 5 mostra os passos realizados pelo Chameleon.

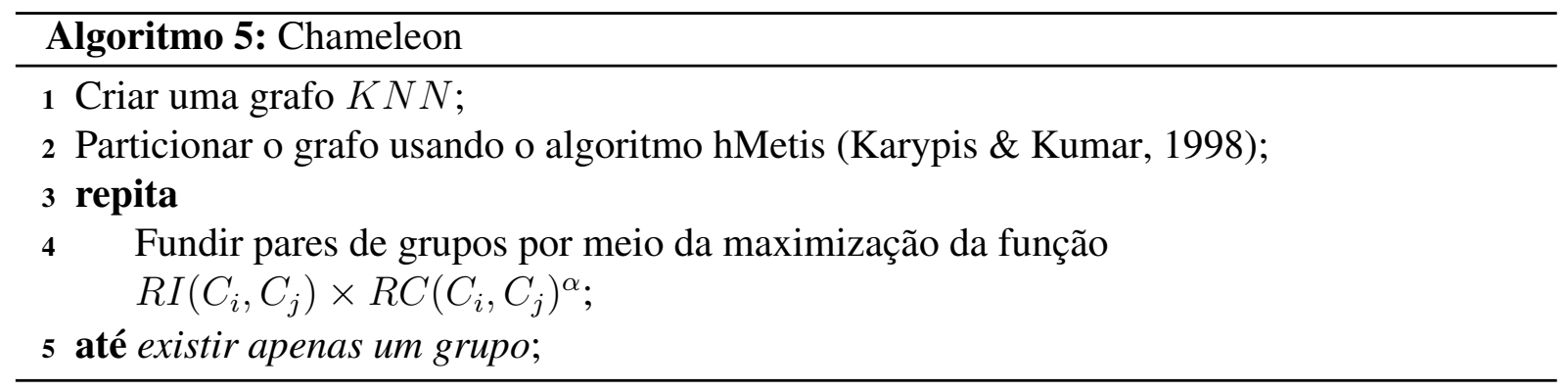

Nas Figuras 2.12(a) e 2.12(b) são exibidas os resultados obtidos a partir da execução do algoritmo Chameleon para algumas bases de dados bidimensionais geradas artificialmente com grupos de formas variadas. Com esses experimentos é possível observar que o Chameleon conseguiu encontrar os grupos originais.

\subsection{Considerações Finais}

Nesse Capítulo foi apresentado uma revisão bibliográfica sobre agrupamento de dados, abordando os tipos de dados e seus atributos bem como algumas funções de similaridade e dissimila- 
ridade. Logo em seguida, foram apresentadas as técnicas tradicionais para realizar agrupamento de dados.

Em redes de sensores sem fio, os dados utilizados durante a tarefa de agrupamento de dado são os próprios sensores. Dessa forma, para agrupa-los de forma eficiente, torna-se necessário entender suas características para que seja possível definir uma medida de similaridade entre os sensores e utilizar algoritmos de agrupamento mais adequados. No Capítulo a seguir, será feita uma revisão bibliográfica sobre agrupamento de dados em redes de sensores sem fio. 


\section{Agrupamento de Dados em Redes de Sensores Sem Fio}

Neste Capítulo, será apresentada a definição de Redes de Sensores sem Fio (RSSF), bem como suas propriedades, limitações e aplicações. Em seguida, serão apresentadas algumas topologias mais comuns de RSSF e será explicado porque é interessante agrupar os sensores da rede. Por fim, serão apresentados alguns algoritmos de agrupamento de sensores em RSSF mais comuns na literatura.

\subsection{Redes de Sensores Sem Fio}

Uma rede de sensores sem fio (RSSF) consiste em um grande número de nós ${ }^{1}$ sensores de baixo custo, baixo poder e multifuncional, posicionados em uma região de interesse (Zheng \& Jamalipour, 2009). Esses hardwares são de pequeno porte mas são equipados com sensores, microprocessadores, transceptores ${ }^{2}$, e portanto não só possuem a capacidade de sensoriamento, mas também de processamento e comunicação. A comunicação entre esses nós é feita por meio sem fio. As RSSFs apresentam as seguintes características e limitações:

- Alta densidade de nós: As RSSF muitas vezes apresentem alta densidade de nós, ou seja, são compostas por uma grande quantidade de nós densamente posicionados na área de monitoramento;

\footnotetext{
${ }^{1}$ Por uma questão de padronização de nomenclatura, o termo "nó" será utilizado nesse trabalho para se referir a qualquer entidade da rede e o termo escravo, somente será utilizado para os nós que coletam informação do ambiente.

${ }^{2}$ Dispositivo que combina um transmissor e um receptor.
} 
- Alimentação por baterias: A maioria dos sensores são alimentados por bateria. Em muitos casos, as RSSF são utilizadas em lugares inóspitos e ou de difícil acesso, que impossibilitam ou inviabilizam a troca ou recarga dessas baterias;

- Limitações energéticas, Computacionais e Armazenamento: Devido ao fato de serem utilizados sensores de baixo custo, esses apresentam limitações energéticas, computacionais e de armazenamento;

- Auto-configurável: É muito comum que os sensores da rede sejam posicionados aleatoriamente. Por exemplo quando se deseja monitorar uma floresta, muitas vezes os sensores são lançados por avião, podendo cair em vários lugares. Dessa forma, depois de posicionados, é necessário que os sensores da rede se configurem automaticamente para que seja possível a comunicação na rede;

- Aplicações específicas: RSSF são desenvolvidas para aplicações específicas, sendo que pequenas alterações no ambiente inviabilizam a utilização dessa rede;

- Não confiáveis: Devido ao baixo custo, os sensores não são confiáveis. Outro fator agravante é o ambiente, muitas vezes hostil, que pode danificar o equipamento;

- Mudança constante de topologia: A topologia da rede não é constante pois, devido a influência do meio em que se encontra, os nós podem falhar, sofrer interferência, acabar a bateria, etc;

- Sem identificação global: Devido ao grande número de nós da rede, é quase impossível construir um esquema global de endereçamento na rede, porque isso introduziria um alto esforço para manter a identificação;

- Padrão de tráfego muitos-para-um: É muito comum que, em RSSF, os dados dos sensores sejam enviados para um nó específico, caracterizando assim um padrão de comunicação muitos-para-um;

- Redundância de dados: A redundância dos dados é muito frequente em RSSF. Isso ocorre devido ao alta densidade de nós da rede que acaba fazendo com que vários nós coletem a mesma informação do ambiente em que se encontram.

\subsection{Aplicações}

Sensores podem ser utilizados para detectar e monitorar uma grande variedade de parâmetros físicos como, por exemplo: luz, som, pressão, temperatura, composição do solo, qualidade do ar ou água, tamanho, peso, posição, velocidade, direção, etc (Akyildiz, 2002). Sensores sem fio apresentam vantagens em relação a sensores cabeados, pois além de reduzir o custo e 
o tempo de posicionamento, podem ser aplicados a qualquer ambiente, principalmente aqueles onde não é viável o uso de fios, como por exemplo, em campos de guerra ou no fundo do oceano (Zhao \& Guibas, 2004).

Inicialmente, a motivação para o uso de RSSF se deu no campo militar. Entretanto, o barateamento desses dispositivos e o avanço tecnológico na comunicação sem fio, possibilitaram a aplicação de RSSF em vários campos. A seguir serão apresentadas algumas dessas áreas de aplicação.

1. Militar:

- Monitoramento de campo de guerra: Sensores podem ser utilizados para monitorar a presença de inimigos e veículos em campo de guerra;

- Proteção de objetos: Sensores podem ser posicionados em objetos estratégicos, como por exemplo pontes, dutos de combustível, centros de comunicação, etc, para monitora-los e protege-los;

- Orientação inteligente: Sensores podem ser posicionados em robôs, tanques de guerra, mísseis, etc, a fim de prover uma direção para que os mesmos atinjam seus objetivos;

- Sensoriamento remoto: Detecção de armas químicas e biológicas, detecção de ataques terroristas, etc;

2. Monitoramento de ambiente: Consiste em extrair e avaliar parâmetros e condições do meio ambiente.

- Habitat: Sensores podem ser utilizados para monitorar condições de animais selvagens ou plantas em seus habitats naturais;

- Qualidade do ar ou água: Sensores podem ser posicionados na água ou ar para monitorar a qualidade dos mesmos;

- Perigo: Monitorar ameaças químicas e biológicas em campo de guerra;

- Desastres: Detectar desastres naturais, podendo ser posicionados sensores em florestas para detectar incêndios ou em rios para detectar inundações.;

3. Saúde: RSSF podem ser utilizadas para o monitoramento de comportamento e saúde de idosos e pacientes.

- Monitorar comportamento: Sensores podem ser utilizados para monitorar paciente em casa para que, por exemplo, quando um idoso caia, ser chamado automaticamente um médico;

- Monitorar saúde: Sensores podem ser incorporados em vestimentas e ligados a internet para monitorar sinais vitais de pacientes para que sejam detectados emergências e seja possível realizar os procedimentos médicos mais rapidamente; 


\subsection{Arquiteturas}

Uma RSSF é tipicamente composta por um grande número de nós sensores densamente posicionados em uma região de interesse. Além desses sensores, uma ou mais estações base (também chamadas de sink) são posicionadas próximo ou dentro da região monitorada pelos sensores. A função da estação base é enviar comandos (consultas) aos sensores da rede que colaboram entre si para realizar o sensoriamento e retornar os dados para a estação base. Em alguns caso a estação base também atua como porta de entrada para outras redes, como por exemplo, a internet, para que um usuário possa obter os dados a distância. Essa arquitetura é ilustrada na Figura 3.1.

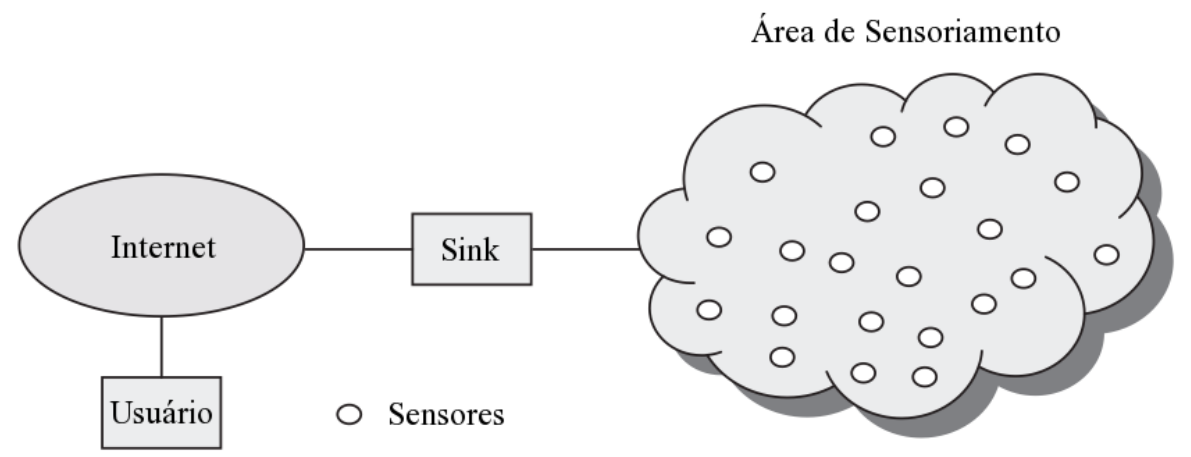

Figura 3.1: Exemplo de arquitetura de RSSF com a presença de sensores escravos e uma estação base (sink) que envia dados para o usuário por meio da internet. Adaptado de (Zheng \& Jamalipour, 2009).

Para que os dados cheguem até a estação base, os nós sensores da rede podem transmitir suas mensagens diretamente para a estação base. Nesse caso, a arquitetura (Fig. 3.2(a)) é chamada de single hop (um salto) pois, durante a comunicação, não há sensores intermediários. Nessa arquitetura, sensores que estão longe da estação base acabam tendo um gasto energético maior que os sensores mais próximos, pois precisam enviar suas mensagens para uma distância maior. Dessa forma, a redução no tráfego e nas distâncias de comunicação diminuem o gasto energético e aumentam a vida útil da rede.

Nesse sentido, é preferível a utilização de redes multihop (saltos múltiplos), que se caracterizam pela presença de nós intermediários entre a comunicação de um nó e a estação base. Considerando que as RSSF são densas, então os nós estão próximos uns dos outros. Assim, a informação de um sensor é geralmente enviada para um nó próximo, que envia para outro e assim sucessivamente até ser transmitida para a estação base. Dessa forma, o gasto energético dos sensores decorrente do envio de mensagem é reduzido. Al-karaki \& Kamal (2004) apresentam dois tipos de redes multihop: planas e hierárquicas, descritas a seguir nas Subseções 3.3.1 e 3.3.2 respectivamente. 


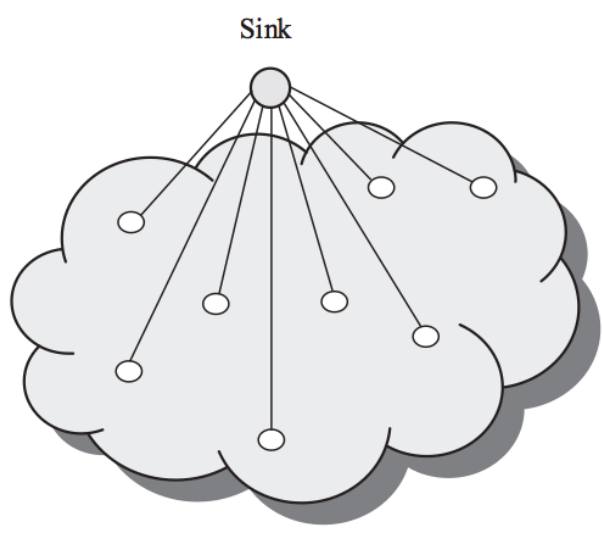

(a)

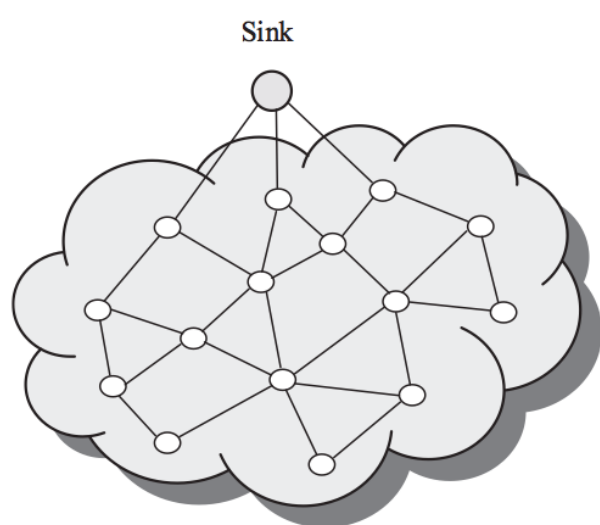

(b)

Figura 3.2: Diferença entre as formas de envio de mensagens dos sensores até à(s) estação base (sink). (a) Rede single hop: a transmissão é feita diretamente para o sink. (b) Rede multihop plana: os dados são transmitidos aos nós mais próximos até chegarem no sink. Adaptado de (Zheng \& Jamalipour, 2009).

\subsubsection{Redes Multihop Planas}

Em redes multihop planas, cada nó da rede desempenha o mesmo papel de sensoriamento. Devido ao grande número de nós, fica inviável associar um identificador global para os nós e isso faz com que a obtenção dos dados seja feita por meio de uma rota, a qual a estação base transmite seus comandos (consultas) para todos os nós via flooding ${ }^{3}$ e os sensores que possuem os dados da consulta respondem à estação base. Nesse tipo de arquitetura, os nós se comunicam com a estação base por meio de multihops.

\subsubsection{Redes Multihop Hierárquicas}

O segundo tipo de rede multihop é o hierárquico, que se caracteriza pela presença de grupos de sensores. Dentro desses grupos existe um sensor especial chamado cluster head $(\mathrm{CH})$ que é responsável por coletar as mensagens do grupo e transmiti-las para a estação base. Existem duas abordagens mais comuns de utilização de sensores $\mathrm{CH}$ : seleção (eleição) ou posicionamento. $\mathrm{Na}$ abordagem por seleção, são utilizados sensores que, ora atuam como $\mathrm{CH}$, ora não, podendo assim dizer, que os CHs são eleitos dentre o conjunto de nós da rede. Na segunda abordagem são utilizados sensores $\mathrm{CH}$ especiais que são posicionado depois que a rede já está formada. A abordagem de seleção é mais comum na literatura pois, na maioria dos casos, as redes se encontram em lugares de difícil acesso, inviabilizando o processo de posicionamento de novos sensores. Entretanto, com o desenvolvimento da robótica, surgem robôs que podem adentrar nesses lugares inóspitos e reposicionar esses sensores de forma mais eficiente. De qualquer uma das formas, é necessário utilizar alguma técnica de agrupamento de dados para seja possível encontrar os grupos. De acordo com a distância entre os $\mathrm{CHs}$ e os sensores, as arquiteturas dos grupos podem ser dividas em single hop, quando os sensores transmitem suas mensagens

\footnotetext{
${ }^{3}$ Tipo simples de algoritmo de roteamento onde cada mensagem recebida é retransmitida por todas as conexões.
} 
diretamente para o $\mathrm{CH}$, ou multihop quando há nós intermediários entre sensores e o $\mathrm{CH}$ (Gupta \& Younis, 2003). Essas duas arquiteturas de grupos podem ser vistas na Figura 3.3.

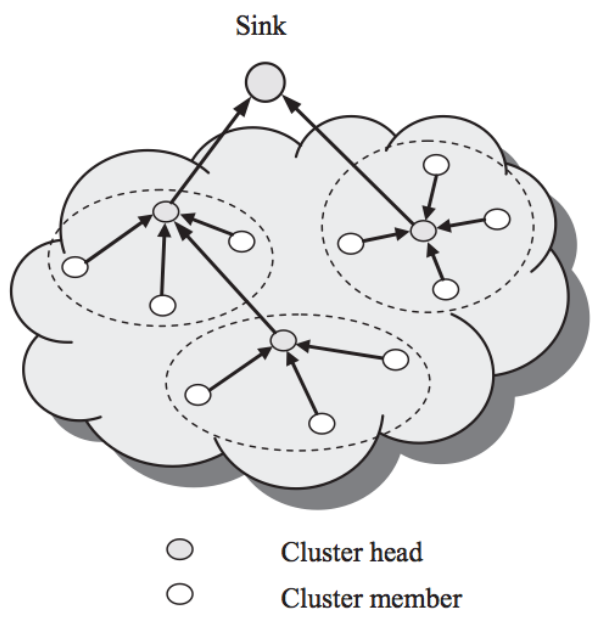

(a)

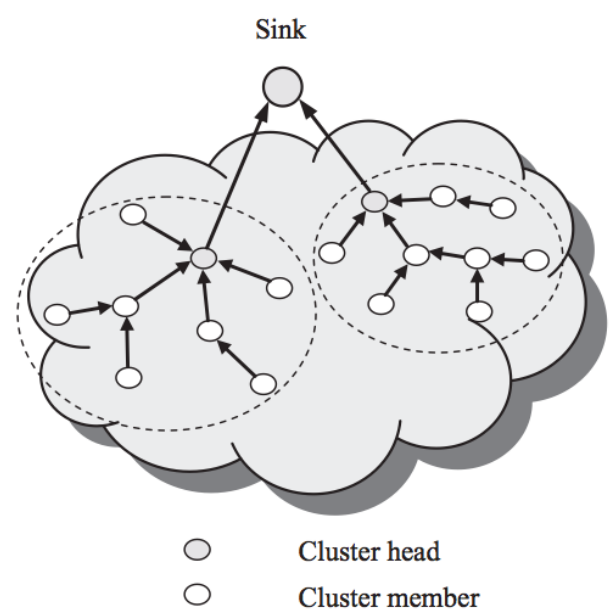

(b)

Figura 3.3: Redes hierárquicas e seus tipos de arquitetura de grupos: (a) Single hop, os sensores do grupo transmitem diretamente para o cluster head. (b) Multihop, existem sensores intermediários entre os sensores do grupo e o CH. Adaptado de (Zheng \& Jamalipour, 2009).

A utilização de CHs não só reduz o consumo de energia, mas também faz o balanceamento do tráfego da rede que consequentemente melhora a escalabilidade da rede quando essa cresce. Em muitos os casos, é comum refazer a seleção ou reposicionar os $\mathrm{CHs}$ ao longo do tempo para refletir as mudanças que ocorrem na topologia da rede. Além disso, também é comum que os CHs façam a fusão dos dados recebidos de seus sensores para reduzir a quantidade de dados transmitidos pela rede e economizar energia (Rajagopalan \& Varshney, 2006).

Em redes hierárquicas, o principal problema do agrupamento é como selecionar ou posicionar esses CHs e como organiza-los em grupos (Abbasi \& Younis, 2007). Para resolver esse problema, alguns algoritmos de agrupamento foram apresentados na literatura (serão apresentados na Seção 3.6) para diferentes objetivos que serão apresentados a seguir na Seção 3.4.

\subsection{Objetivos do Agrupamento de Dados}

Cada técnica de agrupamento de dados é desenvolvida para atender as necessidades de uma ou mais aplicações específicas. Abbasi \& Younis (2007) enumeram os seguintes objetivos mais comuns de agrupamento de sensores:

- Tolerância a falhas: Em muitos tipos de aplicações de RSSF, os nós da redes estão sujeitos a falhas decorrente do ambiente inóspito os quais estão inseridos. Pressão, umidade, choque, etc, podem danificar os sensores e comprometer o funcionamento da rede. Para esses tipos de aplicações, é interessante minimizar a falha dos $\mathrm{CHs}$ e a consequente perda nas mensagens transmitidas na rede. Uma das formas mais simples de tratar a falha de 
$\mathrm{CH}$ é realizar novamente o agrupamento e escolher outro $\mathrm{CH}$. Entretanto, reagrupar pode ser um processo muito custoso e perigoso, pois altera a topologia da rede e prejudica a operação. Para evitar esse problema, técnicas de tolerância a falhas vem sendo desenvolvidas. Uma forma mais eficiente seria fazer um rodízio nos papeis dos sensores, que ora desempenhariam papel de $\mathrm{CH}$, ora não;

- Aumentar conectividade: Os dispositivos usados como $\mathrm{CH}$ muitas vezes tem um raio pequeno de cobertura, alcançando poucos sensores da rede. Assim, surge o problema de maximizar a conectividade da rede e tentar garantir a existência de um caminho entre cada CH e a estação base (Bandyopadhyay \& Coyle, 2003) ou então limitar o tamanho desse caminho (Dai \& Wu, 2005);

- Balanceamento de carga: Dados as tarefas do $\mathrm{CH}$, é intuitivo pensar em balancear a carga entre eles para atingir uma performance adequada (Younis et al., 2003). Em RSSF em que os CHs são eleitos entre os sensores da rede, esse problema ainda é mais evidente (Younis \& Fahmy, 2004) pois, caso sejam encontrados grupos de mesmo tamanho, a vida útil da rede é prolongada e evita que alguns $\mathrm{CHs}$ sejam sobrecarregados, consumindo mais bateria. Consequentemente, também prolonga a vida dos $\mathrm{CHs}$ evitando eles desliguem prematuramente e comprometam parte da rede;

- Minimizar grupos: Esse objetivo é comum quando são utilizados nós ricos em recursos como laptops, robôs ou veículos (Oyman \& Ersoy, 2004). Na maioria dos casos, esses nós são empregados em número limitado por terem custo elevado. Portanto, nesses casos, o objetivo é utilizar o menor número de nós possíveis;

- Maximizar vida útil: Uma das maiores preocupações quando se utiliza RSSF é quanto ao consumo energético. Cada nó da rede possui uma bateria limitada que, em muitos casos, não pode ser trocada ou recarregada devido a ambientes inóspitos ou de difícil acesso como florestas e alto-fornos respectivamente. Uma estratégia para aumentar a vida útil é posicionar os CHs mais próximos dos sensores da rede (Hou et al., 2005) para que a potência de transmissão necessária para comunicação seja menor e consequentemente gaste menos energia. Outra maneira é utilizar técnicas adaptativas de agrupamento (Moscibroda \& Wattenhofer, 2005).

\subsection{Taxonomia dos Atributos de Agrupamento}

Abbasi \& Younis (2007) listaram um conjunto de características das RSSFs e criaram uma taxonomia para que seja possível diferenciar os algoritmos de agrupamento. A Figura 3.4 ilustra essa taxonomia. 
1. Propriedades do grupo: Os algoritmos de agrupamento em RSSF tendem a gerar grupos que possuem certas características desejadas. Essa características podem estar relacionadas a arquitetura dos sensores dentro do grupo ou a interação entre grupos distintos. Os atributos mais relevantes são:

- Quantidade: Na maioria dos métodos de agrupamento, o número de $\mathrm{CHs}$ utilizados é pré-determinado e consequentemente, o número de grupos encontrado pelo algoritmo também é. Por outro lado, algumas técnicas utilizam métodos probabilísticos podendo eleger números variados de $\mathrm{CHs}$ dentre os nós da rede e, portanto, gerar números variados de grupos;

- Estabilidade: Para alguns algoritmos de agrupamento é necessário informar como parâmetro o número desejado de $\mathrm{CHs}$ (grupos). Outros algoritmos variam o número de $\mathrm{CHs}$ ao longo do tempo, sendo esses chamados de adapatativos;

- Topologia no interior do grupo: Refere-se as conexões realizadas pelos nós no interior do grupo. Na maioria dos casos, os nós se conectam diretamente com o $\mathrm{CH}$ do grupo. Entretanto, podem ser utilizados sensores multihop e, nesse caso, os sensores podem enviar suas mensagens para outros nós, que por sua vez enviam para o $\mathrm{CH}$;

- Conectividade entre grupos: Devido a limitação no raio de alcance, em muitos casos os CHs não conseguem fazer uma comunicação direta com a estação base. Nessa situação os CHs devem também rotear mensagens recebidas de outros $\mathrm{CHs}$ até que a informação seja transmitida até a estação base. Em outros casos, é considerado que os CHs fazem comunicação direta com a estação base. Essa diferenciação é ilustrada nas Figuras 3.2(a) e 3.2(b) sendo que na primeira, os CHs se comunicam diretamente com a estação base e na segunda alguns $\mathrm{CHs}$ fazem papel de roteador para outros $\mathrm{CHs}$;

2. Capacidades do cluster head: A capacidade e característica dos CHs influenciam diretamente na abordagem do algoritmo de agrupamento (Seção 2.4). Dentre essas características, as mais comuns são:

- Mobilidade: Os CHs da rede podem ser móveis ou estáticos. Quando possuem mobilidade, os grupos da rede também se alteram para refletir a mudança de posição do $\mathrm{CH}$, ou seja, os grupos não são estáveis (ou fixos). Por outro lado, quando os CHs são estáticos, os grupos também são, facilitando a gerência da comunicação intra e inter grupos;

- Tipos de nós: Refere-se a capacidade dos CHs. Como dito anteriormente, alguns tipos de $\mathrm{CHs}$ podem ser ricos em recursos, provendo-lhes mais funcionalidades, capacidade de processamento, maior alcance, etc. Outro caso mais comum é quando os nós são todos iguais e ora desempenham papel de sensor, ora papel de $\mathrm{CH}$; 
- Papel: Os CHs da rede podem ter papéis diferentes. Na forma mais simples, atuam apenas como um transmissor das mensagens geradas pelos sensores do grupo. Entretanto, esses $\mathrm{CHs}$ podem, em alguns casos (quando ricos em funcionalidades), desempenhar outras atividades, como por exemplo, o processamento e fusão de dados gerados pelos sensores do grupo;

3. Processo de agrupamento: As técnicas de agrupamento de dados em RSSF presentes na literatura variam bastante uma das outras em relação ao processo de agrupamento. As características mais comuns observada nessas técnicas de agrupamento são:

- Metodologia: Quando os CHs são nós comuns, o agrupamento de dados pode ser feito de forma distribuída. Em alguns casos, alguma entidade centralizada controla o partionamento dos grupos. Esquemas híbridos também são utilizados, principalmente quando são utilizados sensores ricos em recursos;

- Objetivo: Os objetivos do agrupamento foram apresentados na Seção 3.4;

- Seleção do cluster head: Os CHs podem ser selecionados utilizando um algoritmo ou então escolhidos aleatoriamente entre os nós da rede;

- Complexidade do algoritmo: A complexidade dos algoritmos de agrupamento está diretamente ligada ao objetivo, metodologia, podendo ser constante ou depender do número de $\mathrm{CHs}$ e ou sensores.

\subsection{Algoritmos de Agrupamento}

As redes de sensores sem fio (RSSF) são compostas, em sua maioria, por um grande número de sensores. Uma maneira eficiente de gerenciar essa grande quantidade de sensores é por meio do agrupamento de dados. Nessa seção serão apresentados os algoritmos de agrupamento de sensores em RSSF mais citados na literatura.

\subsubsection{CLUBS}

Proposto por Nagpal \& Coore (1998), o algoritmo CLUBS realiza o agrupamento de sensores por meio de broadcast local e convergência em tempo proporcional a densidade local de nós da rede. O algoritmo se baseia em três características principais: 1) Todos os nós da rede devem estar conectados a pelo menos um $\mathrm{CH}$ (permite sobreposição); 2) O diâmetro máximo da rede deve ser o mesmo para cada nó; 3) Os nós de um mesmo grupo devem ter a capacidade de se comunicar entre si.

O CLUBS encontra os grupos com no máximo dois hops. Cada nó da rede participa do processo de agrupamento escolhendo aleatoriamente um número inteiro dentro de um intervalo $[0, R)$ determinada pelo usuário. Em seguida, esse nó começa a fazer a contagem regressiva a 

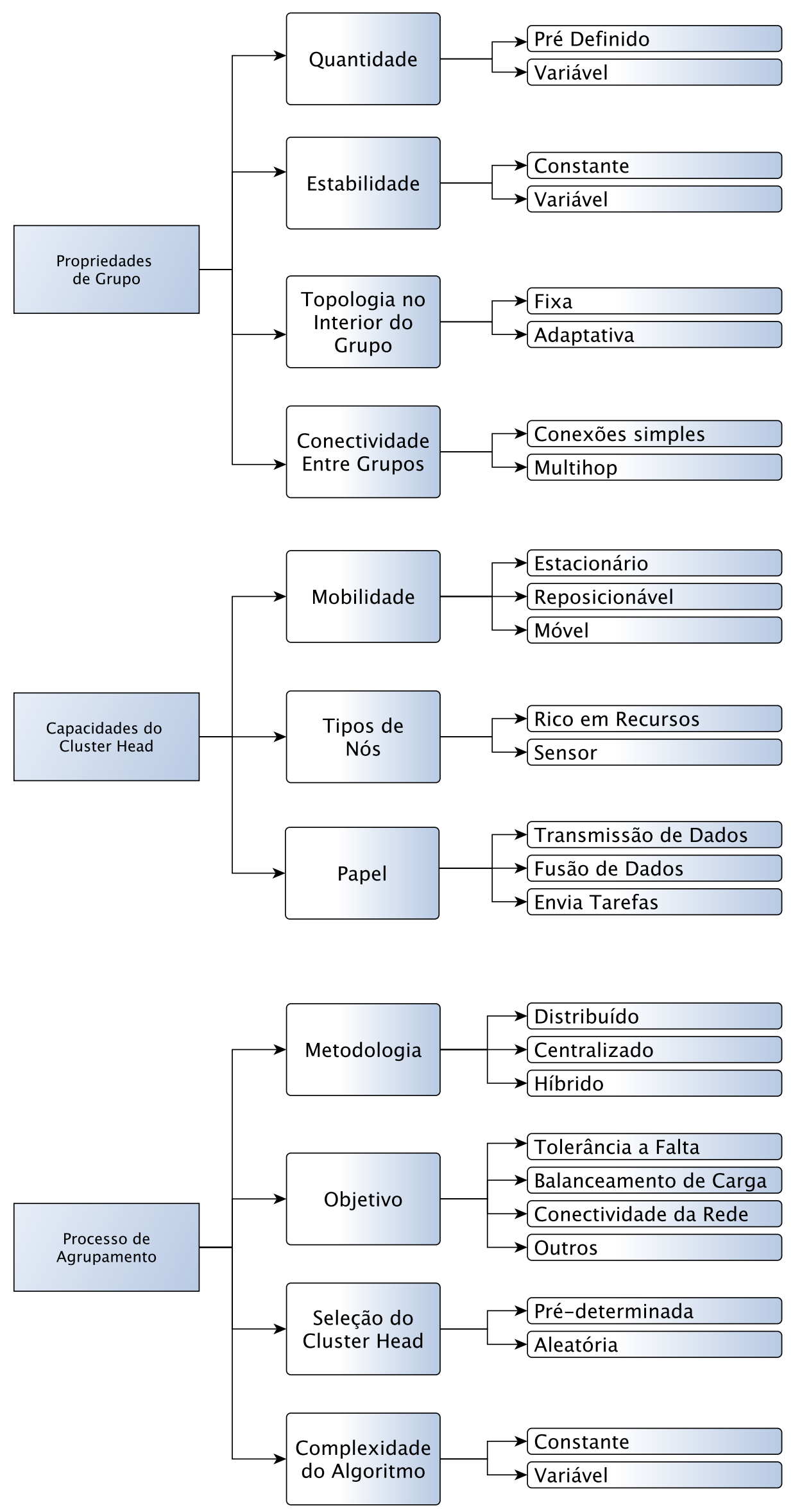

Figura 3.4: taxonomia para a classificação de algoritmos de agrupamento de sensores (Abbasi \& Younis, 2007). 
partir desse número. Se essa contagem não for interrompida por nenhum outro nó vizinho e chegar a zero, então esse nó anuncia que é um CH (líder) e transmite a mensagem de recrutamento (recruit) em broadcast. Quando um vizinho recebe uma mensagem de recrutamento, que vem de um nó com no máximo dois hops, ele então pára sua contagem e aceita o convite para juntar-se a esse grupo. Esse nó então passa a ser chamado de seguidor (follower) e não pode mais se tornar $\mathrm{CH}$. Os nós seguidores continuam a escutar as mensagens de recrutamento e podem se tornar seguidores de mais de um $\mathrm{CH}$. Caso um nó, que esteja tentando ser $\mathrm{CH}$ detecte uma colisão nas mensagens, ele se torna um nó seguidor e assume que possui mais de um $\mathrm{CH}$. Nas iterações futuras ele poderá descobrir qual será seu CH. O CLUBS termina apenas quando todos os nós da rede tenham sido agrupados e classificados como recrutadores ou seguidores. $\mathrm{O}$ processo de agrupamento executado pelo CLUBS é descrito formalmente no Algoritmo 6. Um exemplo de resultado obtido por meio do CLUBS pode ser visualizado na Figura 3.5.

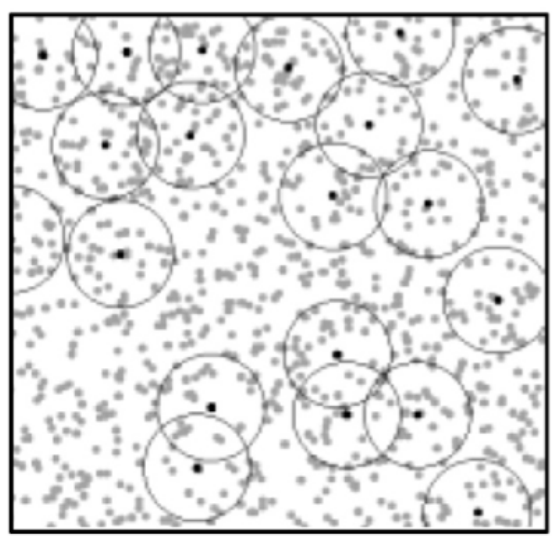

(a)

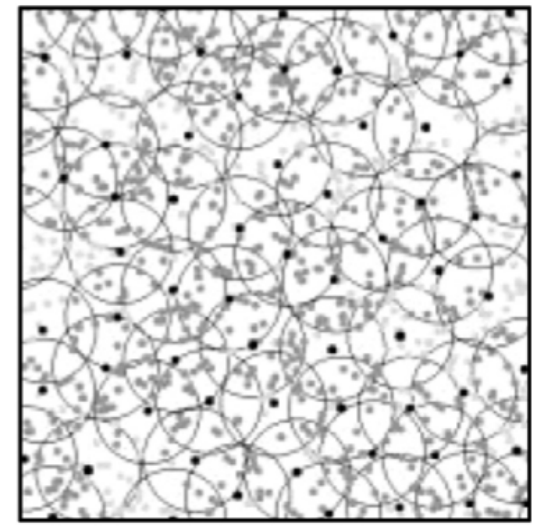

(b)

Figura 3.5: Resultado do processo de agrupamento utilizando o algoritmo CLUBS. (a) Pontos pretos são os CHs, pontos cinzas (recrutadores) são os sensores e os círculos pretos são os raios de cobertura dos CHs. (b) Resultado final com a formação dos grupos. Nós que estão em áreas de interseção pertencem a mais de um CH (sobreposição). (Nagpal \& Coore, 1998)

\subsubsection{LEACH}

O algoritmo mais famoso de agrupamento de dados em RSSF é o Low Energy Adaptive Clustering Hierarchy (LEACH), proposto por Heinzelman et al. (2002). Esse algoritmo distribuído agrupa os sensores usando a força do sinal recebida. Nesse modelo, é considerado que o $\mathrm{CH}$ realiza a comunicação com a estação base diretamente em um hop. Dentro de cada grupo formado, a comunicação também é feita em um hop, ou seja, cada sensor da rede se comunica diretamente com o $\mathrm{CH}$.

Cada nó $i$ da rede tem probabilidade $P_{i}(t)$ de se tornar $\mathrm{CH}$ no tempo $t$. Essa probabilidade é escolhida de tal forma que o número de $\mathrm{CHs}$ seja igual a $k$, ou seja $\sum_{i=1}^{N} P_{i}(t)=k$, onde $N$ é o número de nós da rede. Cada nó, que não é $\mathrm{CH}$, pertence ao grupo do $\mathrm{CH}$ cujo gasto energético para transmissão de mensagens seja mínimo. Periodicamente, os $\mathrm{CHs}$ deixam de 


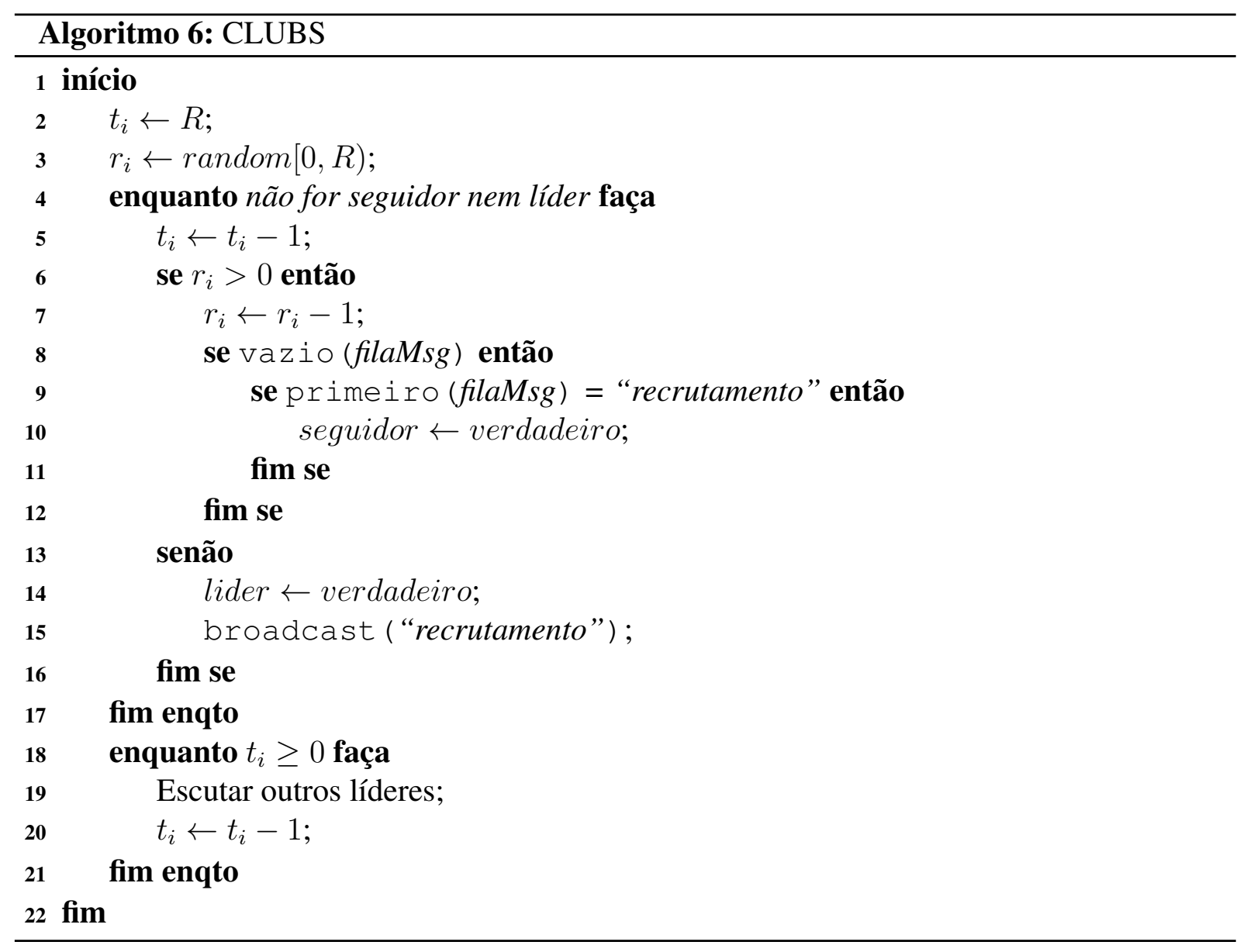


ser $\mathrm{CH}$ e outros sensores passam a atuar como $\mathrm{CH}$. Isso ocorre para que haja um balanço no gasto energético da rede, já que os $\mathrm{CHs}$ tem alto gasto energético. Tomando $C_{i}(t)$ como a função que determina se o nó $i$ já foi um $\mathrm{CH}$ nas últimas rodadas $\left(\operatorname{rmod}\left(\frac{N}{k}\right)\right)$, então $C_{i}(t)=0$ se o nó $i$ foi um $\mathrm{CH}$ ou $C_{i}(t)=1$ caso contrário. Assim, a probabilidade $P_{i}(t)$ na rodada $r$ pode ser calculada pela Equação 3.1, que garante que apenas os nós que não tenham sido $\mathrm{CH}$ recentemente e que possuem mais energia podem se tornar $\mathrm{CH}$ na rodada $r+1$.

$$
P_{i}(t)= \begin{cases}\frac{k}{N-k\left(\operatorname{rmod} \frac{N}{k}\right)} & \text { se } C_{i}(t)=0 \\ 0 & \text { se } C_{i}(t)=1\end{cases}
$$

Uma vez que os nós tenham se elegidos $\mathrm{CH}$, eles precisam informar aos nós restantes da rede que, nessa rodada, eles são $\mathrm{CHs}$. Para isso, cada $\mathrm{CH}$ envia uma mensagem em broadcast com o ID do seu nó. Então, cada nó da rede determina a qual grupo pertence nessa rodada escolhendo o $\mathrm{CH}$ que gaste o mínimo de energia para se comunicar, baseado na força do sinal da mensagem recebido de cada $\mathrm{CH}$. A Figura 3.6 mostra a formação dos grupos para duas rodas do algoritmo LEACH.

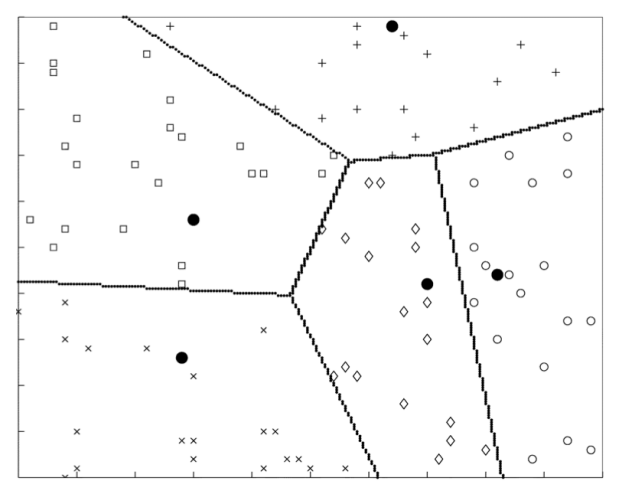

(a)

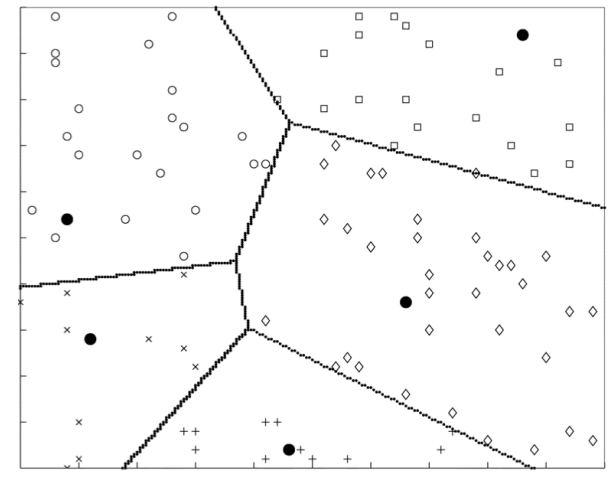

(b)

Figura 3.6: Formação dos grupos em duas rodadas, (a) e (b), do algoritmo LEACH. Pontos pretos maiores $(\bullet)$ simbolizam os $\mathrm{CHs}$, os outros pontos simbolizam os sensores, sendo que símbolos iguais definem os grupos (Heinzelman et al., 2002)

\subsubsection{HEED}

Younis \& Fahmy (2004) propuseram um algoritmo distribuído de agrupamento em RSSF chamado Hybrid Energy-Efficient Distributed (HEED) que, diferente do algoritmo LEACH (3.6.2), não escolhe os $\mathrm{CHs}$ aleatoriamente, mas considera o consumo de energia e o custo de comunicação na rede para fazer a escolha. Baseado nesses conceitos, o HEED possui quatro objetivos principais: 1) prolongar a vida útil da rede distribuindo o consumo de energia; 2) terminar a tarefa de agrupamento em tempo constante; 3) minimizar a sobrecarga de controle; 4) gerar uma boa distribuição dos cluster heads. Esse algoritmo apenas assume que os nós da rede podem controlar seus níveis de força de transmissão. 
Em modelos clássicos de sistemas distribuídos, um nó da rede pode atuar como escravo ou cluster head mas não os dois ao mesmo tempo. No modelo proposto por Younis \& Fahmy (2004) isso é possível. Outras propriedades dos nós da rede também foram assumidas:

- Estacionários: Cada nó da rede não muda de posição;

- Conexões simétricas: Se existe uma aresta ligando os vértice $v_{1}$ e $v_{2}$ então ambos podem comunicar usando o mesmo nível de força de transmissão;

- Consumo de energia não uniforme: O HEED considera que cada nó pode gastar energia de forma diferente;

- localizações desconhecida: Os nós da rede não possuem sistema de posicionamento Global Positioning System (GPS);

- Capacidades similares: Todos os nós da rede tem capacidade de processamento e comunicação semelhantes;

- Isolamento: Não é possível alcançar os nós da rede, depois de posicionados. Consequentemente não é possível trocar ou recarregar a bateria dos nós da rede;

- Indexação: Cada nó da rede possui um número indexador de nível de força transmissão.

Para executar o algoritmo HEED, escolhe-se a priori a porcentagem $C_{p r o b}$ dos $n$ nós da rede para serem CHs. Essa porcentagem é apenas utilizada como limitante superior do número de $\mathrm{CHs}$, mas não tem efeito direto no número final de grupos. Na primeira fase (inicialização) do algoritmo HEED, é necessário calcular a probabilidade $\mathrm{CH}_{\text {prob }}$ de cada nó se tornar um $\mathrm{CH}$. Essa probabilidade é calculada pela Equação 3.2:

$$
C H_{\text {prob }}=C_{\text {prob }} \times \frac{E_{\text {residual }}}{E_{\text {max }}}
$$

onde $E_{\text {residual }}$ é a energia residual atual estimada para esse nó e $E_{\text {max }}$ é a energia máxima que ocorre quando a bateria está totalmente carregada, sendo esse valor constante para todos os nós da rede. $\mathrm{O}$ valor de $C H_{\text {prob }}$ não pode atingir um valor inferior a um limite $p_{\min }$.

A segunda fase consiste em iterar várias vezes para cada nó $v_{i}$ e encontrar o $\mathrm{CH}(m e u C H)$ que esse possa transmitir com o menor gasto energético possível (custo). Caso um sensor não encontre nenhum outro $\mathrm{CH}$ para transmitir, então ele se elege como $\mathrm{CH}$ e envia mensagens (CHmenssagem(NodeId, estado da seleção, custo)) para seus vizinhos informando sua mudança de estado. Então, a probabilidade de se tornar $\mathrm{CH}$ dobra e passa para a próxima iteração. Existem dois tipos de estados: 1) Tentativa, quando um sensor tenta ser um $\mathrm{CH}$, ou seja, possui $C H_{\text {prob }}<1$. Esse sensor $\mathrm{CH}$ pode voltar mais tarde a ser um sensor comum se encontrar um $\mathrm{CH}$ com um menor custo. 2) Final, quando $\mathrm{CH}_{\text {prob }}=1$ e esse sensor passa definitivamente a ser um $\mathrm{CH}$. Esse processo iterativo acaba quando $C H_{\text {prob }}=1$. O Algoritmo 7 descreve formalmente as três etapas de funcionamento do HEED. 


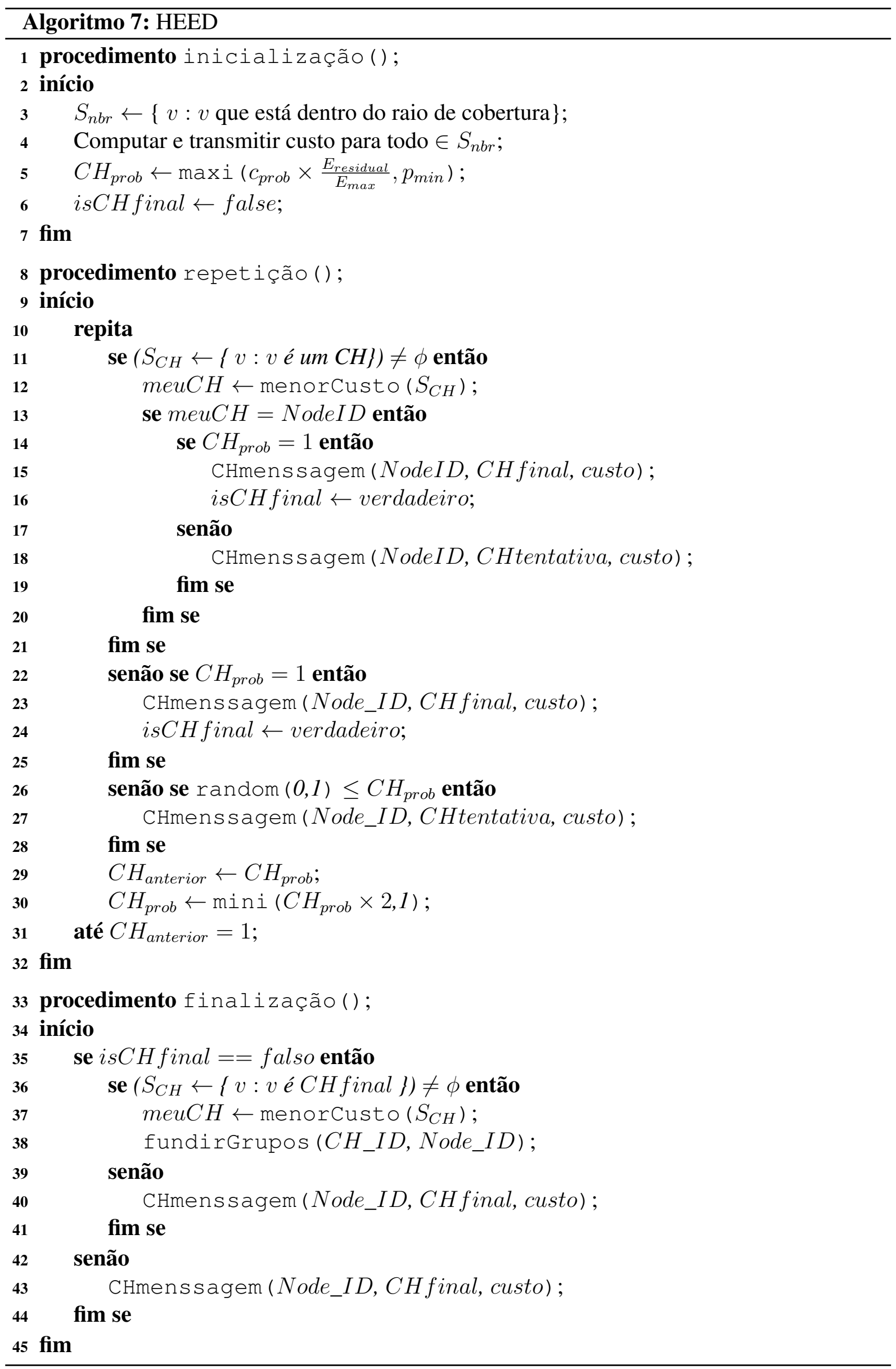




\subsubsection{FLOC}

O algoritmo Fast Local Clustering service (FLOC), proposto por (Demirbas et al., 2004) produz grupos de tamanhos semelhantes e sem sobreposições. Para isso, foi utilizado um modelo de rede simplificado onde cada nó é representado por um ponto cartesiano. O modelo de rádio utilizado se baseia na proximidade entre o $\mathrm{CH}$ e os nós para classifica-los como interior $(i$-band) ou exterior (o-band). Nós $i$-band conseguem enviar a maior parte das mensagens para $\mathrm{CH}$, enquanto que nós $o$-band não se comunicam bem com o $\mathrm{CH}$ e suas mensagens são perdidas em sua grande maioria.

Os nós da rede sabem se são $i$-band ou $o$-band de outro nó da seguinte forma: 1) Nós são capazes de medir a força do sinal das mensagens. Essa medida pode ser utilizada como indicador de distância entre o nó que envia e o que recebe a mensagem. 2) Um nó pode transmitir uma mensagem especial de baixa força de tal forma que os nós que recebem essa mensagem sabem que são i-band do nó que a enviou. 3) Os nós mantêm um registro de mensagens recebidas de seus vizinhos e sabem a relação de vizinhos $i$-band e $o$-band segundo a qualidade das conexões. 4) Um serviço de localização implícito pode prover as distâncias aos nós da rede. A partir desse modelo, o algoritmo FLOC foi construído de tal forma que:

- somente um nó do grupo pode ser $\mathrm{CH}$;

- cada nó $i$-band de um $\mathrm{CH}$ pertence ao grupo desse $\mathrm{CH}$;

- nenhum nó o-band de um $\mathrm{CH}$ pertence ao grupo desse $\mathrm{CH}$;

- todos os nós pertencem à algum $\mathrm{CH}$;

- nenhum nó pertence a mais de um grupo.

Cada nó $j$ da rede mantém apenas duas variáveis: status e cluster_id. O estado do nó $j$ (j.status) pode assumir cinco valores dentro do seguinte domínio: $\left\{i d l e, c a n d, c \_h e a d, i \_b a n d, o \_b a n d\right\}$. j.idle é verdadeiro quando $j$ não faz parte de nenhum grupo. j.cand informa que $j$ pretende ser $\mathrm{CH}$ e $j$.c_head diz se $j$ é um CH. j.i_bande $j . o \_b a n d$ sinalizam se $j$ é $i$-band ou $o$-band de um $\mathrm{CH}$ respectivamente. Por fim, j.cluster_id informa o grupo que $j$ pertence. Inicialmente, para todo nó $j$, j.status $=i d l e$ e $j$.cluster $\_i d=\perp$.

A partir dessas variáveis, os autores definem o algoritmo FLOC considerando seis ações que alteram o estado (variável status) dos sensores. A Figura 3.7 mostra os estados, sendo que as transições são as seguintes ações:

- Ação 1: é ativada quando um nó $j$ ficou um tempo em estado idle, escolhido randomicamente no intervalo $[0 \ldots T]$. Depois dessa ação, $j$ se torna candidato a $\mathrm{CH}$ $(j$. cand $=$ true $)$ e transmite uma mensagem a todos os nós informando sua candidatura; 


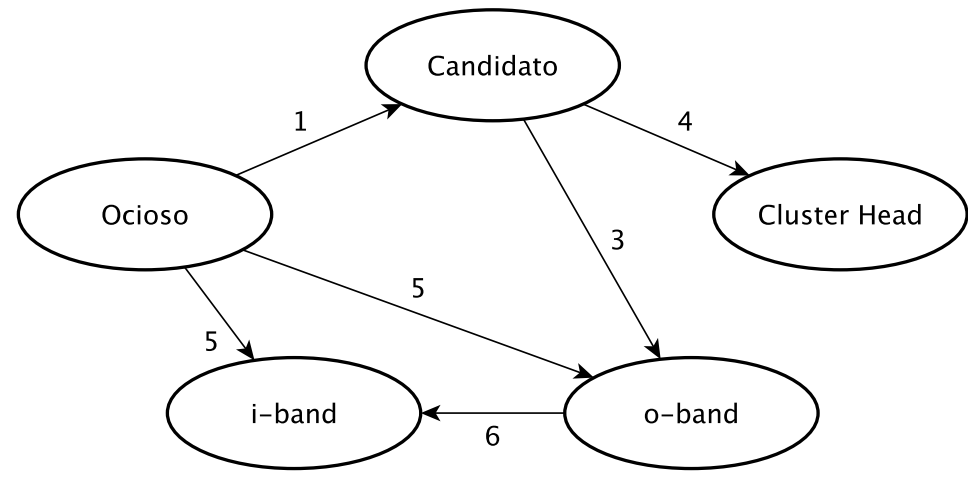

Figura 3.7: Estados da variável status no algoritmo FLOC (Demirbas et al., 2004).

- Ação 2: é ativada quando um nó $i$-band recebe uma mensagem de candidatura. Se esse nó determina que também é $i$-band de outro candidato, então ele responde a mensagem informando o conflito anexando seu cluster_id na mensagem. Um tempo aleatório é escolhido no intervalo $[0 \ldots T]$ para que esse nó espere para mandar a mensagem. Isso ocorre para tentar prevenir que muitos nós tentem responder ao mesmo tempo e acabe gerando muitas colisões;

- Ação 3: é ativada quando o nó $j$ recebe uma mensagem de conflito em resposta a sua mensagem de candidatura. Essa mensagem de conflito indica que, se $j$ forma um grupo, então seus nós $i$-band sofrerão sobreposição com os nós $i$-band do nó que enviou a mensagem de conflito;

- Ação 4: é ativada quando o nó $j$ não recebe mensagem de conflito dentro de um tempo predefinido Delta. Nesse caso, $j$ se torna um $\mathrm{CH}$ e transmite sua decisão enviando a mensagem $c \_h e a d \_m s g_{j}$ para todos os nós;

- Ação 5: é ativada quando um nó com estado $i d l e$ recebe a mensagem $c \_h e a d \_m s g_{j}$. Esse nó então determina se é $i$-band ou $o$-band do $\mathrm{CH}$ que enviou a mensagem, atualiza seu status e passa a fazer parte do grupo desse $\mathrm{CH}$;

- Ação 6: é ativada quando um nó $j o$-band recebe a mensagem $c \_h e a d \_m s g_{j}$ de um $\mathrm{CH} i$ de um outro grupo. Se $j$ determinar que ele é $i$-band do $\mathrm{CH} i$, então $j$ passa a ser $i$-band de $i$ e, consequentemente, passa fazer parte do grupo de $i$.

A Tabela 3.1 faz uma comparação entre os algoritmos descritos apresentados na Seção 3.6, mostrando as característica de cada um. A Tabela 3.2 traz a classificação desses algoritmos segundo a taxonomia (Sec. 3.5) proposta por Abbasi \& Younis (2007). 


\subsection{Considerações Finais}

Nesse capítulo foram apresentados alguns conceitos referentes a redes de sensores sem fio, necessários para o entendimento da proposta desse trabalho. Além disso, esse capítulo teve como objetivo servir de motivação para a aplicação de técnicas de agrupamento de dados em RSSF. No trabalho proposto, as redes de sensores serão representadas por meio de grafos que serão utilizados para agrupar os sensores e posicionar os cluster heads. Dessa forma, no capítulo a seguir será apresentado conceitos de redes complexas que fornecem soluções de agrupamento para redes de larga escala. 

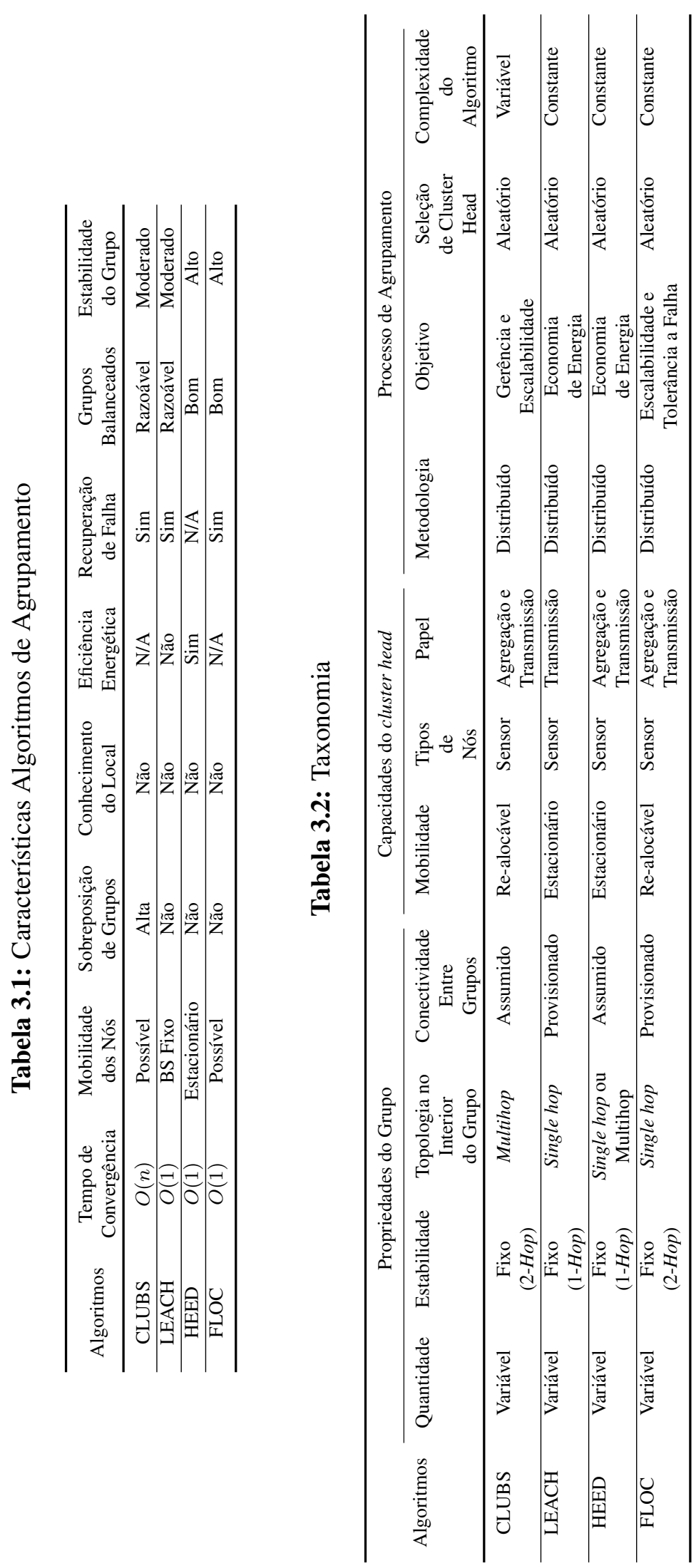
CAPÍTULO 4

\section{Detecção de Comunidades em Redes Complexas}

Nesse capítulo serão apresentados os principais conceitos de grafos ${ }^{1}$ como base para o entendimento de redes complexas. Serão apresentados os principais tipos de redes complexas bem como suas características e propriedades. Em seguida, serão revisadas algumas técnicas de detecção de comunidades em redes complexas.

\subsection{Conceitos de Rede}

Uma rede, também conhecida como um grafo $G=(V, E)$ é uma representação de dados composta por um conjunto $V$ formado por $n$ vértices (também chamados de nós) e um conjunto $E$ formado $m$ arestas (também chamado de conexões). Cada aresta do conjunto $E$ é formado por um par de vértices (Diestel, 2005). Um exemplo para a representação de grafos é apresentado na Figura 4.1(a), onde os vértices são representados por pontos, ou círculos, e as arestas representadas por linhas conectando vértices. Os grafos podem ser utilizados, por exemplo, para a representar de cidades, sendo essas os vértices, e as estradas que conectam as cidades, representadas por arestas. Cada aresta também pode ter um valor associado $w$ (ou peso) e, nesse caso, é dito que é um grafo ponderado (ou com pesos). A representação computacional de grafos pode ser feita de duas maneiras: lista de adjacência ou matriz de adjacência (Cormen et al., 2001). Uma lista de adjacência $A d j$ consiste em um arranjo de $n$ listas, uma para cada vértice de $G$. Tomando o vértice $u$, sua lista de adjacência Adj $[u]$ contém (um ponteiro) todos os vértices $v$ tais que existe uma aresta $(u, v) \in E$. Para representar um grafo não ponderado

\footnotetext{
${ }^{1}$ Nesse trabalho, os termos "grafo" e "rede" possuem o mesmo significado.
} 
usando matriz de adjacência, considera-se que todos os vértices são numerados de 1 a $n$, e a matriz $A(n \times n)$ é preenchida de tal forma que o elemento $a_{i j}=1$ se existe uma aresta entre os vértices $v_{i}$ e $v_{j}$, ou 0 caso contrário. Se o grafo for ponderado, então $a_{i j}=w_{i j}$ se existe uma aresta entre $v_{i}$ e $v_{j}$.

Com relação as arestas, um grafo pode ser dirigido (ou dígrafo) ou não. Em grafos dirigidos, as arestas possuem uma orientação, $\operatorname{logo},(i, j)$ é uma aresta (arco) que parte do vértice $v_{i}$ até o vértice $v_{j}$. Dessa forma, as arestas $(i, j)$ e $(j, i)$ são consideradas diferentes. A representação de grafos dirigidos pode ser visualizada na Figura 4.1(b) onde os arcos são representados por setas. Em grafos não dirigidos, a ordem não é importante, ou seja, as arestas $(i, j)$ e $(j, i)$ são iguais. É dito que a aresta $(i, j)$ incide nos vértices $v_{i}$ e $v_{j}$, chamados de adjacentes ou vizinhos. A vizinhança $N_{i}$ do vértice $v_{i}$ é definida como o conjunto de vértices vizinhos a $v_{i}$. O grau $k_{i}$ de um vértice $v_{i}$ em um grafo não-direcionado é a quantidade de arestas que incidem no vértice. Em um grafo direcionado, o grau de um vértice é a soma das arestas que chegam e saem do vértice. Um exemplo de grafo não-direcionado com os graus dos vértices poder ser observado na Figura 4.1(g). Um laço (ou loop), é uma aresta que começa e termina no mesmo vértice. Quando existe mais de uma aresta entre dois pares de vértices, essas são ditas arestas múltiplas (paralelas). Um multigrafo pode possuir arestas múltiplas e laços. Já um grafo simples, é um grafo não direcionado que não possui arestas múltiplas nem laços. Esse trabalho irá focar em grafos simples, portanto o termo "grafo" será utilizado para se referir a um grafo simples.

Um passeio de um vértice $v_{i}$ até um vértice $v_{j}$ é uma sequência de vértices adjacentes que começa com $v_{i}$ e termina em $v_{j}$. Em um grafo não ponderado, o tamanho (comprimento) do passeio é o número de arestas da sequência. Em um grafo ponderado, o comprimento do passeio é a soma de todos os pesos da sequência. Um ciclo (ou circuito) é um passeio formado por três ou mais vértices que começa e termina no mesmo vértice sendo, cada aresta, utilizada apenas uma vez. Um caminho é um passeio onde cada vértice é visitado apenas uma vez e, quando esse caminho tem comprimento mínimo (distâncias geodésica), ele é chamado caminho mínimo (ou geodésico). Considerando uma matriz $D(n \times n)$ onde o elemento $d_{i, j}$ é a distância geodésica entre os vértices $v_{i}$ e $v_{j}$ de um grafo $G$, o maior valor da matriz $D$ é chamado de diâmetro do gráfo ${ }^{2}$, ou seja, a maior distância geodésica entre todos pares de vértices do grafo $G$. Se não existe um caminho entre um par de vértices $v_{i}$ e $v_{j}$ então, se diz que eles não são alcançáveis uns aos outros e, dessa forma, um conjunto de vértices que estão sob a relação "é alcançável por" é chamado de componente do grafo. A Figura 4.1(h) exibe um grafo com dois componentes diferenciados por cores, sendo que os vértices $\{1,2,3,4\}$ são alcançáveis por qualquer vértice de $\{1,2,3,4\}$. Grafo conexo (ou conectado) é um grafo onde todos os pares de vértices são conectados por um caminho. Caso essa propriedade não seja verdadeira, então diz-se que o grafo é desconexo. Um exemplo de grafo desconexo pode ser observado na Figura 4.1(h). Subgrafo é um conjunto de vértices e arestas $G^{\prime}=\left(V^{\prime}, E^{\prime}\right)$ de um grafo $G=(V, E)$

\footnotetext{
${ }^{2} \mathrm{O}$ algoritmo de Floyd-Warshall pode ser utilizado para o cálculo da matriz $D$. Esse algoritmo é descrito no Apêndice A
} 
tal que $V^{\prime} \subseteq V$ e $E^{\prime} \subseteq E$. Um passeio aleatório, ou caminhada aleatória em grafo conectado é um passeio onde o elemento seguinte da sequência, a partir de um vértice $v_{i}$, é escolhido aleatoriamente com probabilidades $\frac{1}{k_{i}}$.

Defini-se como coeficiente local $C_{i}$ de um vértice $v_{i}$ como sendo o número de triângulos $\lambda_{i}$ formados entre $v_{i}$ e dois vizinhos dividido pelo número máximo de conexões que $v_{i}$ poderia fazer, definido pela Equação (4.1). O coeficiente de clusterização $C$ da rede é definido como a média entre coeficientes locais de todos os vértices da rede, expresso pela Equação (4.2).

$$
\begin{gathered}
C_{i}=\frac{\lambda_{i}}{k_{i}\left(k_{i}-1\right)} \\
C=\frac{1}{n} \sum_{i=1}^{n} C_{i}
\end{gathered}
$$

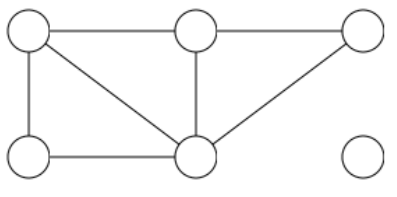

(a)

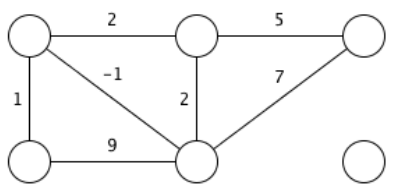

(c)

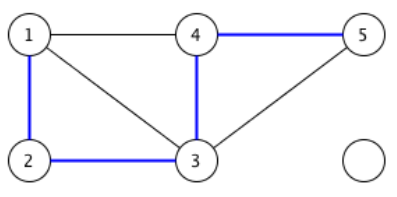

(e)

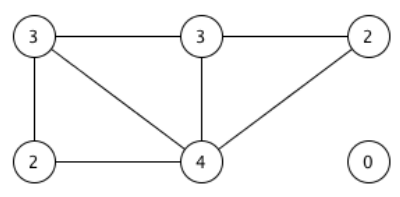

(g)

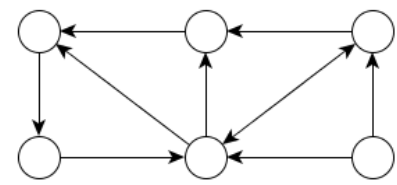

(b)

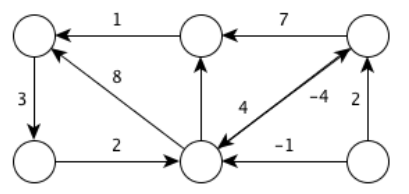

(d)

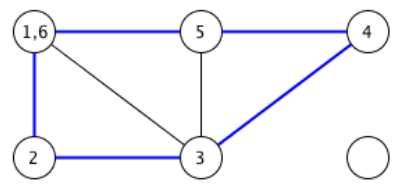

(f)

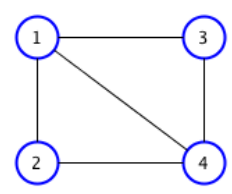

5

(h)

Figura 4.1: (a) Um grafo não-direcionado. (b) Um grafo direcionado. (c) Grafo não direcionado com pesos. (d) Grafo direcionado com pesos. (e) Caminho em um grafo partindo do vértice 1 até 5. (f) Circuito em um grafo partindo do vértice 1 retornando ao mesmo vértice. (g) Grafo com os graus de cada vértices. (h) Grafo desconexo com dois componentes representados pelas cores azul e vermelho.

Acredita-se que a solução do famoso problema das sete pontes de Königsberg, proposto por Leonard Euler em 1735, seja a primeira publicação na área de Teoria dos Grafos. Desde então, 
a área da Teoria dos Grafos vem sendo estuda. Entretanto, a maior parte desses estudos leva em consideração redes de dezenas ou no máximo centenas de vértices. Porém é fácil encontrar redes reais com milhares ou milhões de vértices. Para essas redes é possível evidenciar que as soluções para questões envolvendo redes pequenas não são aplicáveis. Com o intuito de tentar entender as características e propriedades desses grafos de grande escala, surge o conceito de Redes Complexas.

\subsection{Redes Complexas}

As redes complexas são grafos com grande número de vértices onde os padrões de conexões não são triviais (Newman, 2003). Podem ser observadas em redes sociais (Scott, 2000), sendo as pessoas representadas pelos nós e as arestas representam o fato dessas pessoas se conhecerem. Podem também ser utilizadas para representar a internet sendo as páginas representadas por vértices e os hyperlinks por arestas (Huberman, 2001). Podem representar linhas de transmissão de energia (Amaral et al., 2000), bem como o cérebro humano (Sporns, 2002). Na Figura 4.2 pode ser observado um exemplo de rede complexa.

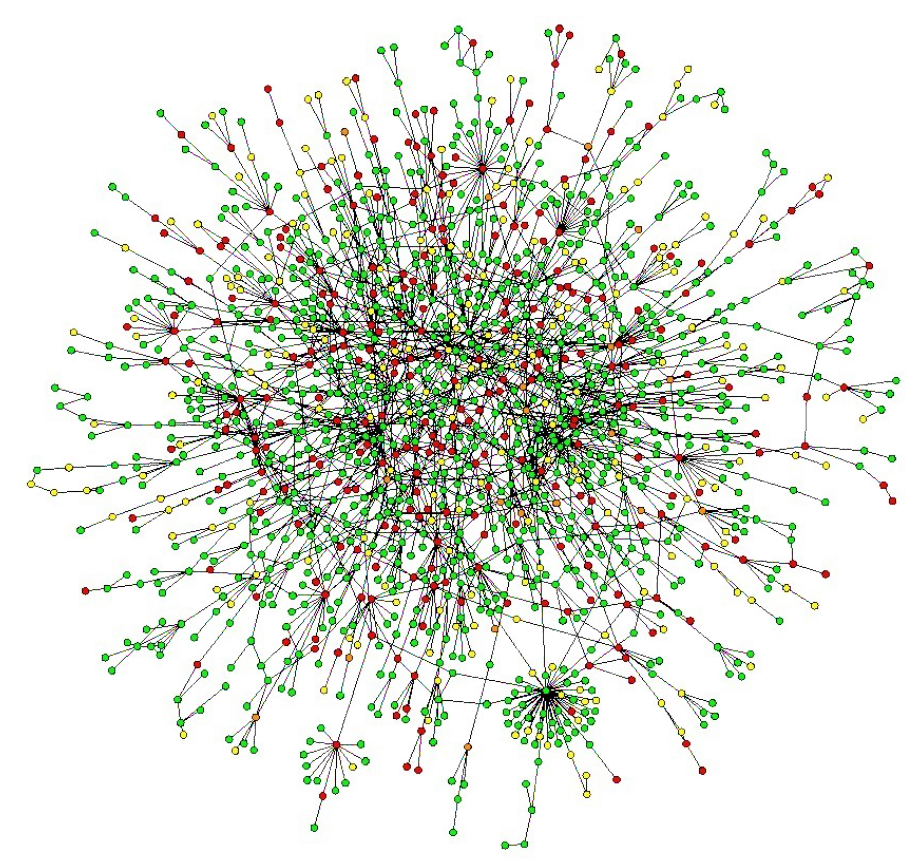

Figura 4.2: Interação entre proteínas de leveduras. Nós vermelhos representam proteínas essenciais e se removidas causam a morte da célula. Nós alaranjados representam proteínas com alguma importância e que, se removidas, retardaram o crescimento da célula. Nós verdes e representam proteínas com pouco significância e nós amarelos representam proteínas com significância desconhecida (Barabási \& Oltvai, 2004)

Desde o surgimento do interesse pela área, vários modelos de redes foram criados e estudados. A seguir serão apresentados os modelos mais conhecidos. 


\subsubsection{Rede Aleatória}

Proposta por Erdös \& Rényi (1959), a rede aleatória é um dos modelos de redes mais antigos e consiste em gerar arestas de forma aleatória. A construção de uma rede aleatória com $n$ vértices é feita considerando um valor $p \in[0,1]$ que representa a probabilidade de conexão entre dois vértices distintos. A cada iteração são selecionados dois vértices $v_{i}$ e $v_{j}$ que não possuem conexões e é gerado um valor aleatório $q$, sendo que se $q \geq p$ então uma conexão é estabelecida, caso contrário não é criada uma aresta entre $v_{i} \mathrm{e} v_{j}$. Esse procedimento é repetido até que seja atingido um valor $\bar{G}$ que é a média dos graus dos vértices da rede. Esse tipo de rede foi muito estudado, porém sabe-se que redes reais não são formadas aleatoriamente. Portanto, esse tipo de rede é mais utilizado como rede artificial.

\subsubsection{Rede Pequeno Mundo}

Em 1929, o escritor húngaro Frigyes Karinthy escreveu a estória Chains-Links dando a ideia de que todas as pessoas do mundo estão conectadas por poucas pessoas, ou seja, uma pessoa conhece outra pessoa, que conhece outra e assim sucessivamente faz com que todos estejam conectados (Karinthy, 1929). Esse fenômeno ficou conhecido como pequeno mundo. Essa hipótese foi testada por Milgram (1967) que verificou que são necessárias em média seis pessoas para que cartas chegassem aos seus destinatários passando de mão em mão. Esse fato ficou conhecido como a teoria dos seis graus de separação tendo sido estudado a fundo por de Sola Pool \& Kochen (1978).

Watts \& Strogatz (1998) propuseram um modelo de rede que apresentasse o fenômeno de pequeno mundo. Esse modelo demonstrou que, a partir de um grafo regular ${ }^{3}$, é necessário adicionar somente poucas arestas, conectando vértices distantes para que o fenômeno de pequeno mundo fosse observado. Assim, para gerar essa rede partindo de uma rede regular, escolhe-se um vértice e realiza a reconexão dessa aresta, segundo uma probabilidade $p$, com um outro vértice também escolhido aleatoriamente com restrição de não conectar vértices já conectados. Esse procedimento é repetido para todos os pares de vértices. O processo para quando todas as arestas da rede inicial tenham sido consideradas. A Figura 4.3 exemplifica esse processo, sendo possível notar que ,caso o valor de $p$ seja muito alto, então a rede gerada será aleatória.

Analisando o crescimento da probabilidade $p$ de reconexão durante a geração das redes, é possível notar a variação do caminho médio $L(p)$ e do coeficiente de clusterização $C(p)$. A Figura 4.4 exibe um gráfico com a variação de $L$ e $C$ em função de $p$ durante o processo de reconexão das arestas, descrito na Figura 4.3. Assim, Watts \& Strogatz (1998) descrevem que para valores pequenos de $p$, é possível obter uma rede pequeno mundo que seja altamente clusterizada (alto $C$ ) mas que apresenta a propriedade de pequeno mundo (baixo $L$ ), como em uma rede aleatória.

\footnotetext{
${ }^{3}$ Rede a qual todos os nós possuem o mesmo grau.
} 


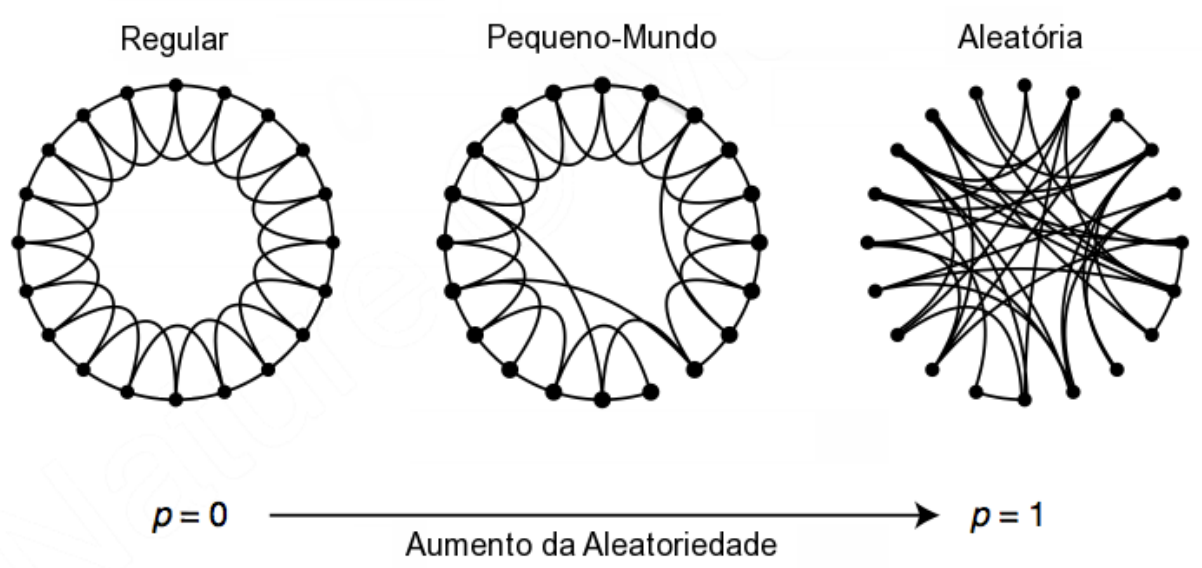

Figura 4.3: Processo de transformação de uma rede regular em uma rede aleatória sem aumentar vértices ou arestas. A rede regular inicial possuí 20 vértices, cada um deles conectado ao seus 4 vértices mais próximos. O processo de geração da rede foi repetido três vezes para diferentes valores de $p$, sendo que a rede pequeno mundo é gerada para valores pequenos de $p$. Extraído e adaptado de (Watts \& Strogatz, 1998).

\subsubsection{Rede Livre de Escala}

Em 1965, o físico de Solla (1965) analisou a rede de citações entre artigos científicos e descobriu que o número de citações que cada artigo recebia seguia a lei da potência. Em outras palavras, a rede possuía muitos nós de baixo grau e poucos nós de alto grau, também chamados de hubs. Essa lei define que a probabilidade de um nó ter $k$ arestas, ou seja, grau $k$, seja equivalente à $k^{-\lambda}$ (Eq. 4.3), onde $\lambda$ é uma constante.

$$
p(k) \sim k^{-\lambda}
$$

Em 1999, Albert et al. (1999) mapearam uma porção da World Wide Web por meio de uma rede e descobriram que muitos hyperlinks apontavam para apenas algumas páginas web evidenciando novamente a lei da potência em redes. Esse modelo de rede ficou conhecido como rede livre de escala (Barabasi \& Albert, 1999) e pode ser observado no exemplo da Figura 4.5.

\subsection{Detecção de Comunidades}

Na Seção 4.2 foram apresentados alguns estudos de modelos de redes e foi possível observar que grande parte deles não possui estrutura randômica, existindo propriedades que definem a topologia dessas redes. Uma propriedade observada em redes reais é o fato de existirem muitas arestas entre vértices de um subgrupo da rede e poucas arestas entre vértices de subgrupos diferentes. Esses grupos de vértices, também chamados de comunidades (Girvan \& Newman, 2002), estão exemplificados na Figura 4.6. Um exemplo real é a World Wide Web onde exitem muitos hyperlinks (conexões) entre as páginas de temas relacionados e poucos hyperlinks para páginas com assuntos diferentes. 


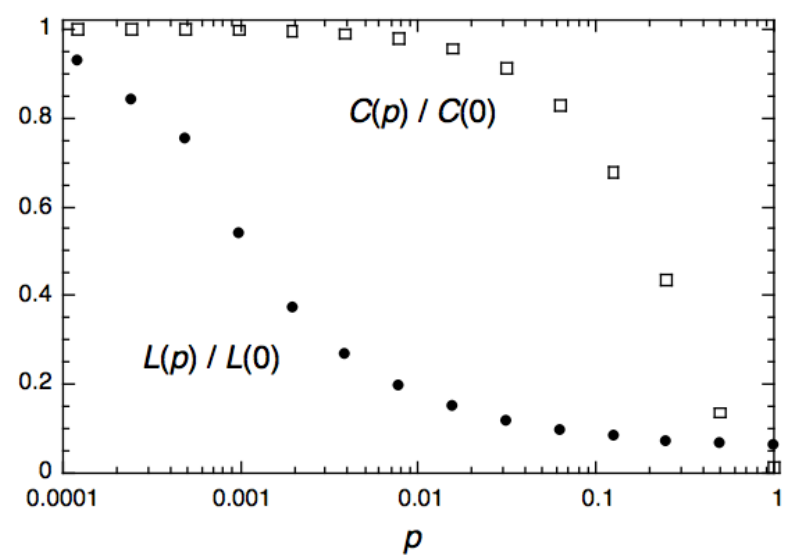

Figura 4.4: Variação do caminho médio $L(p)$ e do coeficiente de clusterização $C(p)$ em função da probabilidade $p$ de reconexão de arestas. Esse gráfico foi gerado com a média dos valores obtidos após repetir 20 vezes o processo descrito na Figura 4.3 normalizados com valores de $L(0)$ e $C(0)$ para a rede regular inicial. A rede utilizada possuía $n=1000$ vértices com grau médio $k=10$. O efeito de pequeno mundo pode ser observado para valores pequenos de $p$ onde $L$ é pequeno e $C$ é grande (Watts \& Strogatz, 1998).

O estudo referente às estruturas de comunidades em redes complexas é interessante para vários campos da ciência pois seu entendimento pode revelar informações relevantes do problema tratado. Por exemplo, na Figura 4.7 é exibida a rede de amizade em uma escola dos Estados Unidos podendo ser observada a presença de comunidades bem definidas (Moody, 2002). Nesse exemplo, as comunidades revelam a segregação racial presente na escola.

$\mathrm{Na}$ tentativa de extrair informações de redes, surgem algoritmos de detecção de comunidades em redes. Esse algoritmos podem ser classificados como aglomerativos ou divisivos. Essas abordagens são equivalentes às abordagens de agrupamento hierárquico, apresentadas na Subseção 2.4.1. Nos algoritmos aglomerativos a detecção de comunidades é realizada considerando que, inicialmente cada vértice é uma comunidade e, a cada iteração, são adicionadas arestas ao grafo juntando (fundindo) pares de comunidades. Os algoritmos divisivos realizam a detecção de forma inversa aos algoritmos aglomerativos. Nesse caso, o algoritmo inicia o processamento considerando que toda a rede forma uma comunidade só e retira, a cada iteração, arestas que ligam pares de vértices. A Figura 4.8 exemplifica as duas classificações de algoritmos. A seguir, alguns dos algoritmos mais utilizados serão apresentados.

\subsubsection{Método Baseado em Betweenness}

Um dos algoritmos mais simples de detecção de comunidade usa o cálculo do betweenness das arestas da rede. Esse algoritmo é classificado como divisivo porém não retira a aresta com menor similaridade, mas sim a que possui maior betweenness. O cálculo do betweenness pode ser realizado de diferentes formas, mas todas baseiam-se na ideia que, se comunidades são conectadas por um conjunto pequeno de arestas, então todos os caminhos de um vértice de uma comunidade para outra comunidade certamente passaram por algumas das arestas do conjunto 


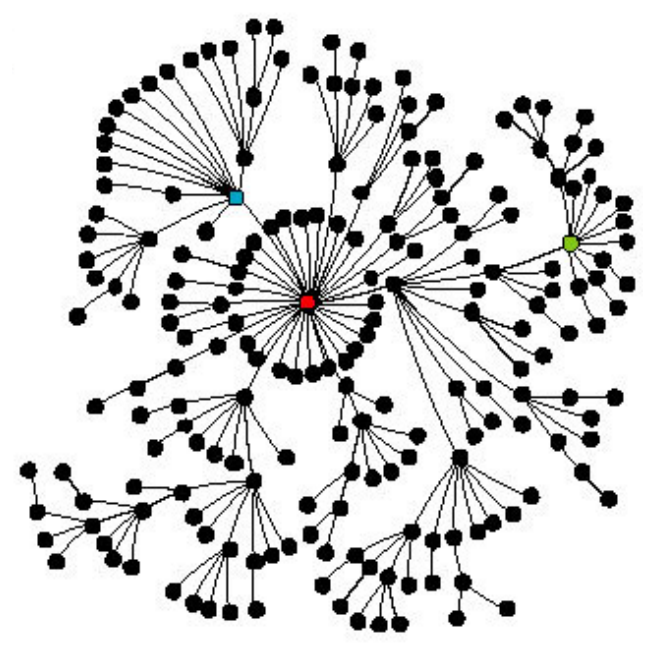

Figura 4.5: Rede livre de escala seguindo regra da potência. A rede possui 200 vértices e 199 arestas onde os vértices coloridos tem maior numero de arestas (hubs) (Strogatz, 2001).

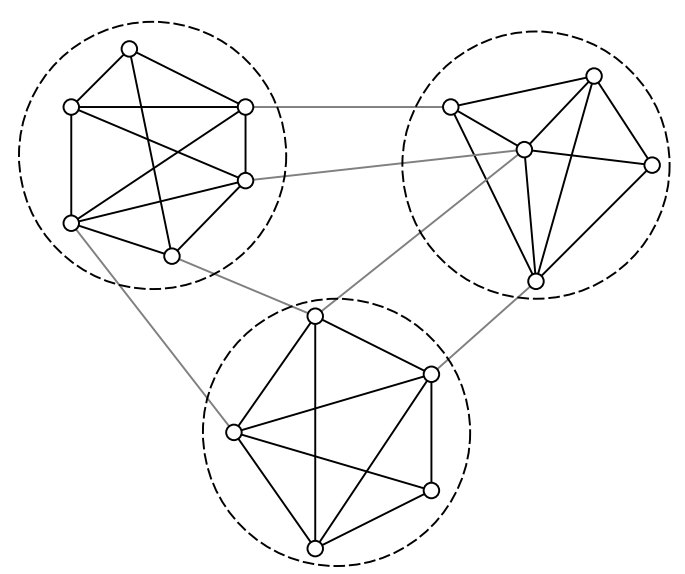

Figura 4.6: Rede com três comunidades circundadas com linhas pontilhadas.

(Newman \& Girvan, 2003). Simplificadamente o Algoritmo 8 explica o processo de detecção de comunidades a partir do cálculo do betweenness.

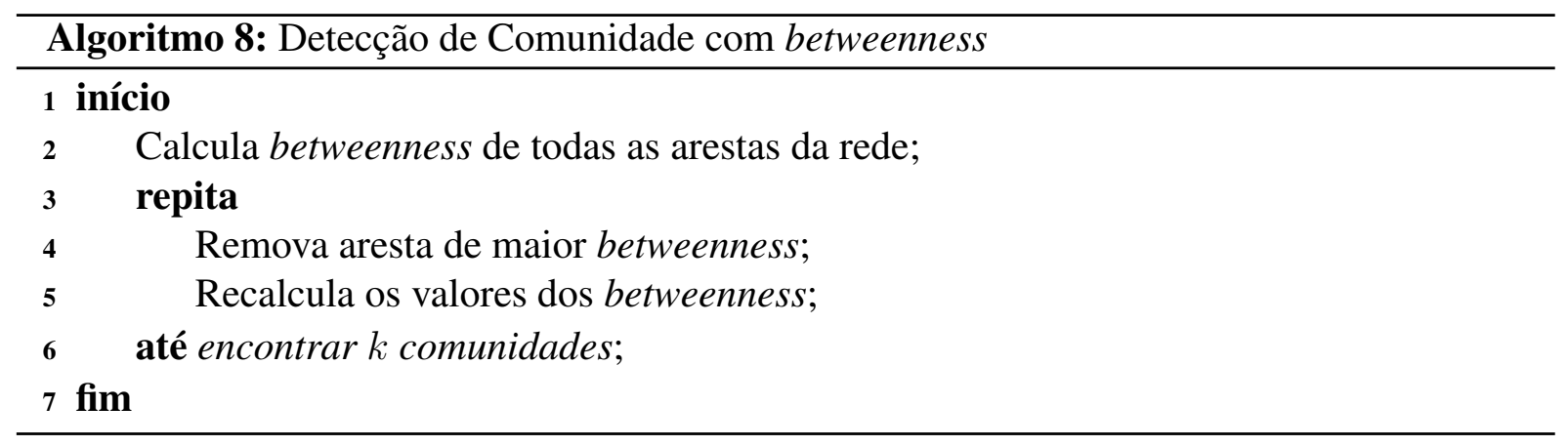




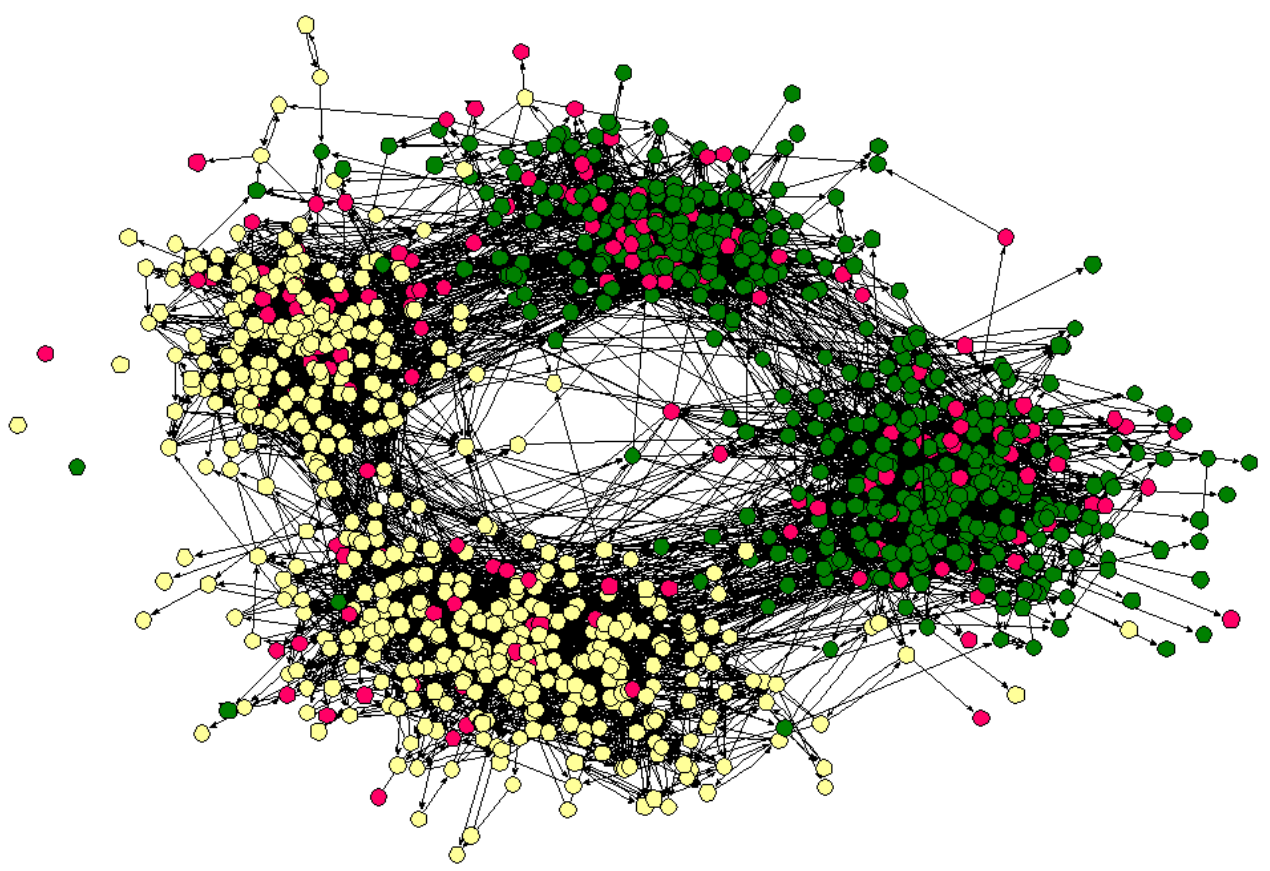

Figura 4.7: Rede de amizade de crianças em escola dos Estados Unidos. Cada vértice representa uma criança e a sua etnia é representada pela cor do vértice. Nós verde representam a etnia afro-descendente, nós bege representam crianças brancas e nós rosa representam outras etnias. As duas comunidades mais acima representam as crianças do ensino médio e as outras duas inferiores representam as crianças do ensino fundamental (Moody, 2002).

\section{Shortest-path Betweenness}

Uma forma de calcular o betweenness é encontrar o caminho geodésico, i.e., menor caminho (shortest-path) entre todos os pares de vértices da rede e, para cada um desses caminhos, contabilizar o número de vezes que cada aresta é utilizada. A aresta que for mais utilizada é a que possui maior betweenness e deve, pois, ser retirada.

\section{Random-walk Betweenness}

É possível obter o betweenness calculando o número médio de vezes que uma aresta é utilizada a partir de caminhadas aleatória (random walk) partindo de um vértice $v_{i}$ até um vértice $v_{j}$.

\section{Current-flow Betweenness}

A terceira maneira de calcular o betweenness é motivada pela teoria de circuitos elétricos onde a rede é transformada em circuito. As arestas da rede são representadas por resistores enquanto que os vértices são as unidades de corrente fonte e destino. Assim, é possível obter o betweenness utilizando as leis de Kirchhoff. 

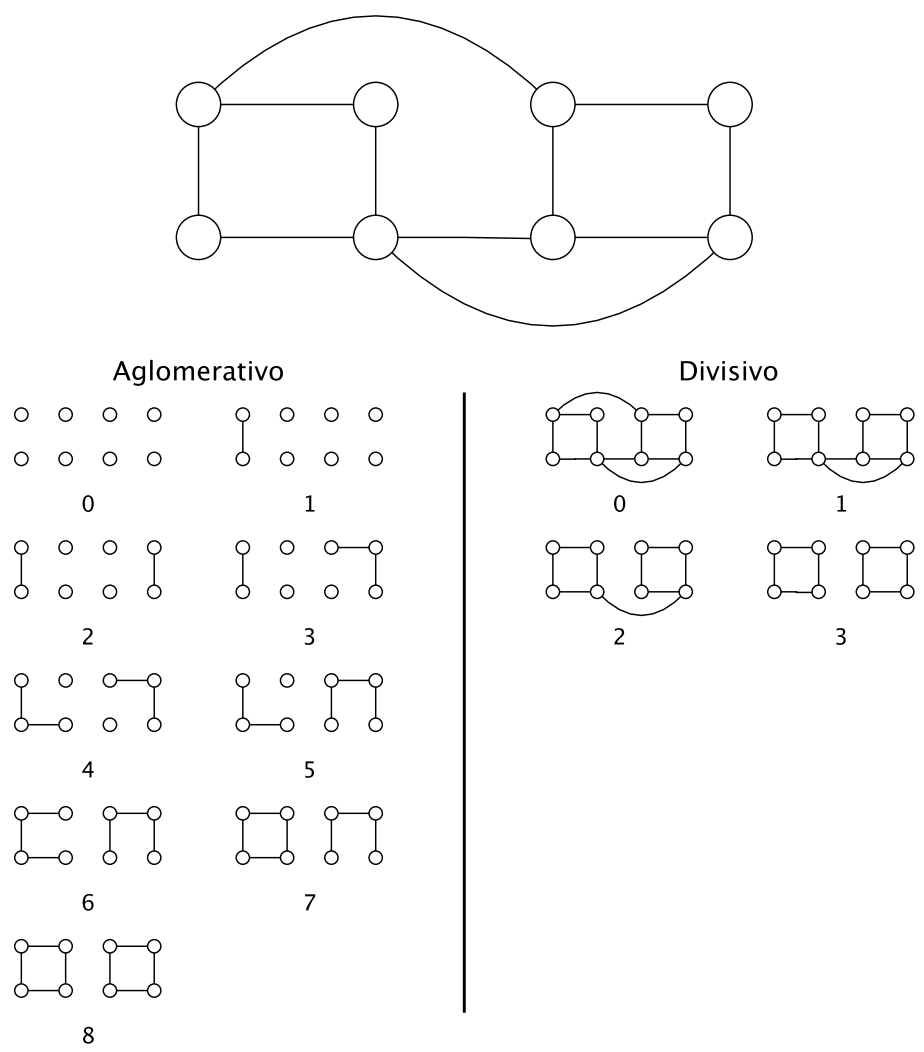

Figura 4.8: Exemplo de iterações em algoritmos de deteç̧ão de comuinidades aglomerativos e divisivos

\subsubsection{Método Baseado em Caminhada Aleatória}

Essa técnica de detecção de comunidades proposta por Zhou (2003) utiliza o conceito de caminhada aleatória de uma partícula browniana para medir as distâncias entre os vértices e detectar comunidades.

Considerando uma rede com $n$ vértices, temos o conjunto de vértices $V=\{1, \ldots, n\}$ e as arestas representadas por uma matriz de adjacência $A$ onde o elemento $a_{i j} \equiv a_{j i}$ representa a força de interação entre esses vértices. Caso não exista aresta entre esses vértices, então esse valor é igual a zero. A cada iteração, a partícula Browniana se movimenta através da rede partindo de um vértice $v_{i}$ indo para um vértice $j \in N(i)$. A escolha do vértice seguinte é feita aleatoriamente segundo uma probabilidade armazenada em uma matriz de transferência $P(n \times n)$ onde o elemento $p_{i j}=a_{i j} / \sum_{l=1}^{n} a_{i l}$ da partícula sair de $v_{i}$ e ir para $v_{j}$.

A distância $d_{i j}$ é calculada a partir da média do número de passos necessários para que a partícula Browniana mova-se do vértice $v_{i}$ até $v_{j}$, podendo ser calculada pela Equação (4.4):

$$
d_{i j}=\sum_{l=1}^{n}\left(\frac{1}{I-B(j)}\right)_{i l}
$$

onde $I$ é a matriz identidade de tamanho $n \times n$ e $B(j)$ é semelhante a matriz $P$ porém com coluna $j$ igual a zero. Assim, a distância do vértice $v_{i}$ para qualquer vértice $v_{j}$ pode ser obtida 
por meio da solução do sistema linear descrito pela Equação (4.5):

$$
[I-B(j)]\left[d_{1, j}, d_{2, j}, \ldots, d_{N, j}\right]^{T}=[1,1, \ldots, 1]^{T}
$$

Considerando as distâncias entre os vértices da rede, é possível definir o conceito de atratores globais e locais. É dito que um vértice $v_{j}$ é atrator global de um vértice $v_{i}$ se $v_{j}$ tem a menor distância média até $v_{i}$ considerando todos os vértices, propriedade essa descrita da seguinte forma: $d_{i, j} \leqslant d_{i, k}$ para todo $k \in V$. De forma análoga, é dito que um vértice $v_{j}$ é atrator local de um vértice $v_{i}$ se $v_{j}$ é o vértice mais próximo de $v_{i}$ dentre os vizinhos mais próximos de $v_{i}$, onde essa propriedade é descrita por: $j \in E_{i}$ e $d_{i, j} \leqslant d_{i, l} \forall l \in E_{i}$.

Considerando que uma rede apresenta estrutura de comunidades, então é intuitivo pensar que um vértice $v_{i}$ tem maior probabilidade de pertencer a mesma comunidade do seu atrator local $j$, logo que ele é o mais próximo de $v_{i}$. Dessa forma, é possível agrupar os vértices da rede em comunidades baseadas em atratores locais chamadas de comunidades- $L$, definas como conjuntos de vértices $L=\left\{i_{1}, i_{2}, \ldots, i_{m}\right\}$ agrupados da seguinte forma:

1. se $v_{i} \in L$ e $v_{j}$ é o atrator local de $v_{i}$, então $v_{j} \in L$.

2. se $v_{i} \in L$ e $v_{i}$ é o atrator local de $v_{k}$, então $v_{k} \in L$.

3. qualquer subconjunto de $L$ não é uma comunidade- $L$.

Semelhante ao conceito de atrator local, o atrator global também pode ser utilizado para identificar comunidades. Da mesma forma, é esperado que os vértices pertençam a mesma comunidade que seus atratores globais, sendo possível detectar comunidades agrupando os vértices segundo seus atratores globais, chamadas de comunidades-G. Em redes pequenas, é esperado que as comunidades globais sejam as mesma comunidades locais, porém isso não é esperado para redes maiores, mas sim, que cada comunidade-G contenha comunidades-L como subgrupo.

\subsubsection{Método Baseado em Sincronização}

Um modelo de detecção de comunidades proposto por Quiles et al. (2009) representa os vértices da rede por meio de neurônios artificiais que se sincronizam em grupos indicando as comunidades da rede. Os neurônios são interligados por meio de conexões excitatórias e inibitórias sendo que as conexões excitatórias tem função de sincronizar neurônios da mesma comunidade enquanto que as conexões inibitórias fazem a separação entre comunidades. Nesse modelo é utilizado um neurônio do tipo integra e dispara (IeD) (Izhikevich, 2004) que pode ser representado pela Equação (4.6):

$$
\frac{d v_{i}}{d t}=-v_{i}+I_{i}(t)+E_{i}(t)-Y_{i}(t)
$$


onde $v_{i}$ representa o potencial do neurônio, $I_{i}(t)$ representa a estimulação externa, $E_{i}(t)$ define o termo de acoplamento excitatório e $Y_{i}(t)$ o termo de acoplamento inibitório entre neurônios. O neurônio dispara sempre que seu potencial $v_{i}$ for maior que um limiar $\theta$.

O termo do acoplamento excitatório $E_{i}(t)$ é definido pela Equação (4.7):

$$
E_{i}(t)=\sum_{j \in \Delta_{i}} \omega_{i j} \delta\left(t-t_{j}\right)
$$

onde $\delta$ é a função delta de Dirac, $t_{j}$ e o instante em que o neurônio $j$ dispara, $\Delta_{i}$ determina a vizinhança que ira cooperar com a excitação do neurônio $i$, levando em consideração as conexões entre neurônios da rede. O termo $\omega_{i j}$ define a força de acoplamento excitatório entre os neurônios $i$ e $j$ podendo ser obtido por meio da Equação (4.8) onde $c_{E}$ é uma constante no intervalo $[0,1]$ e $k_{i}$ é o grau do vértice $v_{i}$.

$$
\omega_{i j}=\frac{c_{E}}{k_{i}}
$$

O termo de acoplamento inibitório é obtido por meio da Equação (4.9), onde $c_{Y}$ é uma constante no intervalo $[0,1]$.

$$
Y_{i}(t)=\frac{c_{Y}}{N} \sum_{j=1 ; j \neq i}^{N} \delta\left(t-t_{j}\right)
$$

O método de detecção de comunidades ocorre por meio das conexões excitatórias e inibitórias. As conexões excitatórias (Eq. (4.7)) sincronizam as atividades de disparos dos neurônios pertencentes a mesma comunidade enquanto que as conexões inibitórias (Eq. (4.9)) realizam a dessincronização de comunidades distintas. Duas vantagens podem ser observadas nesse modelo. Uma vantagem é a simplicidade do algoritmo e a outra é a velocidade de sincronização das comunidades apresentando assim uma eficiência computacional.

Experimentos computacionais foram realizados para verificar a eficiência do modelo. Para esse experimento foi utilizado uma rede aleatória com 128 neurônios e quatro comunidades, ilustrada na Figura 4.9(a). O processo de sincronização dos disparos da rede pode ser observado na Figura 4.9(b), sendo que no início, os disparos estão totalmente dessincronizados, mas com o passar do tempo é possível observar a sincronização dos neurônios das mesmas comunidades.

\subsubsection{Método Baseado em Competição de Partículas}

Uma técnica de detecção de comunidades foi proposta por Quiles et al. (2008) e baseia-se na competição de partículas. Essas partículas são inseridas em vértices da rede de forma aleatória e tem como objetivo percorrer os vértices da rede e marcá-los evitando perder vértices para outras partículas. Após certo tempo de competição, essas partículas conseguem marcar seus vértices e o sistema estabiliza, sendo assim possível detectar comunidades com base na partícula que ocupa os vértices. A dinâmica de funcionamento da competição é similar a processos naturais, 


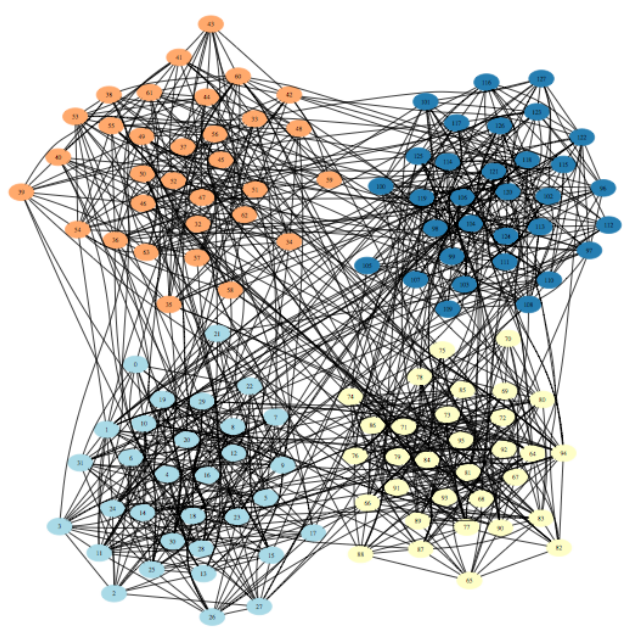

(a)

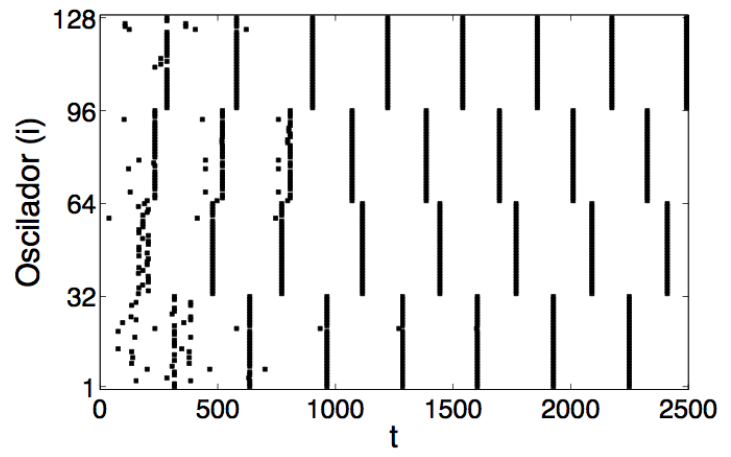

(b)

Figura 4.9: Simulação computacional do método de detecção de comunidades por sincronização utilizando 128 neurônios $(n=128), c_{Y}=c_{E}=0,1$. (a) Rede aleatória onde os vértices de mesma cor são da mesma comunidade. (b) Disparos dos neurônios ao longo do tempo (Quiles et al., 2009).

e.g., a competição por território entre os animais na natureza onde, de forma comparativa, os animais são vistos como as partículas e os territórios representados pelos vértices.

Cada partícula $\rho_{j}$ do sistema é expressa por duas variáveis: a primeira $\rho_{j}^{v}(t)$ que representa o vértice $v_{i}$ visitado pela partícula $\rho_{j}$ no instante $t$ e a segunda $\rho_{j}^{\omega}(t)$ que é o potencial de exploração da partícula no tempo $t$ podendo assumir valores no intervalo $\left[\omega_{\min }, \omega_{\max }\right]$, informados pelo usuário. A dinâmica entre as partículas é descrita a seguir por meio das Equações (4.10) e (4.11), onde $\Delta_{\rho}$ é um parâmetro que controla a intensidade da variação potencial de cada partícula sendo definido no intervalo $(0,1]$.

$$
\begin{gathered}
\rho_{j}^{v}(t+1)=v_{i} \\
\rho_{j}^{\omega}(t+1)= \begin{cases}\rho_{j}^{\omega}(t) & \text { se } v_{i}^{\rho}=0 \\
\rho_{j}^{\omega}(t)+\left(\omega_{\text {max }}-\rho_{j}^{\omega}(t)\right) \Delta_{\rho} & \text { se } v_{i}^{\rho}=\rho_{j} \neq 0 \\
\rho_{j}^{\omega}(t)-\left(\rho_{j}^{\omega}(t)-\omega_{\text {min }}\right) \Delta_{\rho} & \text { se } v_{i}^{\rho} \neq \rho_{j} \neq 0\end{cases}
\end{gathered}
$$

Cada vértice $v_{i}$ da rede é represento por meio de três variáveis: 1) $v_{i}^{\rho}(t)$ define a qual partícula o vértice $v_{i}$ pertence no instante $t$, podendo assumir o valor $\rho_{j}$ se esse vértice pertencer a partícula $\rho_{j}$ ou 0 caso ainda não pertença a alguma partícula. 2) $v_{i}^{\omega}(t)$ representa a intensidade que a partícula $\rho_{j}$ domina o vértice $v_{i}$, ou seja, valores mais altos indicam maior dominância de um vértice por uma partícula. Caso $v_{i}^{\omega}(t)=\omega_{\min }$ então o vértice ainda não está sobre domínio de uma partícula, podendo ser dominado pela primeira partícula que o encontrar. 3) $v_{i}^{\gamma}$ é um valor binário que define se o vértice esta (1) ou não (0) sendo visitado por alguma partícula no exato momento. Com base nas três variáveis, Quiles et al. (2008) descrevem a dinâmica dos vértices por meio das Equações (4.12) e (4.13) onde $\Delta_{v}$ é a taxa de potencial de mudança dos 
vértices.

$$
\begin{gathered}
v_{i}^{\rho}(t+1)= \begin{cases}v_{i}^{\rho}(t) & \text { se } v_{i}^{\gamma}=0 \\
\rho_{j} & \text { se } v_{i}^{\gamma}=1 \text { e } v_{i}^{\omega}(t)=\omega_{\text {min }}\end{cases} \\
v_{i}^{\omega}(t+1)= \begin{cases}v_{i}^{\omega}(t) & \text { se } v_{i}^{\gamma}=0 \\
\max \left\{\omega_{\min }, v_{i}^{\omega}(t)-\Delta_{v}\right\} & \text { se } v_{i}^{\gamma}=1 \text { e } v_{i}^{\rho}(t) \neq \rho_{j} \\
\rho_{j}^{\omega}(t+1) & \text { se } v_{i}^{\gamma}=1 \text { e } v_{i}^{\rho}(t)=\rho_{j}\end{cases}
\end{gathered}
$$

$\mathrm{O}$ algoritmo de detecção de comunidades inicia inserindo $K$ partículas em $K$ vértices escolhidos aleatoriamente. No início, cada partícula $\rho_{j}$ e cada vértice $v_{i}$ possue potencial igual a $\rho_{j}^{\omega}(0)=\omega_{\min }$ e $v_{i}^{\omega}(t)=\omega_{\min }$ respectivamente, sendo que cada vértice se encontra no estado livre $v_{i}^{\rho}(0)=0$. A cada iteração, cada partícula escolhe um vértice para visitar, podendo encontrar as seguintes situações:

1. Se o vértice visitado $v_{i}$ ainda não pertence a uma partícula: $v_{i}^{\rho}(0)=0$, então o vértice passa a pertencer a essa partícula $v_{i}^{\rho}(t)=\rho_{j}$. O potencial da partícula $\rho_{j}$ não é alterado e o potencial do vértice $v_{i}$ recebe o potencial da partícula: $v_{i}^{\omega}(t)=\rho_{j}^{\omega}(t)$.

2. Se o vértice visitado já pertence a partícula, o potencial da partícula $\rho_{j}$ é aumentado e $v_{i}$ recebe novamente o potencial da partícula: $v_{i}^{\omega}(t)=\rho_{j}^{\omega}(t)$.

3. Caso o vértice visitado pertença a outra partícula, então o potencial da partícula e do vértice são diminuídos. Se o potencial da partícula $\rho_{j}^{\omega}$ atingir um valor menor que $\omega_{\min }$, então essa partícula é reiniciada em um novo vértice escolhido aleatoriamente. Caso o potencial do vértice $v_{j}^{\omega}$ atingir um valor menor que $\omega_{\text {min }}$, então o vértice deixa de pertencer à alguma partícula: $v_{j}^{\omega}=0$.

Dessa forma, a dominância de um vértice aumenta se uma mesma partícula visita frequentemente esse mesmo vértice. Caso contrário, a dominância do vértice diminui podendo até perde-lo para outra partícula. O sistema converge quando um equilíbrio é atingido. Nesse estado, a maioria dos vértices não sofrerá mudanças em relação ao seu domínio.

Quiles et al. (2008) exemplificam a técnica desenvolvida por meio de experimentos computacionais onde é aplicado o método em uma rede artificial com quatro comunidades. A Figura 4.10(a) exibe o estado inicial onde quatro partículas são posicionadas aleatoriamente demarcando assim seus vértices, sendo os vértices vermelhos ainda sem dominância. As Figuras 4.10(b) - 4.10(d) ilustram o processo de competição sendo possível observar nessa última a estabilização do sistema.

As principais vantagens dessa técnica são a alta precisão de detecção e baixa ordem de complexidade em tempo. Entretanto, a desvantagem dessa técnica é a necessidade de ajustar vários parâmetros. 


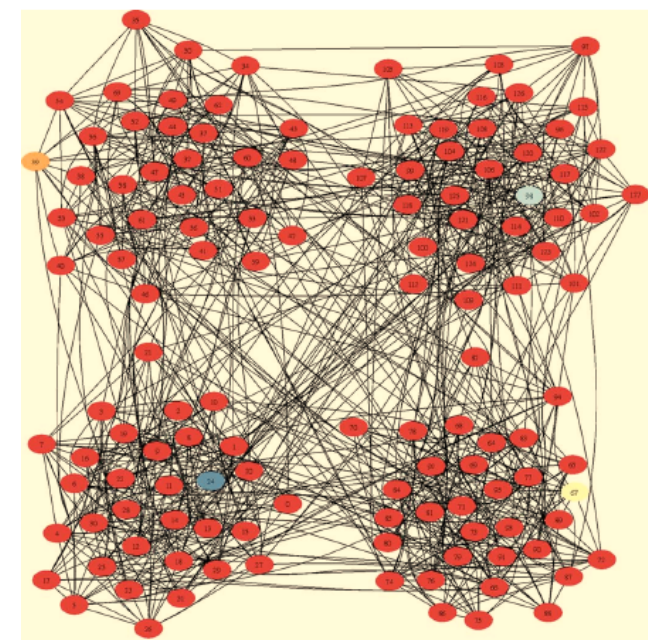

(a)

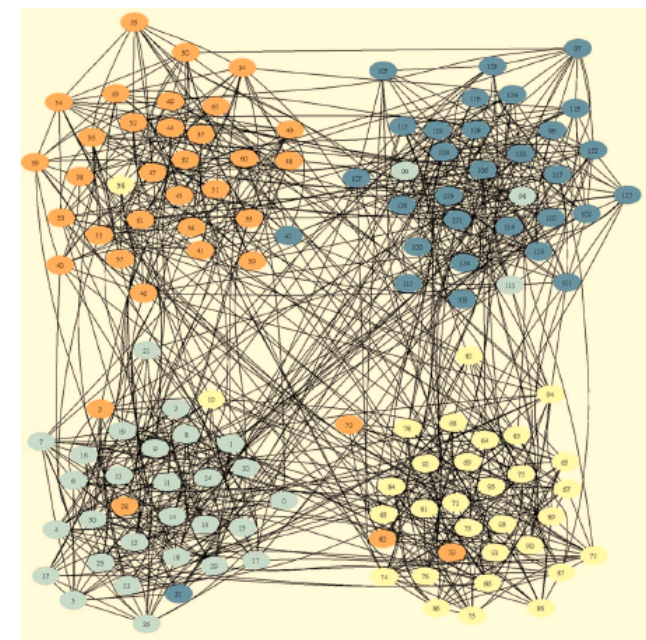

(c)

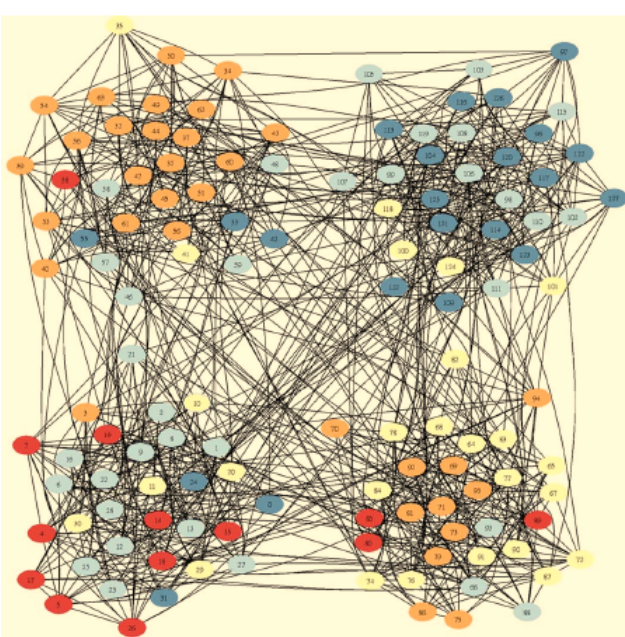

(b)

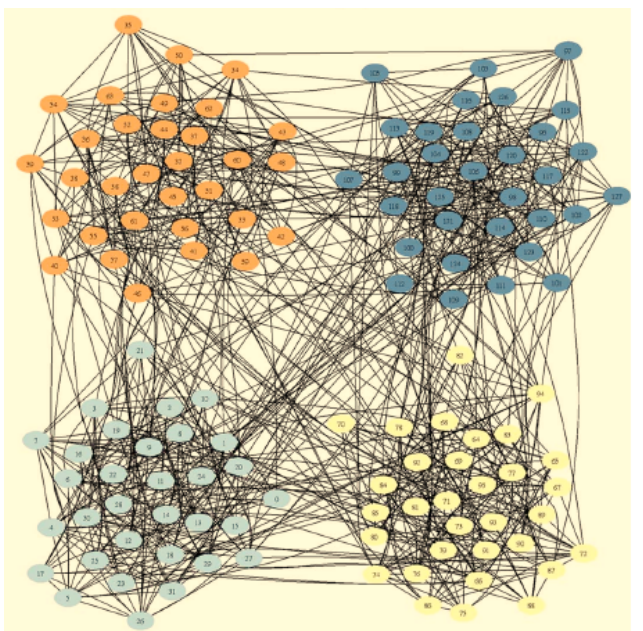

(d)

Figura 4.10: Deteç̧ão de comunidades utilizando técnica de competição de partículas. O número de vértices é $n=128$, apresenta 4 comunidades e a média dos graus dos vértices é $\langle k\rangle=16$. A Figura (a) exibe o estado inicial com quatro partículas posicionadas aleatoriamente sendo representadas pelas cores amarelo, laranjado, azul claro e azul escuro. A cor vermelho é utilizada para representar vértices que ainda não pertencem a uma partícula. (b) 250 iterações. (c) 3500 iterações. (d) 7000 iterações, demonstrando a estabilização do sistema (Quiles et al., 2008).

\subsubsection{Método Baseado em Movimentação de Vértices}

Um algoritmo divisivo para a detecção de comunidades foi proposto por de Oliveira et al. (2008). Essa técnica considera não só a topologia da rede mas também a posição geográfica que os nós se encontram. Para isso, o algoritmo realiza a movimentação dos vértices de tal forma que no fim do processo, os nós da mesma comunidades fiquem posicionados em regiões do espaço. Essa técnica está dividida em duas etapas: formação da rede e sua divisão iterativa. 


\section{Formação da Rede}

Para a modelagem dos dados e formação da rede, é considerado que cada elemento do conjunto de dados é representado como um vértice $v_{i}$ sendo que a conexão entre vértices é estabelecida utilizando a abordagem KNN (descrito em 2.4.5). Assim, é utilizado a distância euclidiana (Eq. (4.14)) para encontrar os $K$ vértices mais próximo a serem conectados. Caso seja utilizado um valor alto para $K$, a rede pode apresentar muitas conexões entre comunidades distintas dificultando a detecção e, no caso contrário, pode apresentar poucas conexões tornando incoerente a quebra da rede em comunidades.

$$
d_{i j}=\left\|v_{j}-v_{i}\right\|
$$

\section{Divisão da Rede}

A divisão da rede é realizada com base na movimentação dos vértices sendo que o algoritmo converge quando os vértices da mesma comunidade estiverem posicionado em um intervalos de ângulos. Dessa forma, vértices da mesma comunidade serão aproximados enquanto vértices de comunidades distintas serão afastados. Cada vértice é inicializado com um ângulo $\theta_{i}(t=0)$ aleatório escolhido entre $[0,2 \pi)$ e é atualizado, a cada iteração $t$, com base nos seus vizinhos por meio da Equação (4.15):

$$
\theta_{i}(t+1)=\theta_{i}(t)+\eta_{i}(t)\left[\frac{\sum_{j=1}^{M_{i}} w_{i j} \theta_{j}(t)}{\sum_{j=1}^{M_{i}} w_{i j}}-\theta_{i}(t)\right]
$$

onde $M_{i}$ é o número de vizinhos do vértice $v_{i}, \eta_{i}$ é a taxa de movimentação do vértice $v_{i}$ na iteração $t$ e $w_{i j}$ é o peso que representa a influência do vértice $v_{i}$ sobre $v_{j}$. Esse peso $w_{i j}$ é composto por duas partes que podem ser observadas na Equação (4.16):

$$
w_{i j}=C N\left(v_{i}, v_{j}\right) \times S N\left(v_{i}, v_{j}\right)
$$

$C N\left(v_{i}, v_{j}\right)$ torna o vértice $v_{i}$ mais importante se esse esta próximo a $v_{j}$, ou seja, aproxima os ângulos de vizinhos próximos. Para isso, é utilizado a Equação (4.17), onde o parâmetro ajustável $\alpha$ é responsável por definir o tamanho da vizinhança de $v_{i}$. Caso a rede tratada não possua pesos, é possível utilizar $C N\left(v_{i}, v_{j}\right)=1$ para todos os pares de vértices $v_{i}$ e $v_{j}$.

$$
C N\left(v_{i}, v_{j}\right)=e^{-\alpha d_{i j}}
$$

Partindo do pressuposto que vértices pertencentes a mesma comunidade possuem muitas arestas entre eles, a função da parte $S N\left(v_{i}, v_{j}\right)$ é aproximar os vértices que pertençam a mesma comunidade. O cálculo de $S N\left(v_{i}, v_{j}\right)$ é realizado por meio da Equação (4.18), onde $c\left(v_{i}, v_{j}\right)$ é 
o número de vizinhos comuns compartilhados pelos vértices $v_{i}$ e $v_{j}$.

$$
S N\left(v_{i}, v_{j}\right)=\frac{c\left(v_{i}, v_{j}\right)}{M_{i}}
$$

A utilização apenas das partes $C N\left(v_{i}, v_{j}\right)$ e $S N\left(v_{i}, v_{j}\right)$ para atualização dos ângulos não elimina a influência entre diferentes grupos. Para solucionar esse problema, de Oliveira et al. introduzem o parâmetro $\eta_{i}(t)$ que é a taxa de atualização dos ângulos e pode ser calculado por meio da Equação (4.19) (de Oliveira et al., 2008), onde $\beta$ é definido pelo usuário e $\sigma_{i}$ é o desvio padrão dos vizinhos do vértice $v_{i}$. No início, os ângulos dos vértices são escolhidos de forma aleatória fazendo com que $\sigma_{i}$ apresente valor alto e $\eta_{i}(t)$ seja próximo de 1 . A cada iteração, os valores de $\sigma_{i}$ e $\eta_{i}(t)$ tendem a diminuir sendo que a estabilidade é atingida quando o valor $\eta_{i}(t)$ aproxima de zero, fazendo com que os ângulos não sejam mais atualizados.

$$
\eta_{i}(t)=e^{\frac{-\beta}{\sigma_{i}}}
$$

A partir de uma rede gerada artificialmente (Fig. 4.11) é possível observar a evolução na atualização dos ângulos na Figura 4.12 e notar a detecção de três clusters, cada um representado por uma cor diferente.

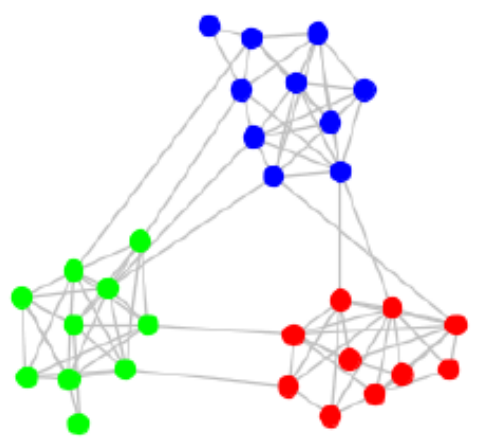

Figura 4.11: Rede artificial após a detecção de comunidades onde cada comunidade é representada por uma cor (de Oliveira et al., 2008).

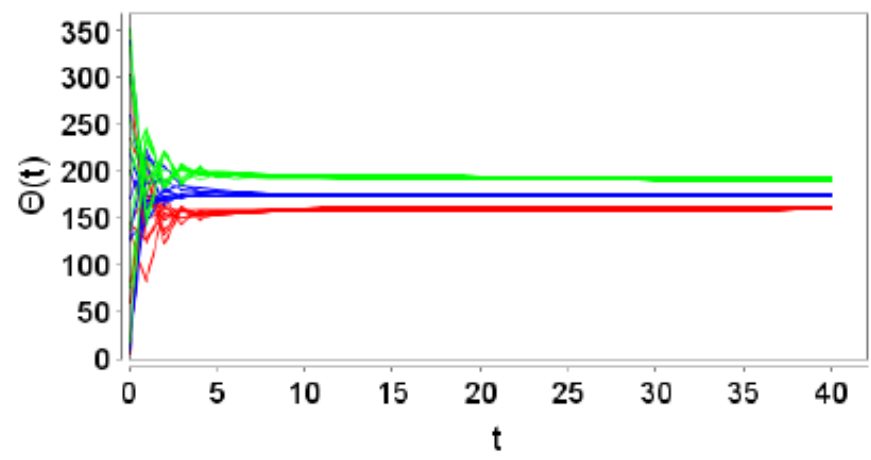

Figura 4.12: Atualização e convergência dos ângulos (de Oliveira et al., 2008). 


\section{Algoritmo de Detecção de Comunidades}

Com base na técnica de atualização dos ângulos, de Oliveira et al. (2008) propõem um algoritmo de detecção de comunidades que será descrito a seguir. Inicialmente toda a rede é considerada uma comunidade $C$ que é armazenada no conjunto de comunidades $C S e t$. Em cada iteração, é aplicada a equação de atualização dos ângulos (Eq. (4.15)) a todas as comunidades $C_{k} \in C$ Set que possuem mais de um vértice $\left(n_{C_{k}}>1\right)$. Em seguida, os ângulos dos vértices de $C_{k}$ são ordenados em ordem decrescente e, a esse conjunto de ângulos, dá-se o nome de $V O_{C_{k}}$. A próxima etapa consiste em identificar a maior diferença entre ângulos ( $\max D$ if $f_{c_{k}}$ ), que é o valor máximo de $V O_{C_{k}}[j]-V O_{C_{k}}[j+1], \forall j \in\left[1, \eta_{k}\right)$. A localização dos ângulos de $V O_{C_{k}}$ com maior diferença entre si $\left(i d_{C_{k}}\right)$ é obtido por: $\operatorname{argmax}\left(V O_{C_{k}}[j]-V O_{C_{k}}[j+1]\right)$. Os valores de maxDif $f_{c_{k}}$ e $i d_{C_{k}}$ devem ser calculados para todas as comunidades $C_{k} \in C$ Set. A comunidade $C_{k} \in C$ Set com maior max Dif $f_{c_{k}}$ será a escolhida para ser dividida, sendo chamada de $C_{\text {max }}$ onde $i d_{C_{\max }}$ define o ponto de divisão do conjunto ordenado de ângulos $V O_{C_{\max }}$. O critério de parada é atingido quando o conjunto de comunidades CSet conter apenas um elemento. O Algoritmo 9 demonstra os procedimentos realizados para agrupar os dados.

É importante observar que essa técnica deixa de considerar apenas a estrutura topológica mas também considera o espaço geométrico em que os elementos da rede se encontram, sendo que a detecção de comunidade é realizada por meio da movimentação de vértices no espaço geométrico. Portanto, essa técnica tem sua característica própria.

\subsubsection{Método Baseado em Modularidade}

Com as várias propostas de algoritmos de detecção de comunidades em redes complexas, surge também a necessidade de verificar o quão boa é a comunidade encontrada, visto que em muitos casos não se conhece as comunidades presentes na rede. Assim, com intuito de medir a qualidade da rede, Newman \& Girvan (2003) introduzem uma medida chamada modularidade.

Considere que uma rede possui $k$ comunidades e que $e$ seja uma matriz de tamanho $k \times$ $k$ onde o elemento $e_{i j}$ dessa matriz seja o número de conexões entre a comunidade $c_{i}$ e $c_{j}$. Os elementos das posições $e_{i i}$ (diagonal da matriz) indicam as arestas que conectam vértices da mesma comunidade. A soma $\operatorname{Tr}=\sum_{i} e_{i i}$ desses elementos (traço da matriz) indica a quantidade total de arestas que conectam vértices das mesmas comunidades sendo que quanto maior esse valor, melhor é a divisão entre as comunidades. Entretanto a utilização do traço para verificar a qualidade das comunidades não é uma boa medida pois, caso todos os vértice sejam colocados em uma única comunidade, o valor do traço seria máximo mesmo não provendo nenhuma informação sobre as estruturas da rede. Para resolver esse problema, outra medida é definida: $a_{i}=\sum_{j} e_{i j}$ representando a soma das arestas que conectam a comunidade $c_{i}$ com as 


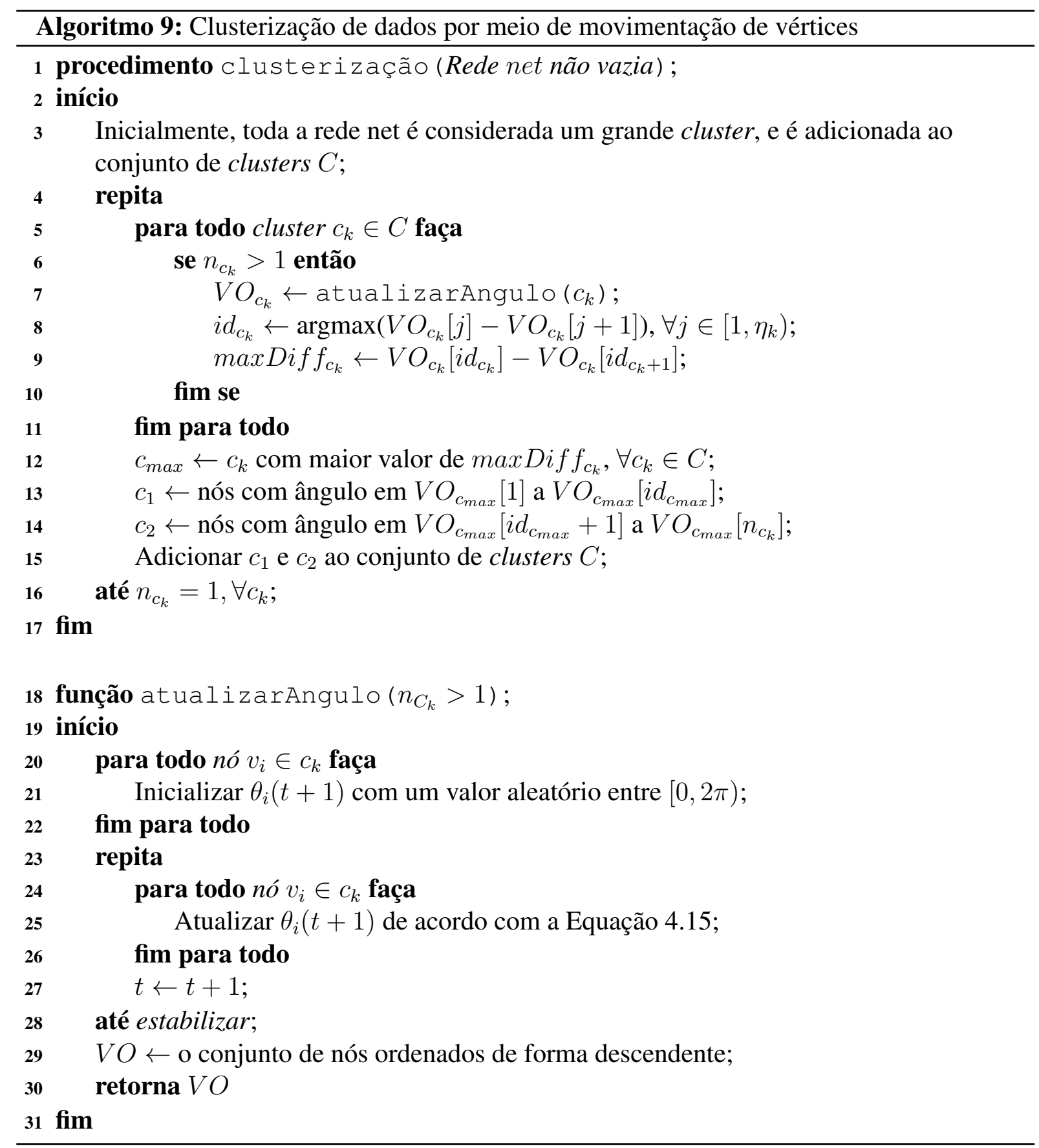


demais comunidades. Assim, pode-se definir a modularidade $Q$ através da Equação (4.20).

$$
Q=\sum_{i}\left(e_{i i}-a_{i}^{2}\right)
$$

A modularidade é calculada (Eq. (4.20)) a partir do número de arestas intra-comunidade menos o valor esperado caso a fração de arestas estivessem dispostas de forma randômica. Valores de $Q$ próximos a 0 significam que a rede não apresenta comunidades, ou seja, que as arestas tem topologia aleatória enquanto valores próximo a 1 (máximo) apontam que existem comunidades bem definidas. Uma maneira de realizar a detecção de comunidades é por meio da otimização da equação da modularidade. Newman (2004) propôs um algoritmo aglomerativo onde inicialmente cada vértice é colocado em uma comunidade e a cada iteração são fundidas, aos pares, as comunidades que apresentarem maior aumento da modularidade $(\Delta Q)$.

Um algoritmo aglomerativo proposto por Clauset et al. (2004) analisa, para todos pares de comunidades, a mudança em $Q$, caso essas duas comunidades fossem fundidas e escolhe, a cada iteração, os pares que causam a maior variação para serem juntadas. Para isso, o algoritmo utiliza as três estruturas de dados a seguir:

1. Uma matriz $\Delta Q_{i j}$ que guarda a variação em $Q$ para todos os pares de vértices $v_{i}$ e $v_{j}$ que possuem pelo menos uma aresta entre eles.

2. Um max-heap $H$ para guardar o maior elemento de cada linha da matriz $\Delta Q_{i j}$.

3. Um vetor $a_{i}$ que guarda, para cada comunidade $c_{i}$, a fração de arestas que estão conectas à aquela comunidade.

A matriz $\Delta Q_{i j}$ e o vetor $a$ são inicializados de acordo com as Equações (4.21) e (4.22).

$$
\begin{gathered}
\Delta Q_{i j}= \begin{cases}\frac{1}{2 m}-\frac{k i k j}{(2 m)^{2}} & \text { se } i, j \text { estão conectadas, } \\
0 & \text { caso contrário, }\end{cases} \\
a_{i}=\frac{k_{i}}{2 m}
\end{gathered}
$$

Depois de inicializar as estruturas de dados, começa o processo de fusão das comunidades escolhendo, a cada iteração, o par de comunidades que causa o maior aumento de $Q$. Após a fusão, atualiza-se as estruturas de dados. Considerando que as comunidades $c_{i}$ e $c_{j}$ foram fundidas, essa nova comunidade passa se chamar $c_{j}$, a $i$-ésima linha e $i$-ésima coluna de $\Delta Q_{i j}$ são removidas e cada elemento (comunidade) $c_{k}$ da $j$-ésima linha e coluna são atualizados de acordo com os três casos a seguir: Se $k$ está conectado a $c_{i}$ e $c_{j}$, então o novo $Q$ será calculado pela Equação (4.23).

$$
\Delta Q_{j k}^{\prime}=\Delta Q_{i k}+\Delta Q_{j k}
$$


Se $c_{k}$ está conectado apenas a $c_{i}$ e não a $c_{j}$, então o novo $Q$ será calculado pela Equação (4.24).

$$
\Delta Q_{j k}^{\prime}=\Delta Q_{i k}-2 a_{j} a_{k}
$$

Se $c_{k}$ está conectado apenas a $c_{j}$ e não a $c_{i}$, então o novo $Q$ será calculado pela Equação (4.25).

$$
\Delta Q_{j k}^{\prime}=\Delta Q_{j k}-2 a_{i} a_{k}
$$

Então, o max-heap $H$ é atualizado com os novos maiores elementos de cada linha e, finalmente o vetor $a$ é atualizado. A nova comunidade $c_{j}$ recebe a fração de arestas de $c_{i}$, i.e., $a_{j}^{\prime}=a_{j}+a_{i}$ e a comunidade $c_{i}$, que não existe mais, não possui mais arestas: $a_{i}=0$. Em cada iteração a modularidade da rede $Q$ é incrementada com o maior variação: $Q=Q+\Delta Q_{i j}$. O critério de parada atinge quando todas as comunidades forem fundidas em apenas uma, entretanto a melhor divisão da rede ocorre quando $Q$ para de crescer. O Algoritmo 10 resume o processo de detecção de comunidades.

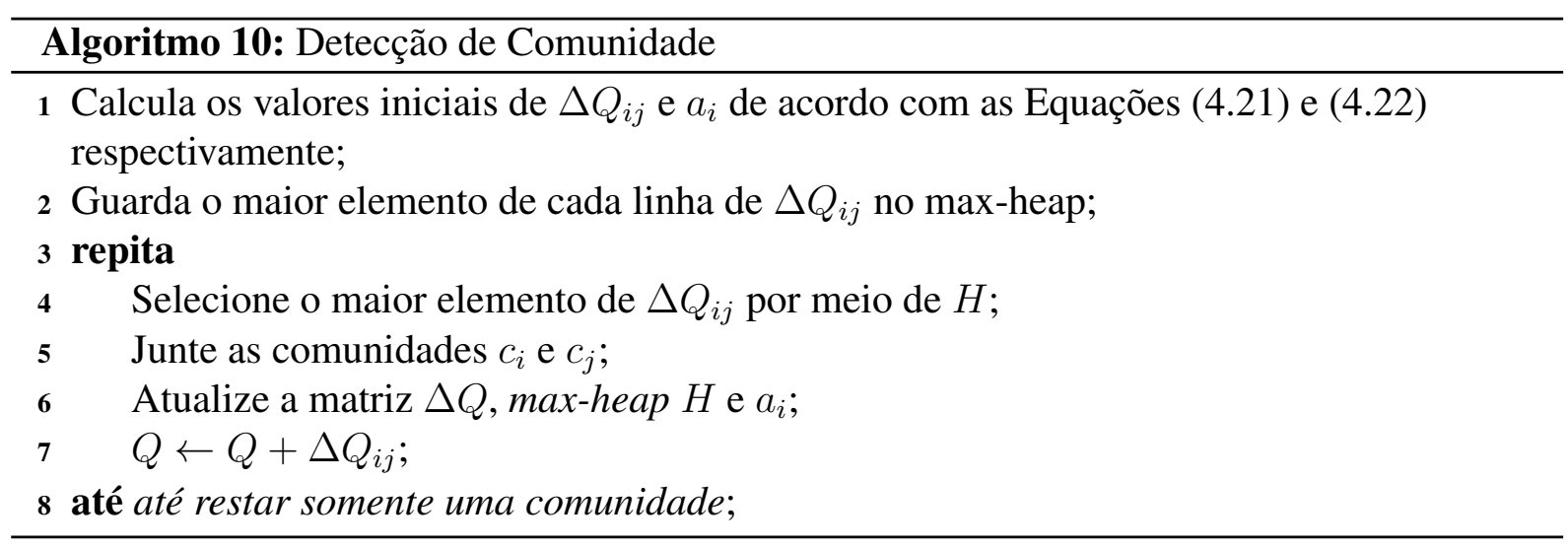

\subsection{Considerações Finais}

Nesse capítulo foi apresentado o conceito de redes complexas bem como os principais tipos de redes complexas e suas propriedades. Também foram apresentados alguns métodos de detecção de comunidades em redes complexas baseados em betweenness, modularidade, caminhada aleatória, sincronização, competição de partículas e movimentação de vértices.

Dessa forma, finaliza-se a revisão bibliográfica sobre os três grandes assuntos necessários para entendimento da proposta desse trabalho: Agrupamento de dados tradicional (Cap. 2), agrupamento de dados em redes de sensores sem fio (Cap. 3) e detecção de comunidades em redes complexas. 


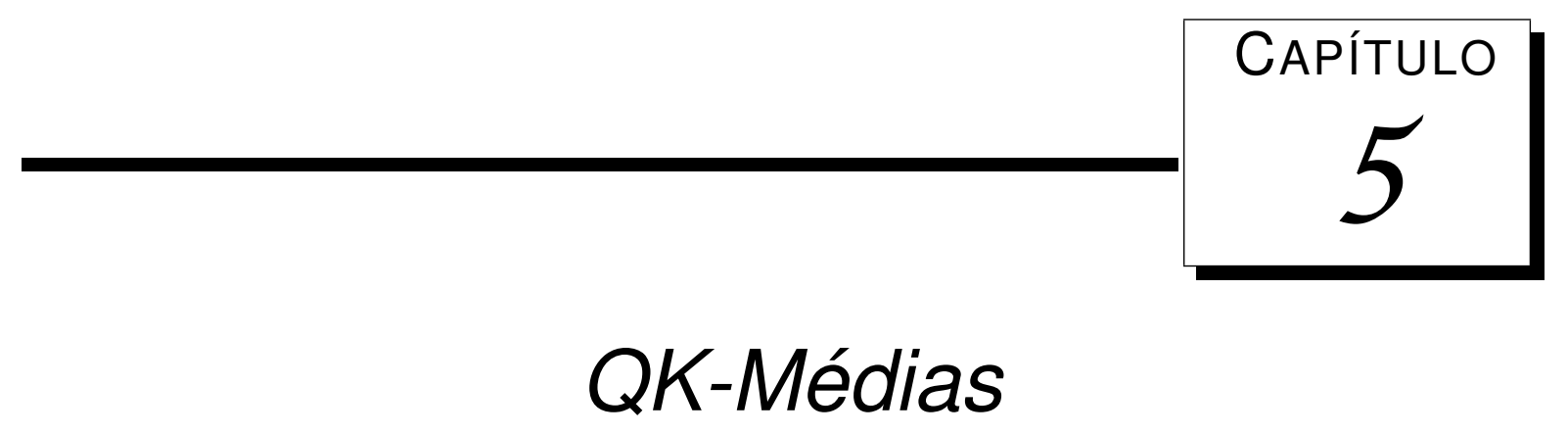

Cada conjunto de dados pode ser formado por várias distribuições estatísticas ou até mesmo pode ser representado de diferentes formas e tamanhos. Dessa forma, desenvolver uma técnica de agrupamento de dados que seja eficiente para identificar diversas distribuições de dados é uma tarefa não trivial. A representação dos dados em forma de grafos revela a interação entre os dados e possibilita utilização de técnicas de agrupamento que conseguem encontrar grupos de formas variadas. Assim, optou-se por utilizar um técnica de detecção de comunidades em redes complexas para encontrar grupos de formas variadas e outra técnica para quebrar essas comunidades em subgrupos de formato esférico para que os $\mathrm{CHs}$ consigam gerenciá-los. Uma vez que as técnicas de detecção de comunidades buscam soluções aproximadas para a tarefa de agrupamento, essas conseguem separar, em tempo razoável, os sensores em conjuntos menores para que algoritmos tradicionais, mais lentos, processem grupos menores de dados.

Nesse capítulo, será apresentado a técnica desenvolvida para fazer o agrupamento de sensores escravos e o posicionamento de sensores cluster head. Essa técnica visa minimizar o número de cluster heads para obter a maior cobertura da rede e diminuir a porcentagem de mensagens perdidas na rede. Foi também necessário construir um modelo simplificado de redes de sensores sem fio que simula a geração de mensagens e a dinâmica do roteamento dessas até a estação base. A partir desse modelo foi possível executar diferentes algoritmos e compará-los.

\subsection{Técnica de Agrupamento de Dados em RSSF}

Nessa seção é proposto um algoritmo híbrido para detecção de grupos em redes de sensores sem fio baseado em duas abordagens: detecção de comunidades em redes complexas e o tradicional algoritmo de clusterização K-Médias. Essa nova técnica tenta aproveitar as vantagens de 
cada técnica e minimizar suas desvantagens. O algoritmo de detecção de comunidades observa a posição de todos os nos da rede e pode encontrar grupos de formas variadas. Já o K-Médias consegue quebrar essas comunidades em subcomunidades de formato de circular para que os CHs consigam gerenciar. Esse algoritmo é chamado de QK-Médias e pode ser dividido em três passos: 1) formação da rede, 2) detecção de comunidades e 3) detecção de subcomunidades. A ideia é criar uma rede artificial conectando os escravos, detectar comunidades e depois encontra subcomunidades que possam ser monitoradas por um cluster head. As três etapas são descritas a seguir.

1. Formação da rede: Considerando que $S_{n}$ nós escravos estão posicionados em uma área de monitoramento, a formação da rede ocorre de acordo com a distribuição dos escravos. Assim, uma aresta artificial é criada entre dois vértices (escravos) diferentes $v_{i}$ e $v_{j}$, caso seja possível posicionar um $\mathrm{CH}$ entre eles, ou seja, se a distância entre eles $\left(d_{i j}\right)$ for menor ou igual ao diâmetro da cobertura do cluster head $\left(2 \mathrm{CH}_{r}\right)$. Por outro lado, se $d_{i j}>2 C H_{r} \forall v_{j} \in V$, então não é possível posicionar um $\mathrm{CH}$ entre o vértice $v_{i}$ e qualquer outro vértice, portanto $v_{i}$ não terá arestas e será desconsiderado na fase de detecção de comunidades. O peso de cada aresta gerada é a distância euclidiana entre o par de vértices que ela conecta. Dois exemplos de redes artificiais de escravos são ilustrados na Figura 5.1.

2. Detecção de comunidades: O segundo passo consiste em utilizar a rede de escravos gerada para detectar comunidades usando o algoritmo proposto por Clauset et al. (2004) (Alg. 10), descrito na Subseção 4.3.6. Serão utilizadas as comunidades encontradas quando a modularidade $Q$ parar de crescer. A Figura 5.2(a) mostra o resultado da aplicação desse algoritmo para a base de dados da Figura 5.1(b).

3. Detecção de subcomunidades: Depois de encontrar as comunidades, é necessário quebralas em subcomunidades para que cada cluster head consiga gerenciar uma pequena porção da rede. Para isso, será executado o algoritmo K-Médias (Alg. 2) descrito na Subseção (2.4.2) para cada comunidade encontrada na etapa anterior. O número de subcomunidades $K\left(C_{i}\right)$ em uma comunidade $C_{i}$ com mais de um elemento é calculado (Eq. 5.1) tomando o teto da divisão do diâmetro da comunidade $\operatorname{Diam}\left(C_{i}\right)$ pelo diâmetro de cobertura do cluster head $\left(2 \mathrm{CH}_{r}\right)$. Para calcular o diâmetro, é montada uma matriz de adjacência $A$ sendo que a posição $A(i, j)$ contem o peso (distância) da aresta que conecta os vértices $v_{i}$ e $v_{j}$. Essa matriz de adjacência é utilizada pelo algoritmo Floyd-Warshall (descrito no apêndice A) para calcular as menores distâncias entre todos pares de vértices. $O$ diâmetro da rede é o maior valor da matriz retornada pelo algoritmo Floyd-Warshall. Depois de descobrir o valor de $K\left(C_{i}\right)$ então é executado o algoritmo K-Médias. Em seguida, um cluster head é posicionado no ponto médio de cada subcomunidade. O QK-Médias é descrito em três passos a seguir no Algoritmo 11. A Figura 5.2(b) mostra o resultado das sucessivas aplicações desse algoritmo para cada comunidade da Figura 5.2(a). 


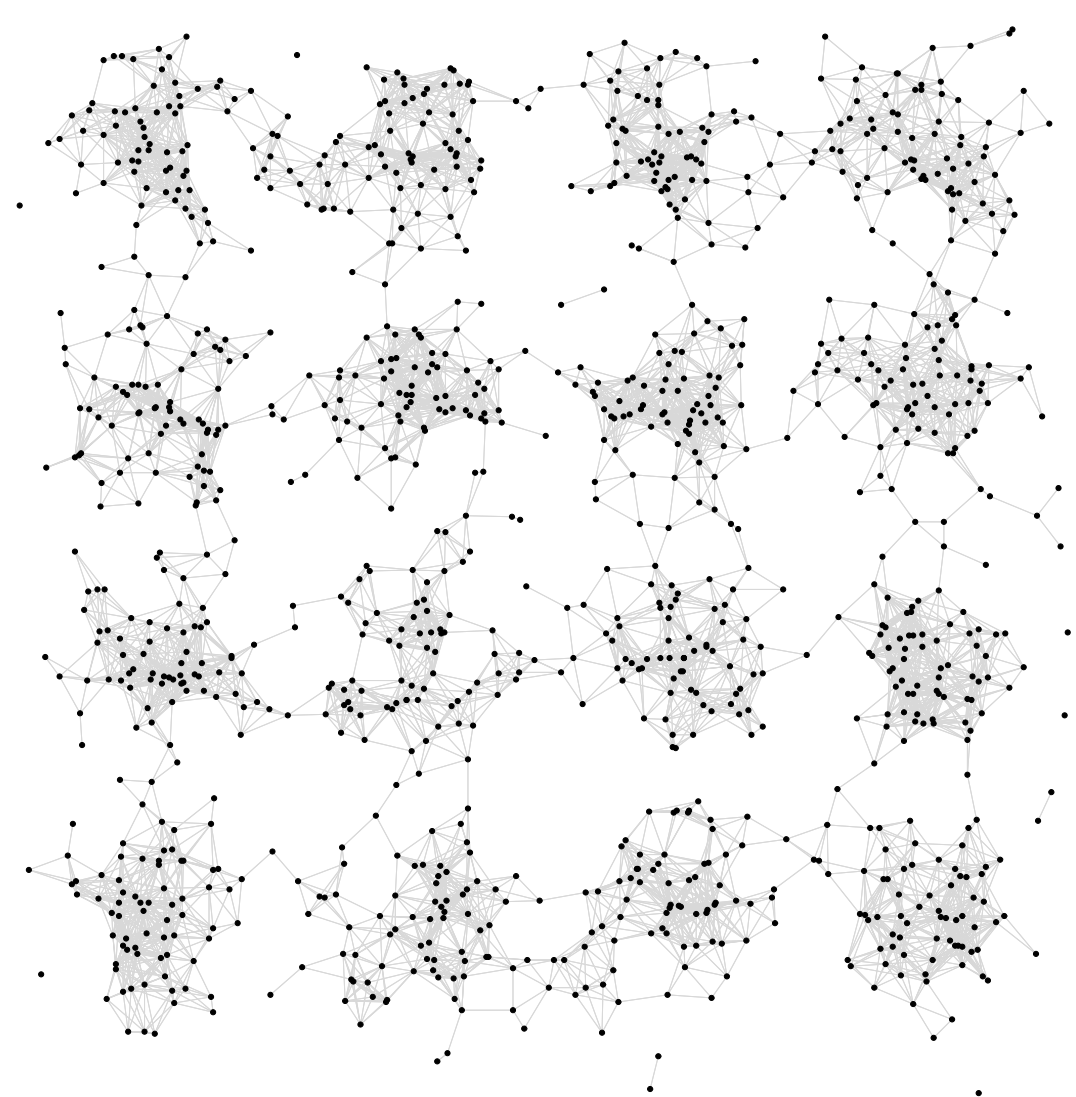

(a)
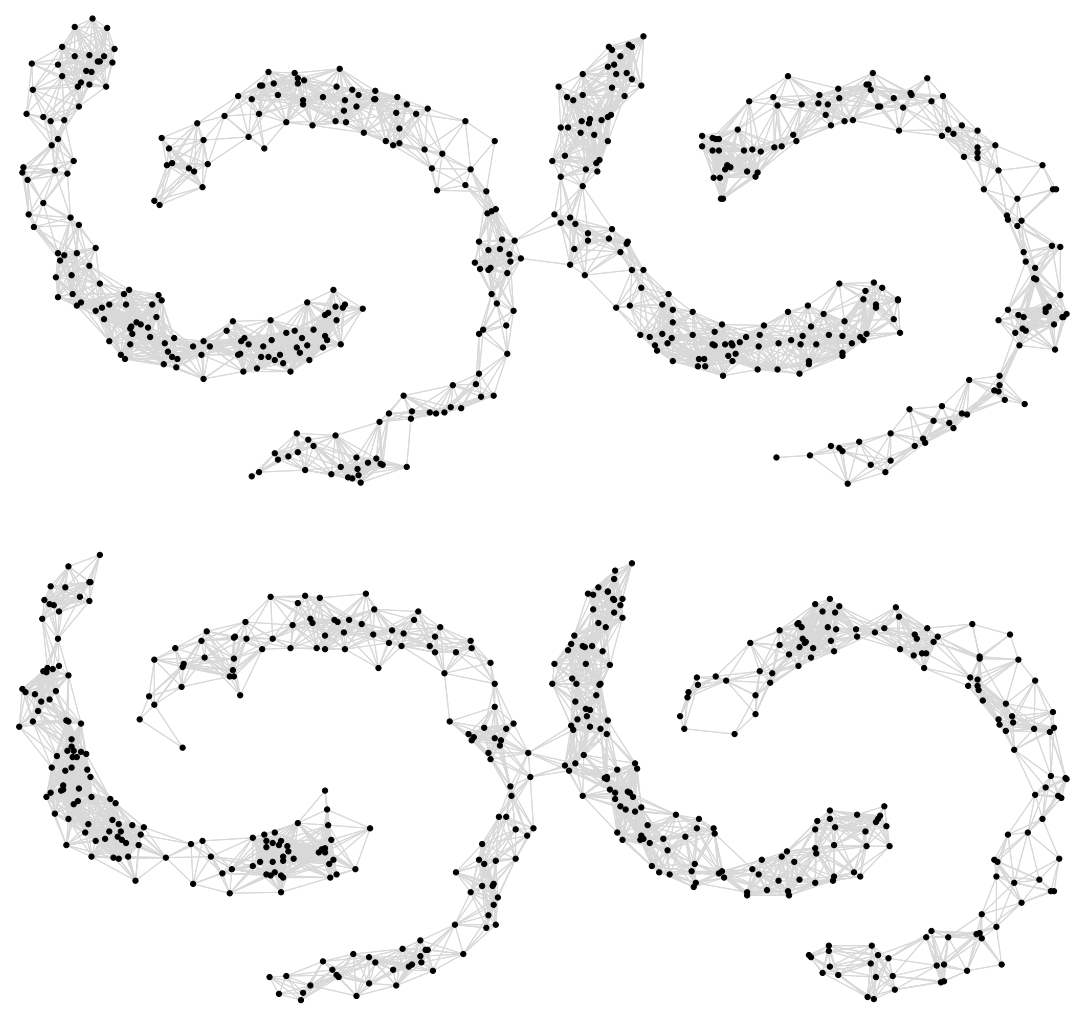

(b)

Figura 5.1: Redes artificiais com 1000 nós escravos distribuídos em: (a) 16 gaussianas e (b) 8 bananas. 

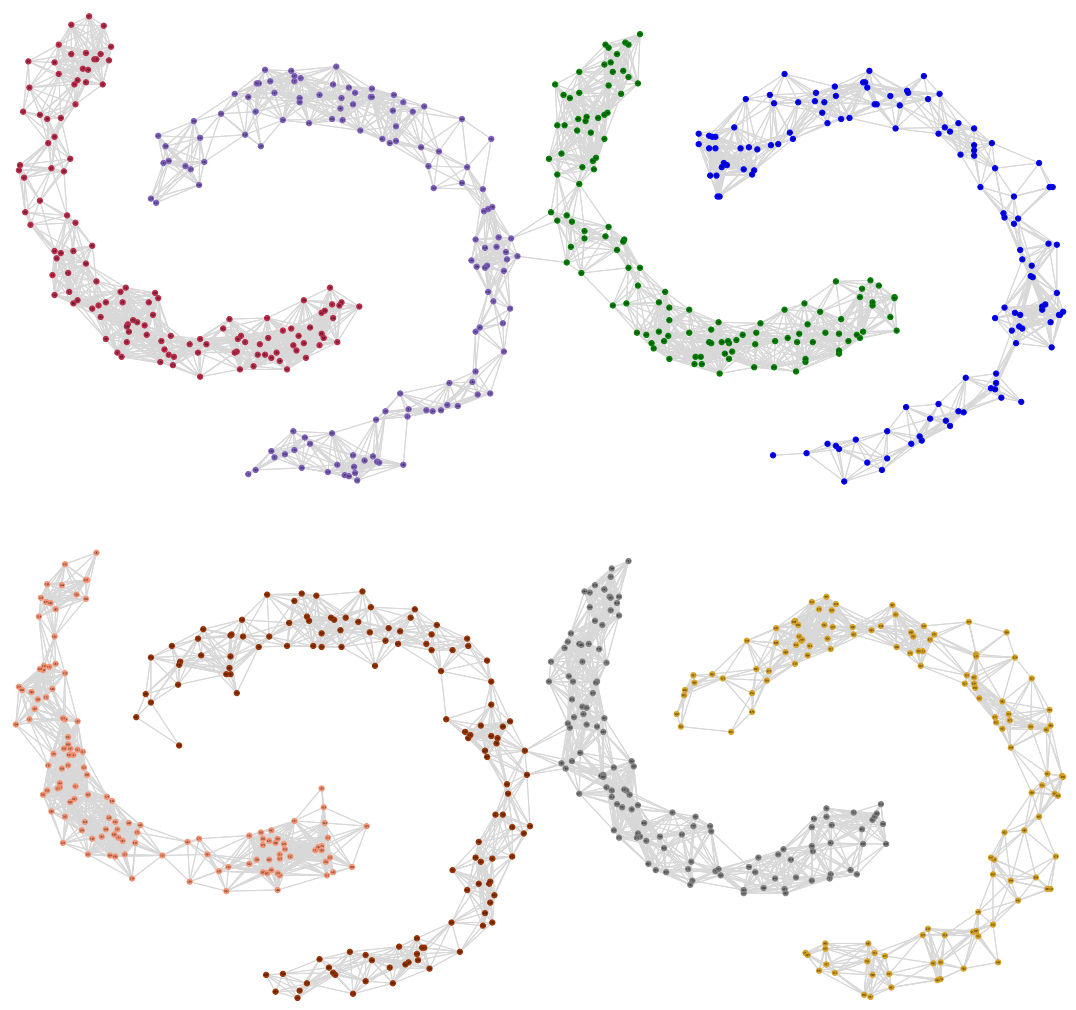

(a)
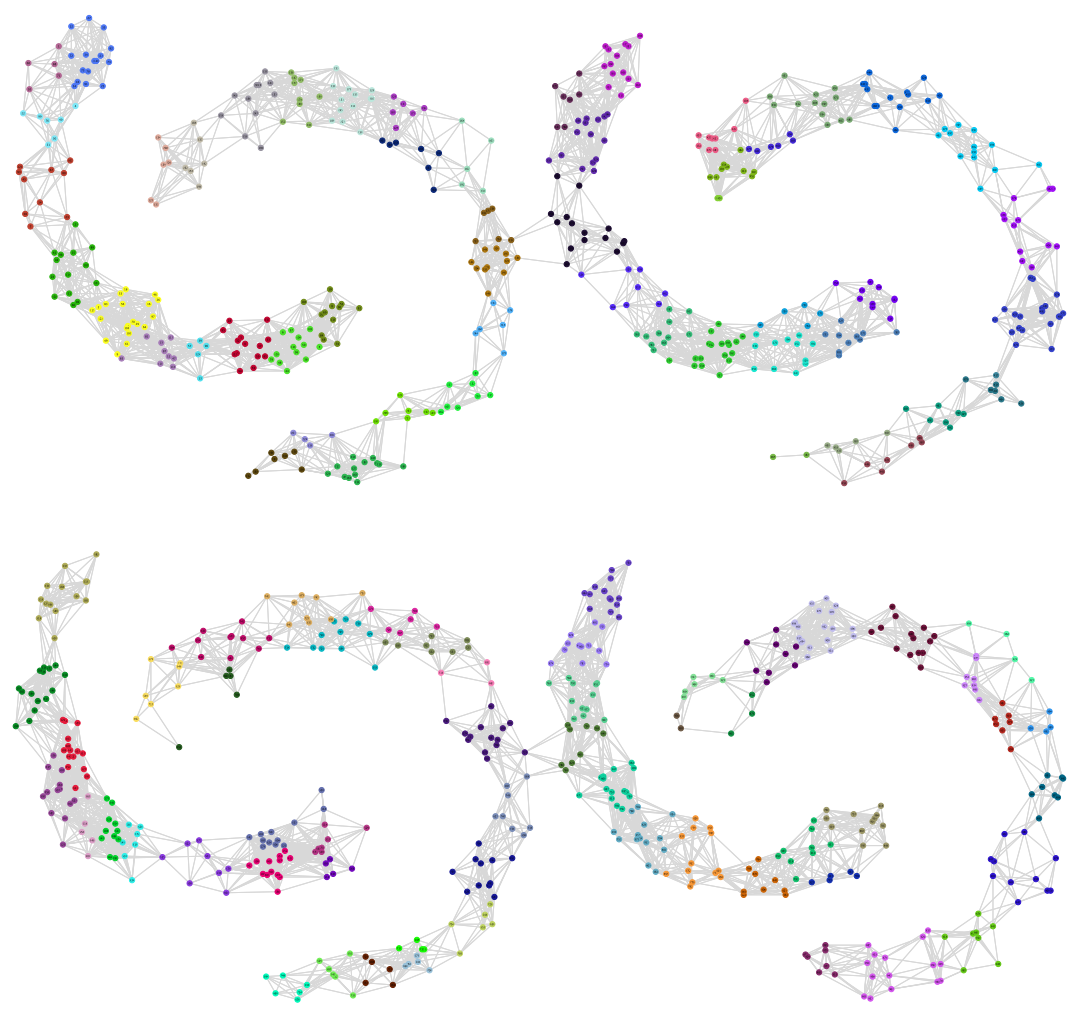

(b)

Figura 5.2: Resultado da detecção de comunidades realizada pelo QK-Médias na base de dados artificial da Figura 5.1(b), sendo que cada cor representa um grupo de sensores. O processo de agrupamento é feito em duas etapas: (a) detecção de comunidades utilizando o algoritmo proposto por Clauset et al. (2004) (Alg. 10) e (b) detecção de subcomunidades utilizando o algoritmo K-Médias (Alg. 2). 


$$
K\left(C_{i}\right)=\left\lceil\frac{\operatorname{Diam}\left(C_{i}\right)}{2 C H_{r}}\right\rceil
$$

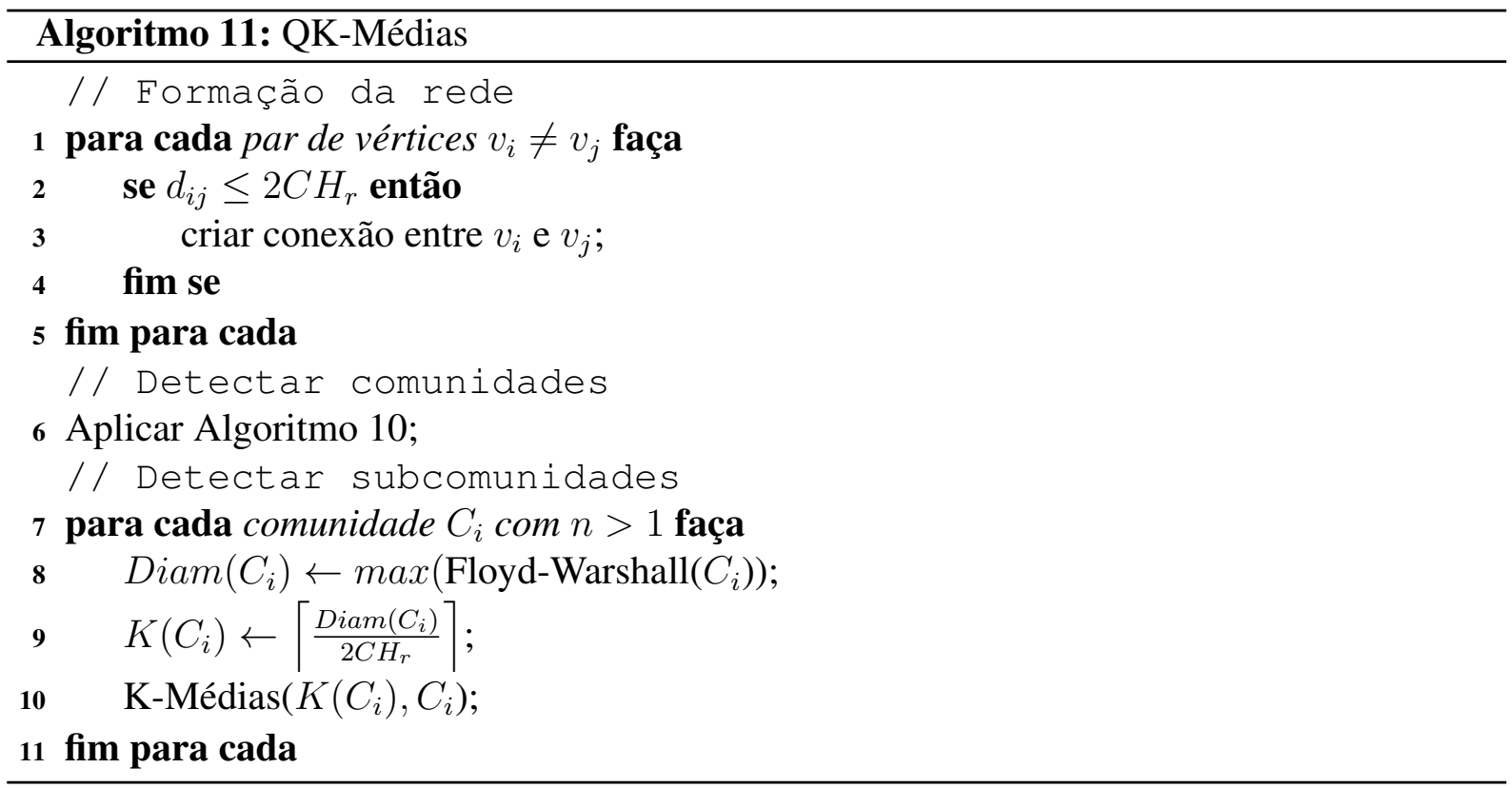

\subsection{Modelo de Simulação de RSSF}

Para fazer as simulações de redes de sensores sem fio (RSSF) foi necessário desenvolver um simulador simplificado para que fosse possível observar o comportamento de milhares de nós. Para o modelo de comunicação, foram considerados três tipos de sensores: mestre (estação base), cluster heads (CHs) e escravos. Os dados são coletados pelos sensores escravos que enviam para seus respectivos $\mathrm{CHs}$ e que, por sua vez, enviam para a estação base que reuni e processa todos os dados coletados. Todos os sensores escravos transmitem mensagens para os $\mathrm{CHs}$ em apenas um salto, considerado apenas uma unidade de tempo. $\mathrm{O}$ mesmo ocorre entre CHs e a estação base. Na primeira fase da simulação ocorre a fase de sensoriamento (geração probabilística de mensagens) e em seguida a fase de envio das mensagens do $\mathrm{CH}$ para a estação base, sendo que para essa segunda fase é considerado que a comunicação é feita em frequência de radio diferente para que não haja interferência nas comunicações entre escravo- $\mathrm{CH}$ e $\mathrm{CH}$ estação base.

Inicialmente a rede é construída posicionando arbitrariamente os sensores escravos. Em seguida é utilizada alguma técnica para detectar grupos entre os sensores e então posicionar, de forma estratégica, os CHs. Todo nó escravo que se encontrar dentro do raio de cobertura de um $\mathrm{CH}$ será conectado a esse. Escravos cobertos por mais de um $\mathrm{CH}$ serão conectados a todos eles. A Figura 5.3 ilustra as conexões entre os três tipos de sensores da rede.

Os parâmetros de simulação considerados para o modelo são: 


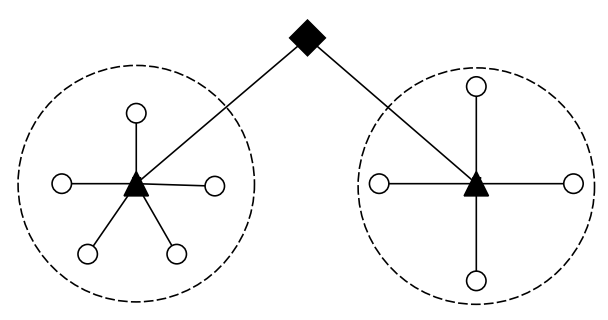

Figura 5.3: Um exemplo do modelo de RSSF onde os nós escravos são representados por círculos, os cluster heads representados por triângulos e a nó mestre (estação base) representado por um losango. Os círculos com linha tracejadas exibe os clusters.

- Número de escravos $\left(S_{n}\right)$ : Número de escravos que serão posicionados dentro da área de monitoramento.

- Número de $\mathrm{CHs}\left(\mathrm{CH}_{n}\right)$ : Número de $\mathrm{CHs}$ que serão posicionados dentro da área de monitoramento e que, de acordo com seu raio de cobertura, serão conectados aos escravos.

- Buffer dos escravos $\left(S_{b}\right)$ : Número de mensagens que cada escravos consegue armazenar.

- Buffer dos $\mathrm{CHs}\left(\mathrm{CH}_{b}\right)$ : Número de mensagens que cada $\mathrm{CH}$ consegue armazenar.

- Tempo de simulação $(T)$ : Número de iterações, usado como critério de parada da simulação.

- Probabilidade de geração de mensagem $(\lambda)$ : A cada iteração, cada escravo tem probabilidade $\lambda$ de gerar uma mensagem.

- Raio de cobertura dos escravos $\left(S_{r}\right)$ : Tamanho do raio de cobertura do Escravo. Raio de sensoriamento de cada escravo.

- Raio de cobertura dos $\mathrm{CHs}\left(\mathrm{CH}_{r}\right)$ : Tamanho do raio de cobertura do $\mathrm{CH}$. Escravos dentro desse raio serão conectados a esse $\mathrm{CH}$.

Inicialmente a simulação considera que $S_{n}$ nós escravos são posicionados arbitrariamente dentro da área de monitoramento. Em seguida, os grupos são detectados, por meio de alguma técnica, e então é posicionado um $\mathrm{CH}$ no ponto médio de cada cluster. Então começa a fase de monitoramento. Os escravos começam a gerar mensagens, que são enviadas aos $\mathrm{CH}$ e depois para a estação base. Para cada iteração da simulação (tempo), cada nó escravo tem probabilidade $\lambda$ de gerar uma mensagem, que é armazenada em seu buffer e enviada para seu $\mathrm{CH}$. O meio de transmissão em RSSF é compartilhado entre os escravos que estão sob a cobertura de um $\mathrm{CH}$. Consequentemente, cada $\mathrm{CH}$ pode receber apenas a mensagem de um escravo por unidade de tempo (iteração) que é armazenada no buffer do $\mathrm{CH}$. Esse comportamento é reproduzido tomando um cluster head ch e adicionando uma mensagem ao buffer $\left(c h_{b}\right)$ do $\mathrm{CH}$. Em seguida é escolhido aleatoriamente um escravo $s$ de $c h$ que não está com seu buffer vazio e uma mensagem 
do buffer $\left(s_{b}\right)$ desse escravo é subtraída. A comunicação entre $\mathrm{CH}$ e estação base é feita de forma semelhante. Caso um escravo gere mensagem e seu buffer esteja cheio, então essa mensagem é contabilizada como mensagem perdida $(L M)$. Caso um $\mathrm{CH}$ esteja com seu buffer cheio e receba mensagem de um escravo, essa mensagem também é considerada pedida. Esse processo de monitoramento é descrito pelo Algoritmo 12.

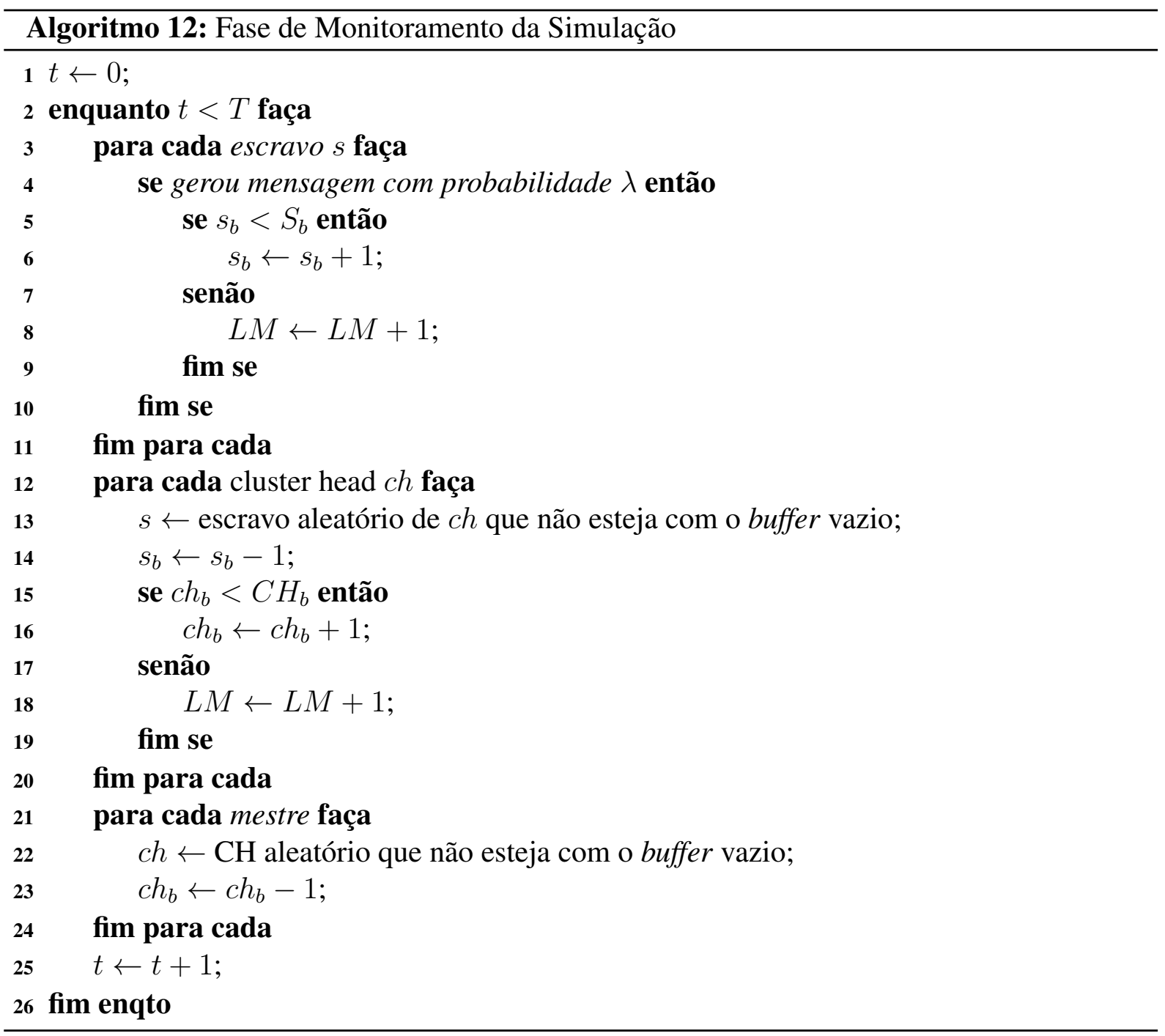

\subsection{Metodologia de Avaliação de Experimentos}

Nesse trabalho, a idéia principal é encontrar os grupos de sensores e posicionar cluster heads de forma conveniente para maximizar a cobertura do sensores com o mínimo de $\mathrm{CH}$ possíveis. Um nó sensor é considerado coberto quando existe um ou mais $\mathrm{CHs}$ dentro de seu raio de cobertura. Assim, a metodologia utilizada consiste em avaliar a porcentagem de mensagens perdidas (LM) da rede para diferentes parâmetros de simulação. Uma mensagem é considerada perdida quando ela não consegue ser transmitida até a estação base sendo que mensagens armazenadas 
em buffer (escravo ou $\mathrm{CH}$ ) não são consideradas mensagens perdidas. Todas as simulações foram realizadas 30 vezes e utilizado o valor médio das execuções.

Além desses estudos empíricos, algumas comparações entre algoritmos de agrupamento foram realizadas. Para os experimentos foram considerados alguns conjuntos de dados artificiais, cada um composto por 1000 sensores escravos. Dois exemplos de conjuntos estão ilustrados nas Figuras 5.1(a) e 5.1(b), sendo que no primeiro conjunto, os escravos estão dispostos formando 16 distribuições gaussianas e no segundo, os escravos foram posicionados em forma de 8 bananas.

Considerando que os algoritmos de agrupamento de dados em RSSF são elaborados para resolver um objetivo específico, a comparação entre eles deveria ser realizada somente se esses objetivos fossem iguais. Outro critério usado na escolha dos algoritmos de comparação está no fato desses precisarem ou não informar o número de grupos desejados como parâmetro. Para utilizar o QK-Médias não é preciso informar a priori o número de grupos desejados. Assim, o QK-Médias foi comparado apenas com algoritmos que encontram o número de grupos automaticamente. A seguir será apresentado o resultado de alguns experimentos.

\subsubsection{Variação do Tamanho do Buffer dos CHs}

No primeiro experimento considerou-se um pequeno buffer para o escravos $\left(S_{b}\right)$ e foi observada a influência da variação do tamanho do buffer dos cluster heads $C H_{b}$ sob a porcentagem de mensagens perdidas (LM). Foi utilizado o algoritmo QK-Médias comparado com outros dois: baseado em modularidade (Alg. 10) e o EM (Descrito na Sub-Seção 2.4.3). A Figura 5.4 mostra o resultado da simulação. É possível notar que, conforme o buffer do $\mathrm{CH}$ aumenta, a porcentagem de mensagens perdidas diminui até atingir um ponto de estabilidade.

\subsubsection{Variação do Tamanho do Buffer dos Escravos}

Nesse experimento foi feito o oposto do experimento anterior. Foi utilizado um valor pequeno para o buffer do $\mathrm{CH}\left(\mathrm{CH}_{b}\right)$ e observado a influência da variação do buffer dos escravos $\left(S_{b}\right)$ sob $L M$. A Figura 5.5 mostra o resultado onde é possível observar que o QK-Médias teve a pior performance. Para explicar esse comportamento são consideradas duas situações possíveis: Quando um escravo está ou não conectado a um cluster head. Se um escravo não está conectado a um $\mathrm{CH}$, então todas as mensagens geradas por ele serão armazenadas em seu buffer e nenhuma mensagem será perdida. Por outro lado, se o escravo estiver conectado a um $\mathrm{CH}$, então ele enviará mensagens ao $\mathrm{CH}$. Porém, como foi utilizado um $\mathrm{CH}_{b}$ pequeno, $\operatorname{logo}$ ficará cheio e irá começar a perder mensagens. Esse comportamento ocorre por que os outros algoritmos encontram menos clusters que o QK-Médias resultando em uma cobertura menor da rede.

Nesse experimento foi verificado a influência da variação de $\lambda$ sob $L M$. A Figura 5.6 mostra o resultado, e como esperado, conforme $\lambda$ aumenta, $L M$ também aumenta. É possível observar 


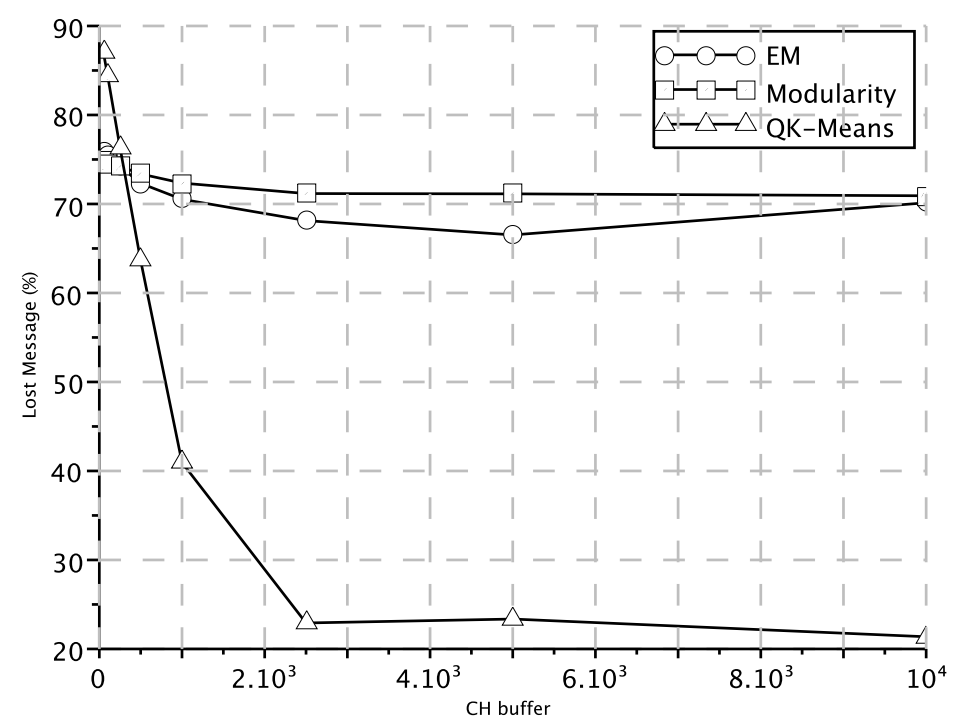

Figura 5.4: Variação do tamanho do buffer dos cluster head e a influência sob a porcentagem de mensagens perdidas (LM) para alguns algoritmos de agrupamento. Para essa simulação foram considerados 1000 sensores escravo divididos em forma de 8 bananas (Fig. 5.1(b)). Os parâmetros de simulação são: $S_{r}=50 \mathrm{~m}, \mathrm{CH}_{r}=25 \mathrm{~m}, S_{b}=50$ mensagens e $\lambda=10 \%$. Cada ponto do gráfico representa a média dos resultados de 30 execuções da simulação.

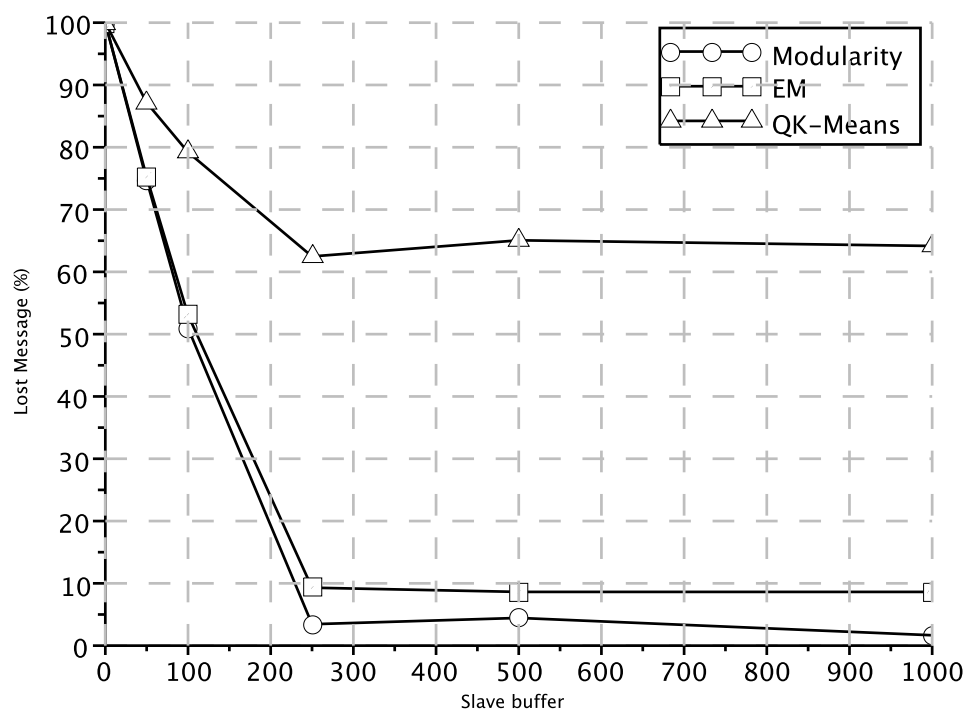

Figura 5.5: Variação do $S_{b}$ e sua influência sob $L M$ para alguns algoritmos de clusterização. Para essa simulação foram considerados 1000 sensores escravo divididos em forma de 8 bananas (Fig. 5.1(b)). Os parâmetros de simulação são: $S_{r}=50 \mathrm{~m}, C H_{r}=25 \mathrm{~m}, C H_{b}=50$ mensagens e $\lambda=10 \%$. Cada ponto do gráfico representa a média dos resultados de 30 execuções da simulação. 
que o QK-Médias apresenta uma curva mais suave que os outros algoritmos pois posiciona melhor e mais cluster heads.

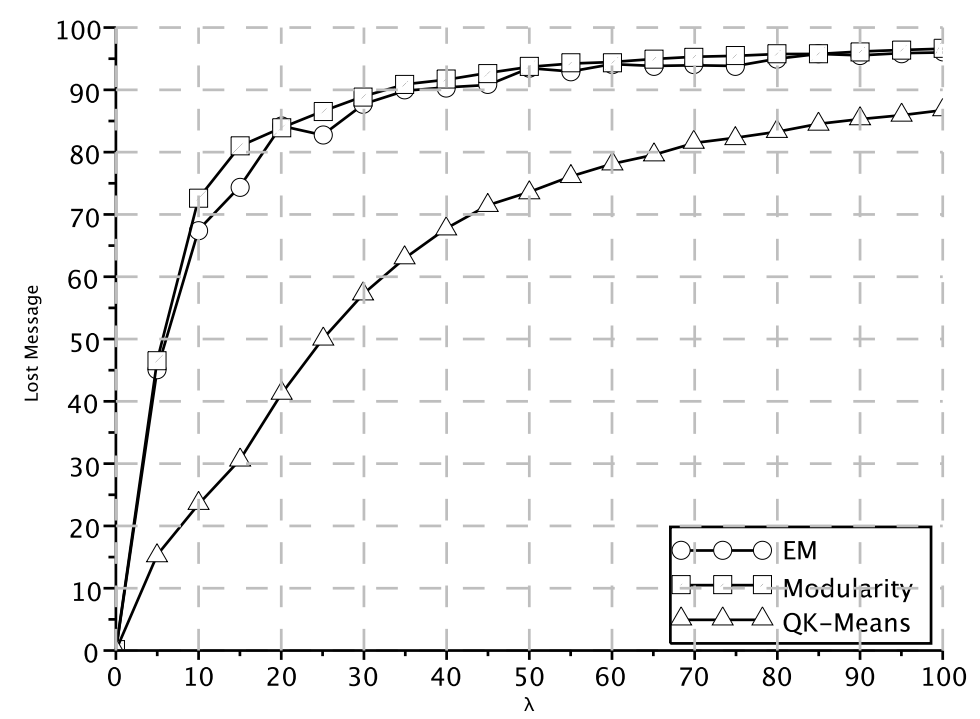

Figura 5.6: Variação de $\lambda$ e sua influência sob $L M$ para alguns algoritmos de clusterização. Para essa simulação foram considerados 1000 sensores escravo divididos em 16 gaussianas (Fig. 5.1(a)). Os parâmetros de simulação são: $S_{r}=50 \mathrm{~m}, C H_{r}=25 \mathrm{~m}, S_{b}=50$ mensagens e $C H_{b}=2500$ mensagens. Cada ponto do gráfico representa a média dos resultados de 30 execuções da simulação.

\subsubsection{Variação do Tamanho das subcomunidades}

O algoritmo QK-Médias usa a Equação 5.1 para encontrar o número de subcomunidades em uma comunidades. Nesse experimento foi multiplicado essa equação por alguns fatores e observado a influência sob a cobertura e $L M$ na rede. Em outras palavras, esse experimento consiste em variar o tamanho das subcomunidades, ou seja, o número de sensores escravos por $\mathrm{CH}$. Inicialmente foi utilizado a Equação original (5.1) e, em seguida, foi multiplicada por 2, 4 e 8. A Figura 5.7 mostra o resultado desse experimento. É possível observar que, conforme $K$ aumenta, a cobertura da rede também aumenta e $L M$ cai.

\subsubsection{Variação no Raio de Cobertura e no Buffer dos CHs}

Nesse experimento foram observadas as influencias da variação conjunta do raio de cobertura $\left(\mathrm{CH}_{r}\right)$ e do tamanho do do buffer dos $\mathrm{CHs}\left(\mathrm{CH}_{b}\right)$ sob o número de mensagens perdidas da rede $(L M)$. A Figura 5.8 mostra o resultado. Se fixarmos algum valor para o raio de cluster head, é possível observar que ao aumentar o tamanho buffer o número de mensagens perdidas na rede diminui, atingi um mínimo (tons de azul) e depois volta a crescer (tons de vermelho). A partir desse gráfico, entende-se que existe uma determinado combinação de valores entre $C H_{r}$ e $\mathrm{CH}_{b}$ que minimiza o número de mensagens perdidas na rede. 


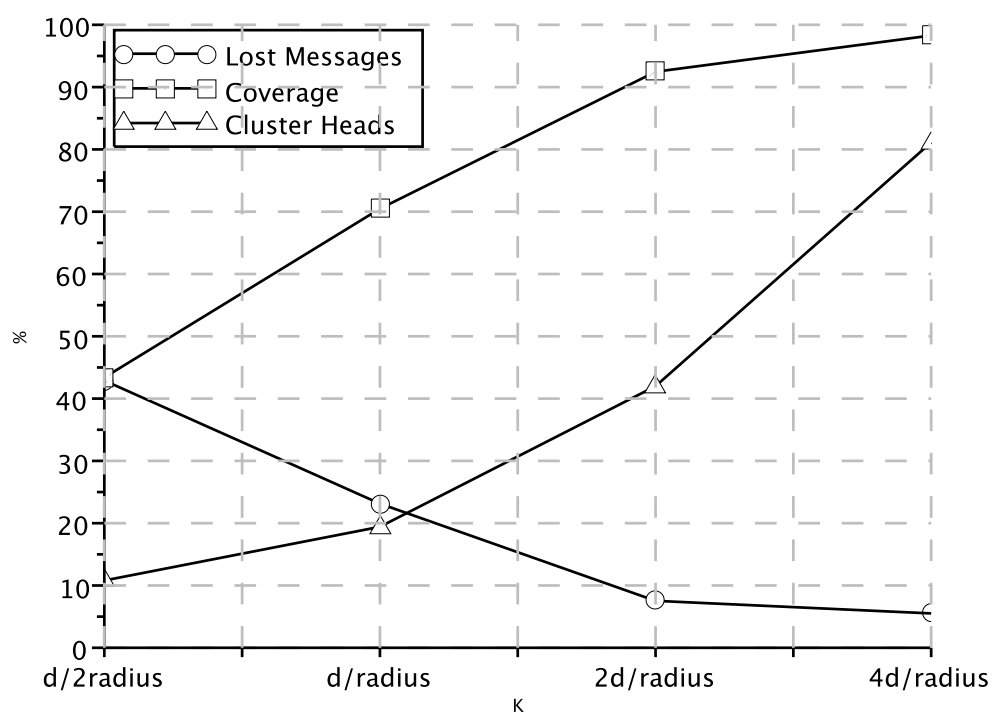

Figura 5.7: Variação do tamanho das subcomunidades e influência sob a cobertura da rede e $L M$. Para essa simulação foram considerados 1000 sensores escravo divididos em 16 gaussianas (Fig. 5.1(a)). Os parâmetros de simulação são: $S_{r}=50 \mathrm{~m}, C H_{r}=25 \mathrm{~m}, S_{b}=50$ mensagens, $C H_{b}=2500$ mensagens e $\lambda=10 \%$. Cada ponto do gráfico representa a média dos resultados de 30 execuções da simulação.

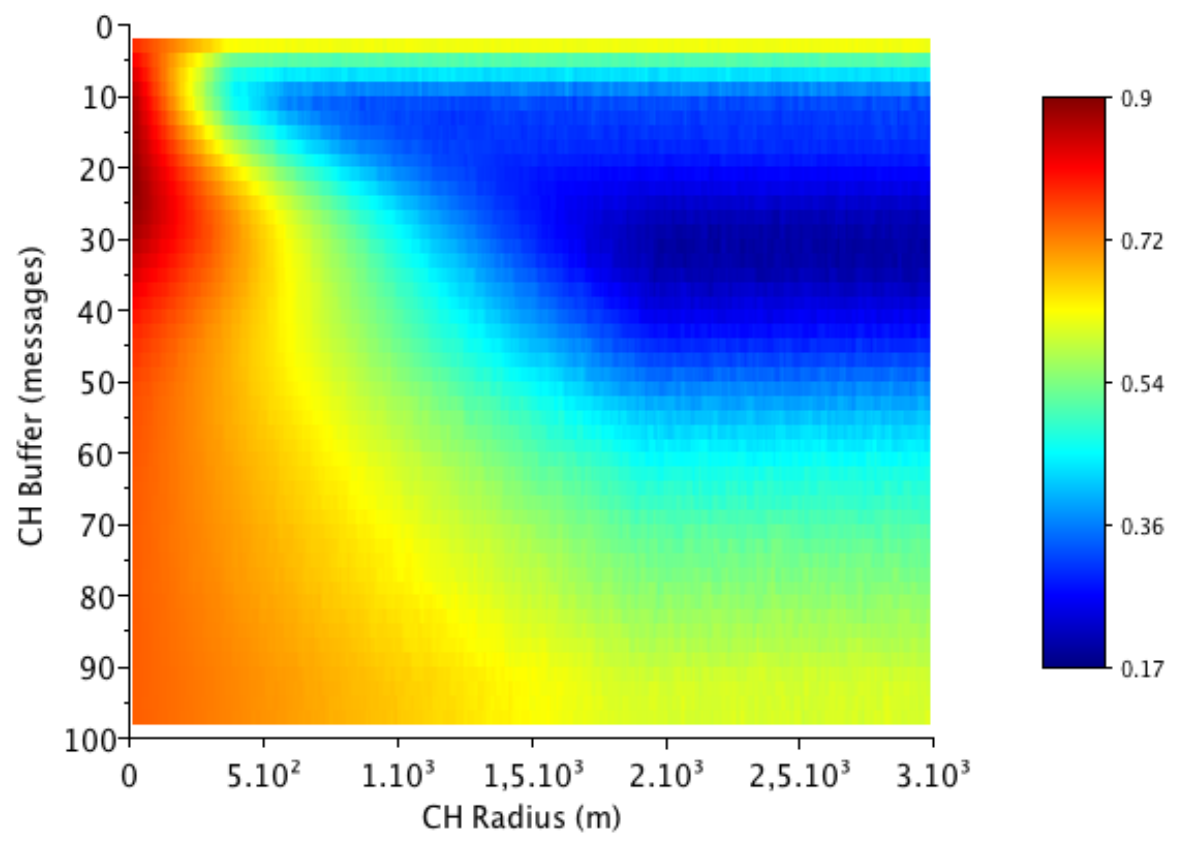

Figura 5.8: Variação do $C H_{r}$ e $C H_{b}$ e sua influência sob $L M$. Para essa simulação foram considerados 1000 sensores escravo divididos em forma de 8 bananas (Fig. 5.1(b)). Os parâmetros de simulação são: $S_{r}=50 \mathrm{~m}, S_{b}=50$ mensagens e $\lambda=10 \%$. Cada ponto do gráfico representa a média dos resultados de 30 execuções da simulação. 


\subsubsection{Variação nos Raios de Cobertura dos CHs e dos Escravos}

Nesse experimento foram observadas as influencias da variação do raio de cobertura $\left(\mathrm{CH}_{r}\right)$ e do tamanho do buffer dos escravos $\left(S_{b}\right)$ sob o número de mensagens perdidas da rede $(L M)$. A Figura 5.9 mostra o resultado. Como pode ser visto, o raio de cobertura dos nós escravos não influencia no número de mensagens perdidas para o conjunto de dados distribuídos em 8 bananas e para os parâmetros usados. Isso ocorre porque o raio de cobertura dos escravos influencia apenas na formação (conexões) da rede. Ou seja, para alguns casos, o número de conexões formado não influência no resultado pois sempre gera uma rede com as mesmas comunidades. Isso pode acontecer quando os nós escravos de cada comunidades estão muito próximos entre si e a distância entre as comunidades é suficientemente grande.

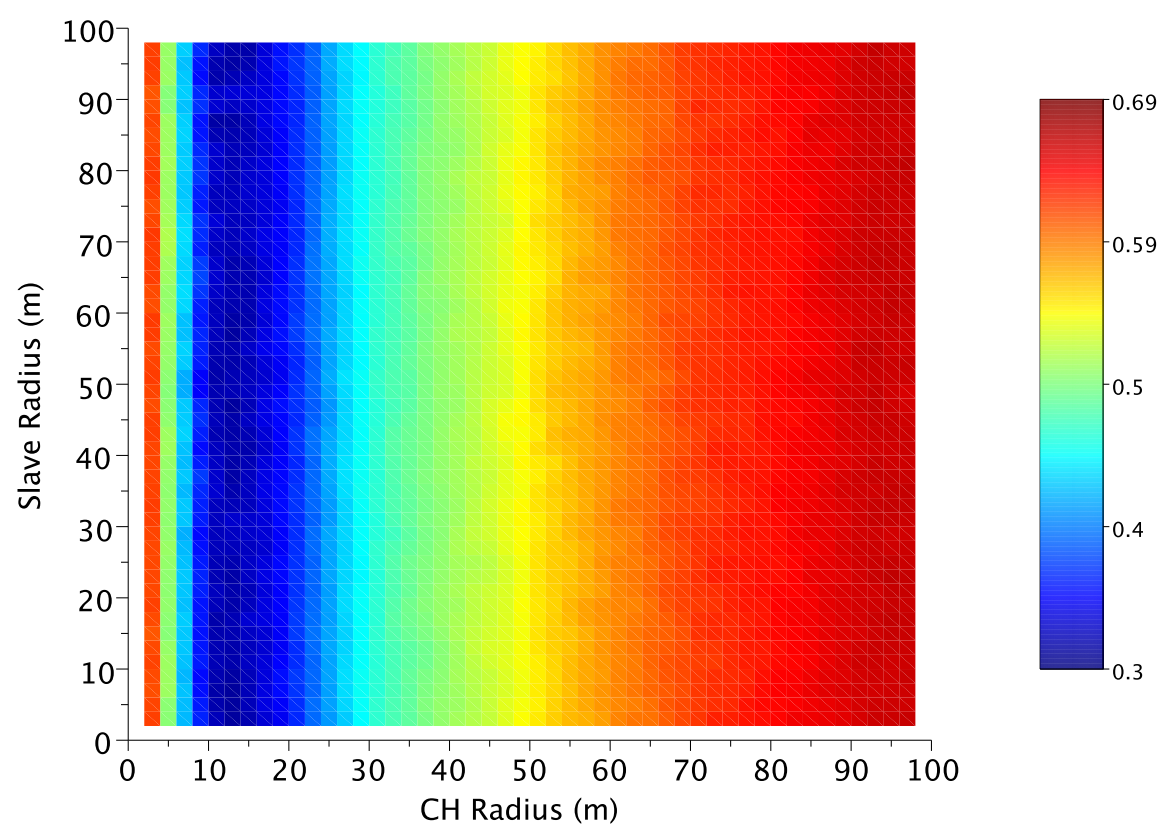

Figura 5.9: Influência da variação do $C H_{r}$ e $S_{r}$ sob $L M$. Para essa simulação foram considerados 1000 sensores escravo divididos em forma de 8 bananas (Fig. 5.1(b)). Os parâmetros de simulação são: $S_{b}=50, C H_{b}=1000$ mensagens e $\lambda=10 \%$. Cada ponto do gráfico representa a média dos resultados de 30 execuções da simulação.

\subsubsection{Variação na Probabilidade de Geração de Mensagens e no tamanho do Buffer do CHs}

Nesse experimento foram observadas as influencias da variação da probabilidade de geração de mensagens $(\lambda)$ e do tamanho do buffer dos cluster heads $\left(\mathrm{CH}_{b}\right)$ no número de mensagens perdidas $(L M)$ da rede. A Figura 5.10 mostra o resultado da simulação onde pode ser observado que aumentos pequenos em $\lambda$ geram um aumento significativo no número de mensagens 
perdidas da rede $(L M)$. Isso indica que para alguns casos, não basta agrupar os sensores e posicionar bem os $\mathrm{CHs}$, mas também é necessário configurar parâmetros de simulação. Por exemplo, é necessário ter um tamanho de buffer mínimo para os $\mathrm{CH}$ e para os escravos para que seja viável agrupar os sensores.

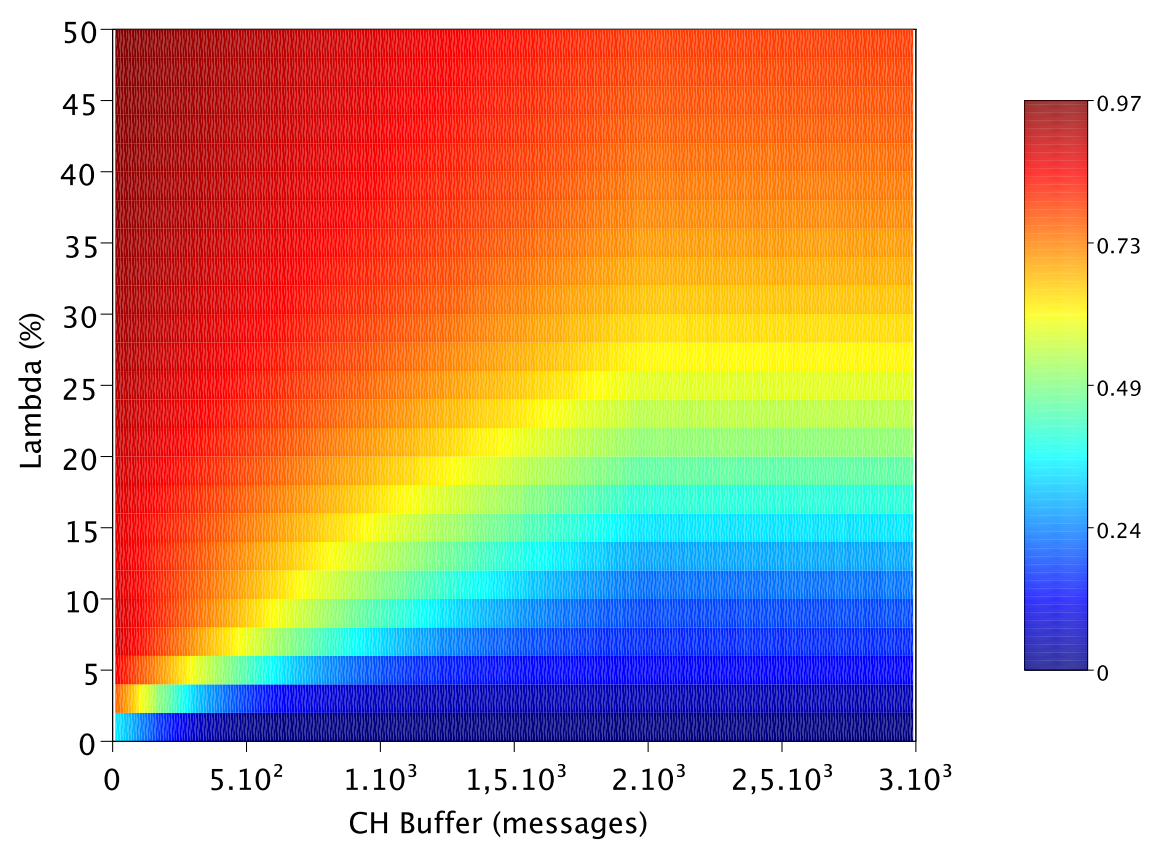

Figura 5.10: Influência da variação do $\lambda$ e $C H_{b}$ sob $L M$. Para essa simulação foram considerados 1000 sensores escravo divididos em forma de 8 bananas (Fig. 5.1(b)). Os parâmetros de simulação são: $S_{b}=50$ mensagens, $S_{r}=25 \mathrm{~m}$ e $C H_{r}=50 \mathrm{~m}$. Cada ponto do gráfico representa a média dos resultados de 30 execuções da simulação.

\subsubsection{Algoritmos Tradicionais de Agrupamento em RSSF}

Nesse experimento foram implementados alguns algoritmos tradicionais de agrupamento de dados de em redes de sensores sem fio e comparado com o algoritmo QK-Médias. Na Figura 5.11(a) é possível notar que o QK-Médias teve um desempenho melhor que os outros algoritmos para o conjunto de dados formados por 16 gaussianas quando $\lambda$ não é grande. Inclusive quando comparado com o algoritmo CLUBS, que garante que todos os escravos estejam conectados a um CH, ou seja, mesmo com $100 \%$ de cobertura o CLUBS apresenta resultado pior que o QKMédias. Isso ocorre porque o CLUBS é sensível a outliers e o QK-Médias não, uma vez que são descartados escravos que necessitem de um $\mathrm{CH}$ só para ele (outliers). Quando $\lambda$ cresce muito, todos os sensores passam a gerar muitas mensagens, inclusive os sensores outliers. Nesse caso o CLUBS consegue capturá-las mas o QK-Médias não. Por isso que, a partir de um limiar (nesse experimento quando $\lambda \simeq 25 \%$ ), o CLUBS é melhor que o QK-Médias. A Figura 5.11(b) exibe as quantidades de $\mathrm{CHs}$ utilizados pelos algoritmos de agrupamento sendo que, para o 
posicionamento aleatório, o número de $\mathrm{CHs}$ utilizados é o mesmo número encontrado pelo QK-Médias. As Figuras 5.12 e 5.13 mostram a mesma comparação para algumas outras bases de dados.

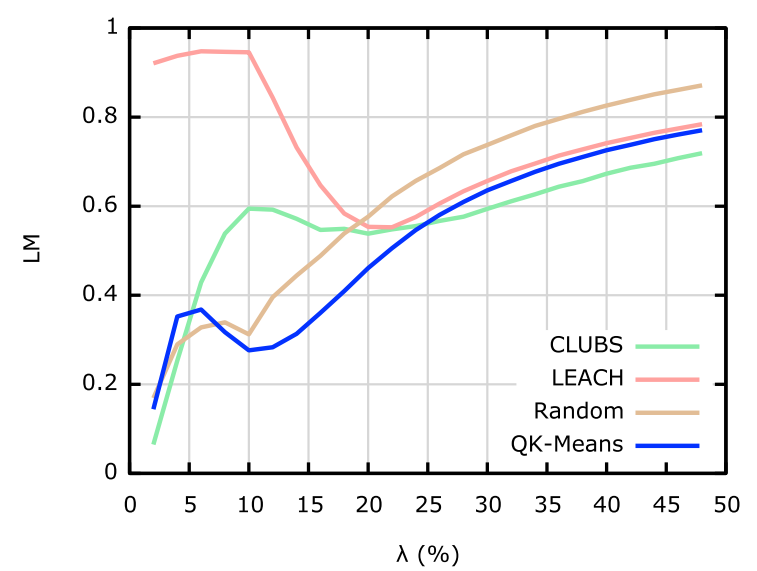

(a)

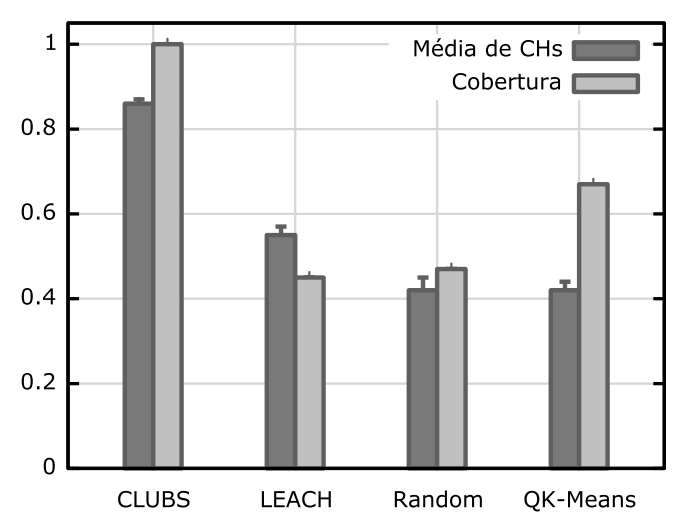

(b)

Figura 5.11: (a) Influência da variação de $\lambda$ para alguns algoritmos tradicionais de agrupamento de dados em RSSF. Para essa simulação foram considerados 1000 sensores escravo divididos em forma de 16 gaussianas (Fig. 5.1(a)). Os parâmetros de simulação são: $S_{r}=25 \mathrm{~m}, C H_{r}=50 \mathrm{~m}, S_{b}=200 \mathrm{e}$ $C H_{b}=500$. Cada ponto do gráfico representa a média dos resultados de 30 execuções da simulação. (b) Porcentagem de CHs utilizado pelos algoritmos de agrupamento.

\subsection{Considerações Finais}

Nesse Capítulo foram apresentadas as propostas do algoritmo QK-Médias e do modelo de simulação de redes de sensores sem fio. Alguns experimentos foram feitos analisando as influências das variações de parâmetros de simulação sob a porcentagem de mensagens perdidas da rede. Alguns outros experimentos foram realizados no intuito de comparar o número de mensagens perdidas na rede quando utilizado QK-Médias e técnicas tradicionais de agrupamento de dedos. Nesses experimentos pode-se observar que, para as bases de dados utilizadas, o QK-Médias consegue posicionar menos cluster heads e obter uma taxa menor de mensagens perdidas na rede. 


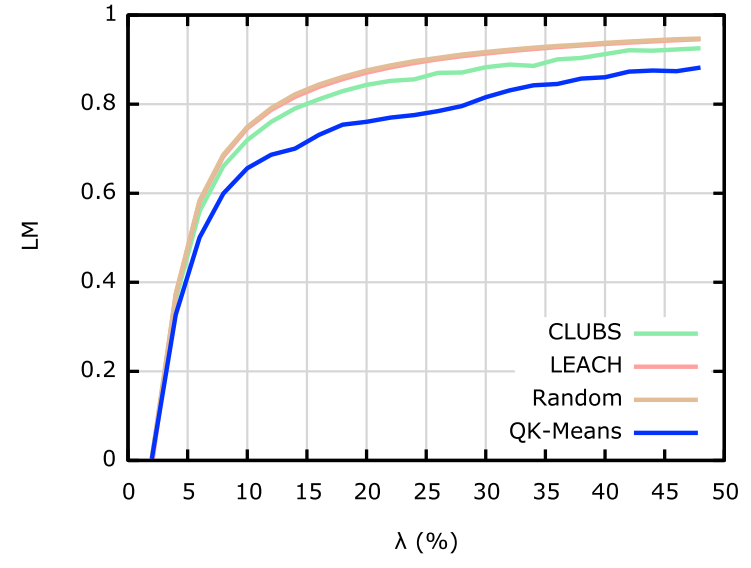

(a)

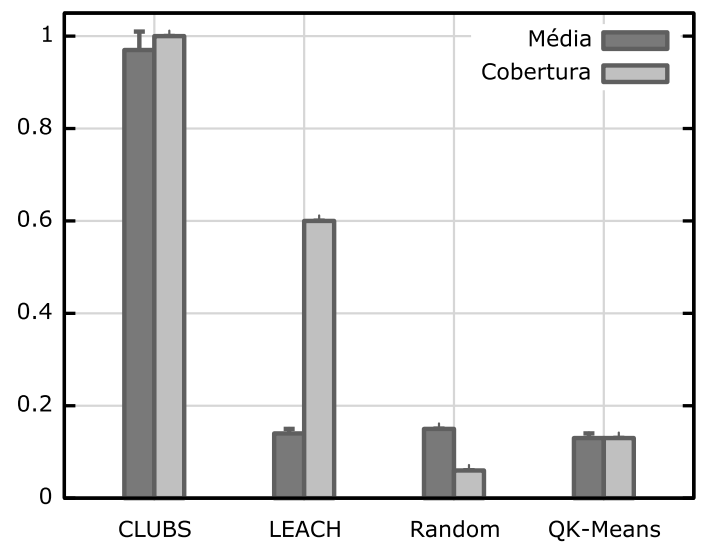

(b)

Figura 5.12: (a) Influência da variação de $\lambda$ para alguns algoritmos tradicionais de agrupamento de dados em RSSF. Para essa simulação foram considerados 1000 sensores escravo posicionados esparsamente aleatorios em uma área de $2800 \times 2800$. Os parâmetros de simulação são: $S_{r}=5 \mathrm{~m}, C H_{r}=10 \mathrm{~m}$, $S_{b}=50$ e $C H_{b}=1000$. Cada ponto do gráfico representa a média dos resultados de 30 execuções da simulação. (b) Porcentagem de CHs utilizado pelos algoritmos de agrupamento.

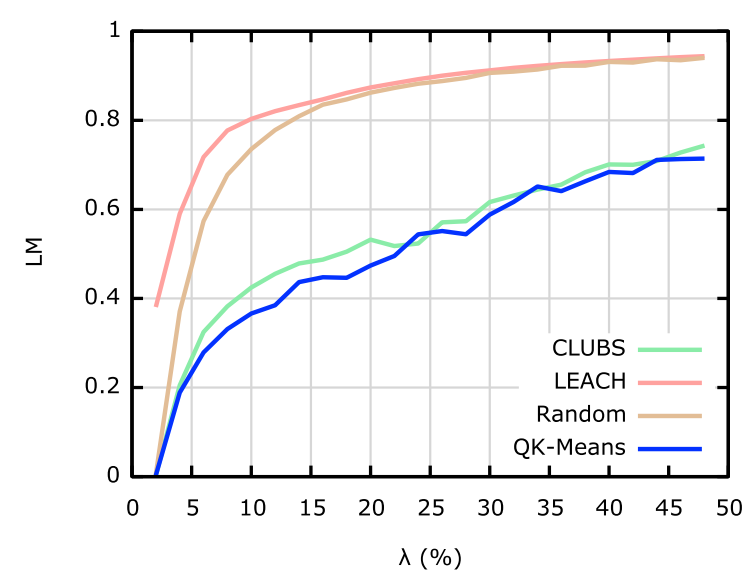

(a)

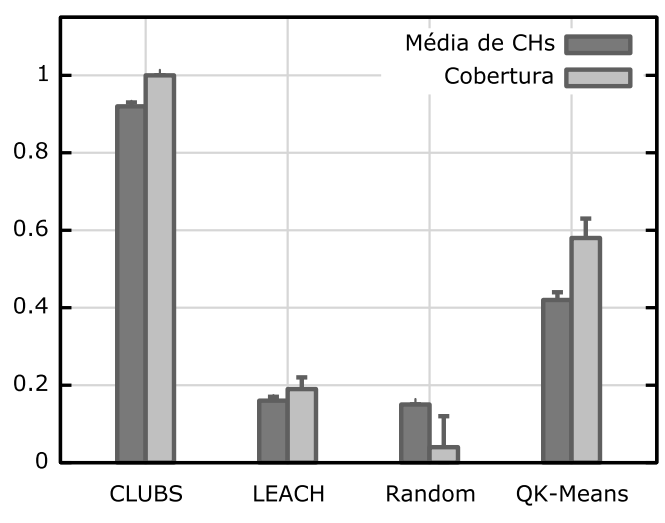

(b)

Figura 5.13: (a) Influência da variação de $\lambda$ para alguns algoritmos tradicionais de agrupamento de dados em RSSF. Para essa simulação foram considerados 1000 sensores escravo divididos em forma de 16 gaussianas (Fig. 5.1(a)). Os parâmetros de simulação são: $S_{r}=25 \mathrm{~m}, C H_{r}=50 \mathrm{~m}, S_{b}=200 \mathrm{e}$ $\mathrm{CH}_{b}=500$. Cada ponto do gráfico representa a média dos resultados de 30 execuções da simulação. (b) Porcentagem de $\mathrm{CHs}$ utilizado pelos algoritmos de agrupamento. 


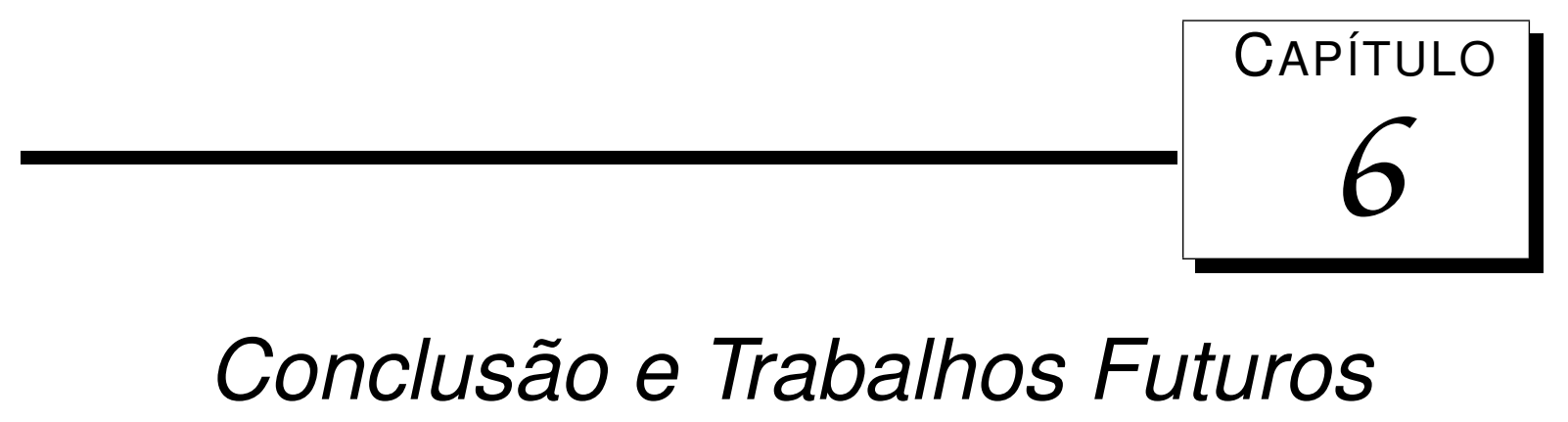

Nesse trabalho foi apresentado a proposta do algoritmo híbrido QK-Médias e o modelo de redes de sensores sem fio utilizado para simulação e comparação entre os algoritmos. Esse novo algoritmo utiliza detecção de comunidades em redes complexas para encontrar grupos de formas variáveis e conseguir detectar formas mais complexas. Depois de detectadas as comunidades, essas podem ter um diâmetro muito grande, o que impossibilita que um cluster head consiga capturar todas as mensagens geradas pelos sensores. Dessa forma, considerando o raio de cobertura do $\mathrm{CH}$, foi utilizado o algoritmo K-médias que consegue detectar bons grupos em forma de elipse em planos cartesianos.

\subsection{Conclusões}

A vantagem no cálculo do diâmetro da comunidade elimina o problema de não se saber o número $K$ de grupos que formam a comunidade. Entretanto a alta complexidade do algoritmo Floyd-Warshall $\left(O\left(n^{3}\right)\right)$ pode inviabilizar a utilização do algoritmo para grandes redes. Contudo, o K-Médias é utilizado para quebrar comunidades encontradas, o que reduz o número de vértices para o algoritmo Floyd-Warshall e ameniza o problema.

O modelo de RSSF possibilitou simular redes de grande porte, executar algoritmos de agrupamento e comparar os resultados. Mesmo de forma simplificada, foi possível simular os principais problemas referentes ao agrupamento de dados para o posicionamento de sensores cluster heads. Dentre esses problemas, estão por exemplo, a diferença na forma e na densidade dos grupos.

As técnicas de agrupamento de dados presentes na literatura foram desenvolvidas a fim de atingir um objetivo diferente. O QK-Médias foi idealizado com o intuito de aumentar a conectividade dos sensores escravos por meio do posicionamento estratégico de sensores cluster 
heads e consequentemente diminuir o número de mensagens perdidas na rede. A partir dos experimentos realizados no Capítulo 5, conclui-se que a abordagem híbrida utilizada pelo QKMédias pode resolver de forma mais eficiente o problema de agrupamento de dados em redes de sensores sem fio. A partir das simulações, observou-se que o QK-Médias consegue posicionar melhor os CHs, pois agrupa os sensores escravos usando menos sensores cluster head que outras técnicas além de diminuir a porcentagem de mensagens perdidas na rede. Em outros casos, a porcentagem de mensagens perdidas se manteve igual a outros algoritmos mas o número de sensores utilizados foi menor. Dessa forma foi possível prover uma solução para o agrupamento de dados com custo menor.

\subsection{Trabalhos futuros}

No intuito de aprimorar esse trabalho, algumas idéias são apresentadas a seguir como continuação desse trabalho:

- Quando os sensores escravos estão densamente posicionados em uma região menor que o raio de cobertura de um cluster head, o QK-Médias posiciona apenas um $\mathrm{CH}$. Entretanto o grande número de sensores gera muita interferência e consequentemente aumenta o número de mensagens perdidas na rede. O QK-Médias poderia considerar sensores cluster heads com raio de cobertura variável e então poder encontrar subcomunidades de tamanhos variáveis. Dessa forma, a região densa seria quebra em subcomunidades;

- Considerando o raio de cobertura dos cluster heads, é interessante a utilização do algoritmos K-Médias para encontrar subcomunidades de formato circular. O problema de encontrar o número $K$ de grupos para servir de parâmetro para o K-Médias é resolvido utilizando o algoritmo Floyd-Warshall. Contudo, esse algoritmo tem alta complexidade de tempo $\left(O\left(n^{3}\right)\right)$ o que pode inviabilizar sua utilização para redes muito grandes. Assim, seria interessante utilizar abordagens heurísticas para encontrar o diâmetro da rede, uma vez que não é necessário uma solução ótima como a provida pelo Floyd-Warshall.

- Implementar e comparar diferente combinações de algoritmos de detecção de comunidades, como técnicas baseadas em competição de partículas, e algoritmos tradicionais como DBSCAN ou Mapas auto organizáveis;

- Poderiam ser incluídos parâmetros no QK-Médias como: número máximo de sensores cluster heads ou fração máxima de sensores escravos por $\mathrm{CH}$. Assim o QK-Médias poderia ser configurado para melhor encontrar os grupos para diferentes situações;

- Comparar novas métricas de avaliação de desempenho, como por exemplo a porcentagem de mensagens entregues à estação base; 
- O modelo de simulação proposto poderia ser aprimorado para considerar outras características reais das RSSFs como por exemplo a energia dos sensores. Dessa forma, alguns nós da rede poderiam ser removidos com o passar do tempo para simular a falta de energia dos sensores e assim tornar a topologia da rede seria dinâmica;

- O QK-Médias pode ser adaptado e generalizado para resolver outros problemas que envolvem o agrupamento de dados espaciais com restrições no tamanho dos grupos. 


\section{Referências Bibliográficas}

ABbAsi, A. A.; Younis, M. A survey on clustering algorithms for wireless sensor networks. Computer Communications, v. 30, n. 14-15, p. 2826 - 2841, 2007.

Agrawal, R.; Gehrke, J.; Gunopulos, D.; Raghavan, P. Automatic subspace clustering of high dimensional data for data mining applications. SIGMOD Rec., v. 27, p. 94-105, 1998.

AKYILDIZ, I. Wireless sensor networks: a survey. Computer Networks, v. 38, n. 4, p. 393422, 2002.

Al-KARAKI, J. N.; KAMAL, A. E. Routing techniques in wireless sensor networks: A survey. IEEE Wireless Communications, v. 11, p. 6-28, 2004.

Albert, R.; JeOng, H.; Barabasi, A. L. The diameter of the world wide web. Nature, v. 401, p. 130-131, 1999.

Amaral, L. A. N.; Scala, A.; Barthélémy, M.; Stanley, H. E. Classes of smallworld networks. Proceedings of the National Academy of Sciences of the United States of America, v. 97, n. 21, p. 11149-11152, 2000.

Anderberg, M. R. Cluster analysis for applications. Academic Press, 1973.

BALL, G.; HALL, D. A clustering technique for summarizing multivariate data. Behaviorial Sciences, v. 12, n. 2, p. 153-155, 1967.

BANDYOPADHYAY, S.; COYLE, E. J. An energy efficient hierarchical clustering algorithm for wireless sensor networks. 2003.

Barabasi, A. L.; Albert, R. Emergence of Scaling in Random Networks. Science, v. 286, n. 5439, p. 509-512, 1999.

BARABÁsi, A.-L.; Oltvai, Z. N. Network biology: understanding the cell's functional organization. Nature Reviews Genetics, v. 5, n. 2, p. 101-113, 2004.

Bellman, R. On a Routing Problem. Quarterly of Applied Mathematics, v. 16, p. 87-90, 1958.

BILMES, J. A gentle tutorial of the EM algorithm and its application to parameter estimation for Gaussian mixture and hidden Markov models. Relat Tico TR-97-021, ICSI, 1997. 
Bock, H.-H. Clustering Methods: A History of k-Means Algorithms. In: BRITO, P.; CUCumel, G.; Bertrand, P.; Carvalho, F., eds. Selected Contributions in Data Analysis and Classification, Studies in Classification, Data Analysis, and Knowledge Organization, cap. 15, Springer Berlin Heidelberg, p. 161-172, 2007.

Celeux, G.; Govaert, G. A classification em algorithm for clustering and two stochastic versions. Comput. Stat. Data Anal., v. 14, p. 315-332, 1992.

Cheeseman, P.; Stutz, J. Advances in knowledge discovery and data mining. cap. Bayesian classification (AutoClass): theory and results, Menlo Park, CA, USA: American Association for Artificial Intelligence, p. 153-180, 1996.

Chong, C.-Y.; Ieee; Kumar, S. P.; Member, S. Sensor networks: evolution, opportunities, and challenges. In: Proceedings of the IEEE, 2003, p. 1247-1256.

Clauset, A.; Newman, M. E. J.; Moore, C. Finding community structure in very large networks. 2004.

Cormen, T. H.; Stein, C.; Rivest, R. L.; Leiserson, C. E. Introduction to algorithms. 2nd ed. McGraw-Hill Higher Education, 2001.

DAI, F.; WU, J. On constructing k-connected k-dominating set in wireless networks. In: Proceedings of the 19th IEEE International Parallel and Distributed Processing Symposium (IPDPS'05) - Papers - Volume 01, IPDPS '05, Washington, DC, USA: IEEE Computer Society, 2005, p. 81.1-(IPDPS '05, ).

Demirbas, M.; Arora, A.; Mittal, V. Floc: A fast local clustering service for wireless sensor networks. In: Workshop on Dependability Issues in Wireless Ad Hoc Networks and Sensor Networks (DIWANS/DSN, 2004.

Dempster, A. P.; LAird, N. M.; Rubin, D. B. Maximum Likelihood from Incomplete Data via the EM Algorithm. Journal of the Royal Statistical Society. Series B (Methodological), v. 39, n. 1, p. 1-38, 1977.

Diestel, R. Graph Theory, v. 173 de Graduate Texts in Mathematics. Third ed. SpringerVerlag, Heidelberg, 2005.

Dijkstra, E. W. A note on two problems in connexion with graphs. Numerische Mathematik, v. 1, n. 1, p. 269-271, 1959.

ERdös, P.; RÉnYi, A. On random graphs, I. Publicationes Mathematicae (Debrecen), v. 6, p. 290-297, 1959.

ESTER, M.; KRIEGEL, H.-P.; JÖRG, S.; XU, X. A density-based algorithm for discovering clusters in large spatial databases with noise. 1996.

Everitt, B. S.; Landau, S.; Leese, M. Cluster Analysis. 4th ed. Wiley, 2009.

FERREIRA, L.; Pinto, A.; ZhaO, L. Qk-means: A clustering technique based on community detection and k-means for deployment of cluster head nodes. In: Neural Networks (IJCNN), The 2012 International Joint Conference on, 2012, p. 1 -7. 
Ferreira, L.; Pinto, A. R.; Lopes, A. A.; Zhao, L. Community detection approach for cluster formation in wireless sensor networks. In: Congresso Brasileiro de Inteligência Computacional, 2011. CBIC11, 2011.

Ford, L. R.; Fulkerson, D. R. Flows in Networks. Princeton University Press, 1962.

FORGY, E. W. Cluster analysis of multivariate data: efficiency vs interpretability of classifications. Biometrics, v. 21, p. 768-769, 1965.

Fredman, M. L. New bounds on the complexity of the shortest path problem. SIAM J. Comput., v. 5, n. 1, p. 83-89, 1976.

Girvan, M.; Newman, M. E. J. Community structure in social and biological networks. Proceedings of the National Academy of Sciences of the United States of America, v. 99, n. 12, p. 7821-7826, 2002.

GuPTA, G.; Younis, M. Load-balanced clustering of wireless sensor networks. In: Communications, 2003. ICC 'O3. IEEE International Conference on, 2003, p. 1848 - 1852 vol.3.

Hartigan, J. Clustering algorithms. John Wiley and Sons, New York, 1975.

HARTLEy, H. O. Maximum Likelihood Estimation from Incomplete Data. Biometrics, v. 14, n. 2, p. 174-194, 1958.

Heinzelman, W.; Chandrakasan, A.; Balakrishnan, H. An application-specific protocol architecture for wireless microsensor networks. Wireless Communications, IEEE Transactions on, v. 1, n. 4, p. 660 - 670, 2002.

Hinneburg, A.; Hinneburg, E.; Keim, D. A. An Efficient Approach to Clustering in Large Multimedia Databases with Noise. In: in Proc of 4th International Conference in Knowledge Discovery and Data Mining (KDD 98), 1998, p. 58-65.

Hou, Y. T.; Shi, Y.; Sherali, H. D.; MidkifF, S. F. On energy provisioning and relay node placement for wireless sensor networks. Wireless Communications, IEEE Transactions on, v. 4, n. 5, p. 2579-2590, 2005.

Huberman, B. A. The Laws of the Web: Patterns in the Ecology of Information. The MIT Press, 2001.

IZHIKEVICH, E. M. Which model to use for cortical spiking neurons? IEEE transactions on neural networks / a publication of the IEEE Neural Networks Council, v. 15, n. 5, p. 10631070, 2004.

JAIN, A. K.; Dubes, R. C. Algorithms for clustering data. Prentice-Hall, Inc., 1988.

Johnson, D. B. Efficient Algorithms for Shortest Paths in Sparse Networks. Journal of the $A C M$, v. 24, n. 1, p. 1-13, 1977.

KARINTHY, F. Chain-links. 1929.

Karypis, G.; Eui; News, V. K. Chameleon: Hierarchical Clustering Using Dynamic Modeling. Computer, v. 32, n. 8, p. 68-75, 1999. 
KARYPIS, G.; KUMAR, V. hmetis 1.5: A hypergraph partitioning package. Relat Tico, University of Minnesota, Dept. of Computer Science, 1998.

KAUFMAN, L.; RousSEeUW, P. Finding groups in data an introduction to cluster analysis. New York: Wiley Interscience, 1990.

Krishna, K.; Narasimha Murty, M. Genetic k-means algorithm. Systems, Man, and Cybernetics, Part B: Cybernetics, IEEE Transactions on, v. 29, n. 3, p. 433 -439, 1999.

LIU, C. L. Introduction to combinatorial mathematics / c.l. liu. McGraw-Hill, New York :, 1968.

MacqueEn, J. B. Some methods of classification and analysis of multivariate observations. In: Proceedings of the Fifth Berkeley Symposium on Mathematical Statistics and Probability, 1967, p. 281-297.

Milgram, S. The Small World Problem. Psychology Today, v. 2, p. 60-67, 1967.

Moody, J. Race, School Integration, and Friendship Segregation in America. American Journal of Sociology, v. 107, p. 679-716, 2002.

Moscibroda, T.; Wattenhofer, R. Maximizing the lifetime of dominating sets. In: Proceedings of the 19th IEEE International Parallel and Distributed Processing Symposium (IPDPS'05) - Workshop 12 - Volume 13, IPDPS '05, Washington, DC, USA: IEEE Computer Society, 2005, p. 242.2- (IPDPS '05, ).

NAGPAL, R.; COORE, D. An algorithm for group formation in an amorphous computer. In: Proceedings of the 10th International Conference on Parallel and Distributed Computing Systems (PDCS'98), Nevada, USA, 1998.

Newman, M. E. J. The Structure and Function of Complex Networks. SIAM Review, v. 45, n. 2 , p. $167+, 2003$.

Newman, M. E. J. Fast algorithm for detecting community structure in networks. Physical Review E, v. 69, n. 6, p. 066133+, 2004.

Newman, M. E. J.; GiRvan, M. Finding and evaluating community structure in networks. 2003.

de Oliveira, T.; Zhao, L.; Faceli, K.; De Carvalho, A. Data clustering based on complex network community detection. In: Evolutionary Computation, 2008. CEC 2008. (IEEE World Congress on Computational Intelligence). IEEE Congress on, 2008, p. 2121 $-2126$.

OYMAN, E. I.; ERSOY, C. Multiple sink network design problem in large scale wireless sensor networks. In: Proceedings of the IEEE International Conference on Communications (ICC), Paris, France, 2004, p. 3663-3667.

Quiles, M. G.; Zhao, L.; Alonso, R. L.; Romero, R. A. F. Particle competition for complex network community detection. Chaos: An Interdisciplinary Journal of Nonlinear Science, v. 18, n. 3, p. 033107, 2008. 
Quiles, M. G.; Zhao, L.; Breve, F. A.; Romero, R. A. F. Detecção de comunidades em redes complexas: um modelo de correlação oscilatória. VII Encontro Nacional de Inteligência Artificial (ENIA), p. 889-898, 2009.

Rajagopalan, R.; VARShney, P. K. Data aggregation techniques in sensor networks: A survey. Comm. Surveys \& Tutorials, IEEE, v. 8, p. 48-63, 2006.

Scotт, J. P. Social Network Analysis: A Handbook. SAGE Publications, 2000.

SELIM, S. Z.; IsMAIL, M. A. K-means-type algorithms: A generalized convergence theorem and characterization of local optimality. Pattern Analysis and Machine Intelligence, IEEE Transactions on, v. PAMI-6, n. 1, p. 81 -87, 1984.

Sneath, P. H. A. The application of computers to taxonomy. Journal of general microbiology, v. 17, n. 1, p. 201-226, 1957.

SOKAL, R. R.; Michener, C. D. A statistical method for evaluating systematic relationships. University of Kansas Scientific Bulletin, v. 28, p. 1409-1438, 1958.

De Sola Pool, I.; Kochen, M. Contacts and influence. Social Networks, v. 1, p. 5-51, 1978.

DE Solla Networks of Scientific Papers. Science, v. 149, n. 3683, p. 510-515, 1965.

SøREnSEN, T. A method of establishing groups of equal amplitude in plant sociology based on similarity of species and its application to analyses of the vegetation on Danish commons. Biol. Skr., v. 5, p. 1-34, 1948.

SPORns, O. Networks analysis, complexity, and brain function. Complex., v. 8, p. 56-60, 2002.

Strehl, A.; GHOSH, J. A scalable approach to balanced, high-dimensional clustering of market-baskets. In: Proc. High Performance Computing (HiPC 2000), Bangalore, Springer, 2000, p. 525-536 (LNCS, v.1970).

Strogatz, S. H. Exploring complex networks. Nature, v. 410, n. 6825, p. 268-276, 2001.

Tan, P.-N.; Steinbach, M.; Kumar, V. Introduction to Data Mining. 1 ed. Addison Wesley, 2005.

WARD, J. Hierarchical grouping to optimize an objective function. Journal of the American Statistical Association, v. 58, p. 236-244, 1963.

Watts, D. J.; Strogatz, S. H. Collective dynamics of 'small-world' networks. Nature, v. 393, n. 6684, p. 440-442, 1998.

WEEK, B. 21 ideas for the 21st century, p. 78-167. 1999.

Xu, R.; WunsCH, D. Survey of clustering algorithms. Neural Networks, IEEE Transactions on, v. 16, n. 3, p. 645-678, 2005.

Xu, R.; WunsCH, D. Clustering (IEEE Press Series on Computational Intelligence). WileyIEEE Press, 2008. 
Younis, M.; AkKayA, K.; Kunjithapatham, A. Optimization of task allocation in a cluster-based sensor network. In: Proceedings of the Eighth IEEE International Symposium on Computers and Communications, ISCC '03, Washington, DC, USA: IEEE Computer Society, 2003, p. 329-(ISCC '03, ).

Younis, O.; FAHMY, S. Heed: A hybrid, energy-efficient, distributed clustering approach for ad hoc sensor networks. IEEE Transactions on Mobile Computing, v. 3, p. 366-379, 2004.

Zhao, F.; Guibas, L. Wireless Sensor Networks: An Information Processing Approach. Morgan Kaufmann, 2004.

Zheng, J.; JAMALIPOUR, A. Wireless sensor networks: A networking perspective. John Wiley \& Sons, 2009.

ZhOU, H. Network landscape from a brownian particle's perspective. Phys. Rev. E, v. 67, n. 4, p. 041908, 2003.

Zhuang, X.; Huang, Y.; Palaniappan, K.; ZhaO, Y. Gaussian mixture density modeling, decomposition, and applications. IEEE Transactions on Image Processing, v. 5, n. 9, p. 1293-1302, 1996. 


\section{Caminhos Mais Curtos de Todos os Pares}

O problema de encontrar caminhos mais curtos entre todos os pares de vértices de um grafo simples ponderado $G=(V, E)$ pode surgir quando se deseja obter o diâmetro $(\operatorname{Diam}(G))$ do grafo. Para resolver esse problema, é possível construir uma matriz de distâncias $D$ onde o elemento $d_{i j}$ é o peso do caminho mais curto entre os vértice $i$ e $j$ sendo que o peso do caminho é a soma dos pesos das arestas constituintes. Para construir a matriz $D$ pode ser utilizado o algoritmo de Floyd-Warshall (Alg. 13) (Cormen et al., 2001). O algoritmo inicia preenchendo a matriz $D$ em cada posição $d_{i j}$ com o peso $w(i, j)$ de cada par de vértice $i$ e $j$ caso exista uma aresta entre eles. Caso contrário será considerado uma distância infinita. Elementos da diagonal principal da matriz são iguais a zero: $\left\{d_{1,1}, d_{2,2}, \ldots, d_{n, n}\right\}=0$. Considerando que cada execução da Linha 5 demora tempo $O(i)$, o tempo de execução do algoritmo de FloydWarshall é definido pelos três laços (Para), ou seja, $\Theta\left(n^{3}\right)$.

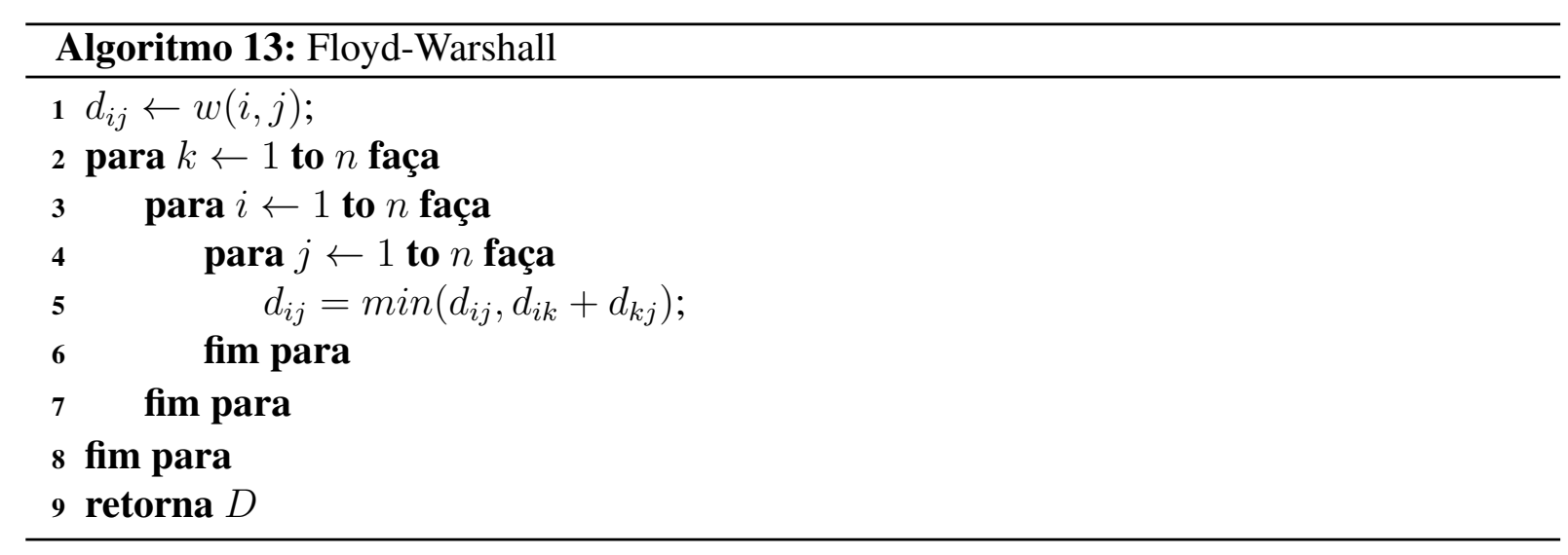

Um exemplo de execução do algoritmo de Floyd-Warshall para o grafo da Figura A.1 pode 
ser observado a seguir, onde $D^{(0)}$ é o estado inicial e $D^{(5)}$ o estado final com todos os menores caminhos computados.

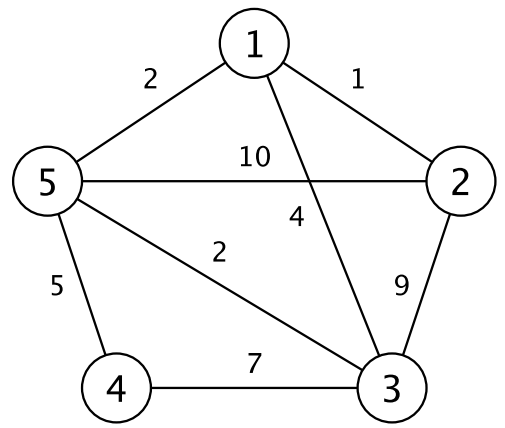

Figura A.1: Exemplo de grafo ponderado.

$$
\begin{aligned}
D^{(0)}=\left(\begin{array}{ccccc}
0 & 1 & 4 & \infty & 2 \\
1 & 0 & 9 & \infty & 10 \\
4 & 9 & 0 & 7 & 2 \\
\infty & \infty & 7 & 0 & 5 \\
2 & 10 & 2 & 5 & 0
\end{array}\right) & D^{(1)}=\left(\begin{array}{ccccc}
0 & 1 & 4 & \infty & 2 \\
1 & 0 & 5 & \infty & 3 \\
4 & 5 & 0 & 7 & 2 \\
\infty & \infty & 7 & 0 & 5 \\
2 & 3 & 2 & 5 & 0
\end{array}\right) \\
D^{(2)} & =\left(\begin{array}{ccccc}
0 & 1 & 4 & \infty & 2 \\
1 & 0 & 5 & \infty & 3 \\
4 & 5 & 0 & 7 & 2 \\
\infty & \infty & 7 & 0 & 5 \\
2 & 3 & 2 & 5 & 0
\end{array}\right) \quad D^{(3)}=\left(\begin{array}{ccccc}
0 & 1 & 4 & 11 & 2 \\
1 & 0 & 5 & 12 & 3 \\
4 & 5 & 0 & 7 & 2 \\
11 & 12 & 7 & 0 & 5 \\
2 & 3 & 2 & 5 & 0
\end{array}\right) \\
D^{(4)} & =\left(\begin{array}{cccccc}
0 & 1 & 4 & 11 & 2 \\
1 & 0 & 5 & 12 & 3 \\
4 & 5 & 0 & 7 & 2 \\
11 & 12 & 7 & 0 & 5 \\
2 & 3 & 2 & 5 & 0
\end{array}\right) D^{(5)}=\left(\begin{array}{llllll}
0 & 1 & 4 & 7 & 2 \\
1 & 0 & 5 & 8 & 3 \\
4 & 5 & 0 & 7 & 2 \\
7 & 8 & 7 & 0 & 5 \\
2 & 3 & 2 & 5 & 0
\end{array}\right)
\end{aligned}
$$

Outros algoritmos também resolvem o problema de encontrar caminhos mais curtos entre todos os pares de vértices. Esse problema pode ser resolvido a partir de um algoritmo que calcula os caminhos mais curtos de apenas um vértice a todos os outros, executando $|V|$ vezes, uma para cada vértice como origem. Caso existam apenas arestas com peso positivo, então o algoritmo de Dijkstra (1959) pode ser utilizado dessa forma. Se implementado com arranjo linear da fila de prioridade mínima, o tempo de execução será $O\left(V^{3}\right)$. Se implementado com heap binário da fila de prioridade mínima, o tempo de execução será $O(V E \lg V)$. Caso existam arestas com pesos negativos, então o algoritmo de Bellman-Ford pode ser utilizado, levando tempo $O\left(V^{2} E\right)$ por ser mais lento (Bellman, 1958; Ford \& Fulkerson, 1962). Outra forma de resolver o problema é utilizar o algoritmo de Johnson (1977) usa os algoritmos de Dijkstra e 
Bellman-Ford para calcular a matriz de distâncias $D$ em tempo $O\left(V^{2} \lg V+V E\right)$. O algoritmo proposto por Fredman (1976) faz $O\left(V^{\frac{5}{2}}\right)$ comparações entre somas de pesos de arestas e resolve o problema em tempo $O\left(V^{3}\left(\lg \lg \frac{V}{\lg V}\right)^{\frac{1}{3}}\right)$, sendo ligeiramente mais rápido que o algoritmo de Floyd-Warshall. 
